\title{
WestVirginiaUniversity
}

THE RESEARCH REPOSITORY @ WVU

Graduate Theses, Dissertations, and Problem Reports

2006

\section{Analysis of energy consumption in continuous galvanizing lines}

Raviraj Ratnakar Chavan

West Virginia University

Follow this and additional works at: https://researchrepository.wvu.edu/etd

\section{Recommended Citation}

Chavan, Raviraj Ratnakar, "Analysis of energy consumption in continuous galvanizing lines" (2006). Graduate Theses, Dissertations, and Problem Reports. 1749.

https://researchrepository.wvu.edu/etd/1749

This Thesis is protected by copyright and/or related rights. It has been brought to you by the The Research Repository @ WVU with permission from the rights-holder(s). You are free to use this Thesis in any way that is permitted by the copyright and related rights legislation that applies to your use. For other uses you must obtain permission from the rights-holder(s) directly, unless additional rights are indicated by a Creative Commons license in the record and/ or on the work itself. This Thesis has been accepted for inclusion in WVU Graduate Theses, Dissertations, and Problem Reports collection by an authorized administrator of The Research Repository @ WVU. For more information, please contact researchrepository@mail.wvu.edu. 


\title{
Analysis of Energy Consumption in Continuous Galvanizing Lines
}

\author{
by \\ Raviraj Ratnakar Chavan \\ Thesis submitted to the College of Engineering and Mineral Resources \\ at West Virginia University \\ in partial fulfillment of the requirements \\ for the degree of \\ Master of Science \\ in \\ Industrial Engineering
Dr. Bhaskaran Gopalakrishnan, Committee Chairperson
Dr. Robert Creese
Dr. Xingbo Liu
Dr. Peter Angelini

Industrial and Management Systems Engineering

\section{Morgantown, West Virginia \\ 2006}

Keywords: Energy Analysis, Continuous Galvanizing, Energy Consumption, Steel Coating, Pot Hardware. 


\section{ABSTRACT \\ Analysis of Energy Consumption in Continuous Galvanizing Lines}

\section{Raviraj Ratnakar Chavan}

The pot hardware in continuous galvanizing lines is prone to failure and needs to be replaced quite frequently. This resulted in considerable loss of production time. Also equipment like, the molten zinc pot and annealing furnace cannot be turned off during downtime resulting in considerable energy consumption during downtime too.

A profound study of the energy aspect of the equipment used on galvanizing line was done. A systematic approach was used to collect and analyze the data from galvanizing facilities. A decision support system (DSS) that will take into account all the major energy consuming equipment in a typical hot dip continuous line was developed. This DSS allows the user to model their galvanizing line in Excel ${ }^{\mathrm{TM}}$ based software. The DSS maintains track of the current production and energy consumption for up to three different processes. It can simulate a scenario to identify the magnitude of benefits that can be obtained as a result of any energy savings measures implemented.

The economic justification of whether or not to replace the hardware can be evaluated with the help of this DSS. Charts pertaining to energy consumed by different equipment groups, total cost of energy spent on natural gas and electricity, MMBtu/ton, tons/year and production time before shutdowns are obtained from the DSS. 


\section{ACKNOWLEDGEMENTS}

I would like to wholeheartedly thank my advisor Dr. B. Gopalakrishnan for his continued support, guidance and encouragement during the course of this research work. I also wish to thank Dr. Robert Creese, Dr. Xingbo Liu and Dr. Peter Angelini, my committee members, for their advice and support. I wish to extend my special thanks to Mr. John Wray, Mr. Christopher Winger, Mr. Sean Koga and all the industries that provided invaluable data and support for the success of the project.

Above all, I wish to thank god, my parents and all my friends for their constant support and blessings and enabling my success and happiness in all my pursuits and endeavors in life.

Raviraj Ratnakar Chavan. 


\section{Table of Contents}

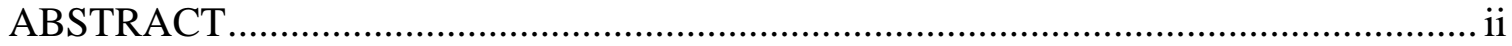

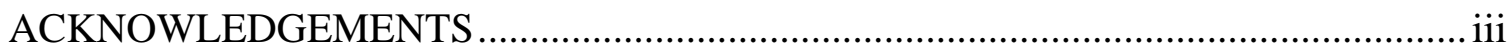

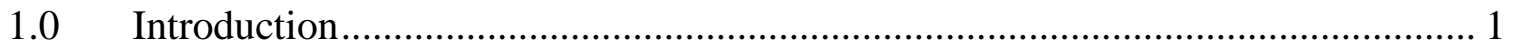

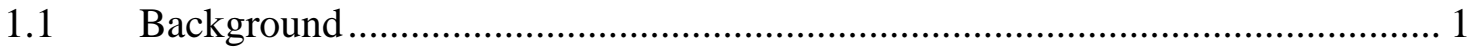

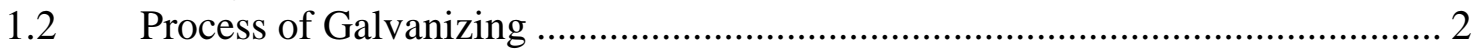

1.2.1 Inspection prior to galvanizing ............................................................. 2

1.2.2 Degreasing ........................................................................................... 3

1.2.3 Acid Cleaning (Pickling) .......................................................................... 3

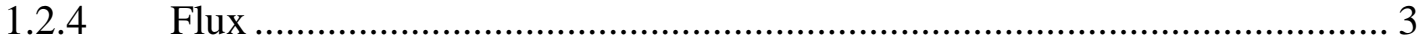

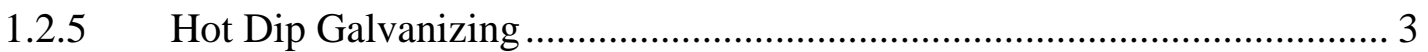

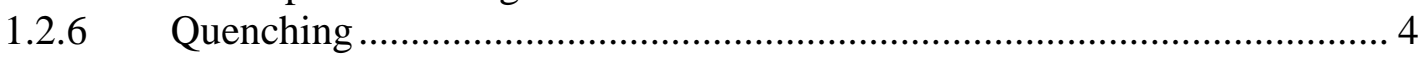

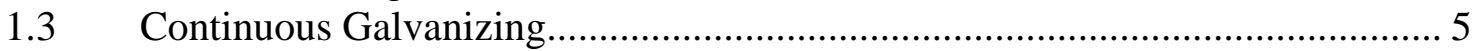

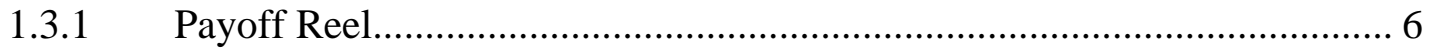

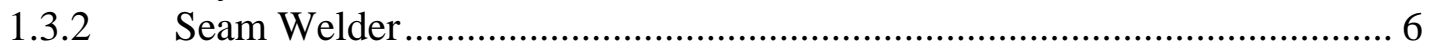

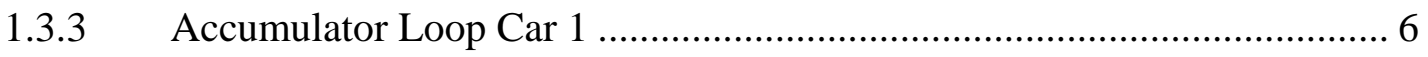

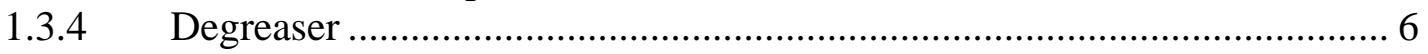

1.3.5 Annealing Furnace .............................................................................. 7

1.3.6 Molten Metal Pot .............................................................................. 7

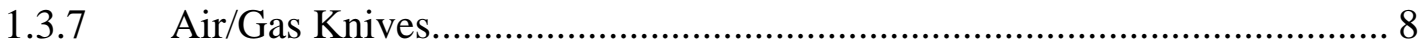

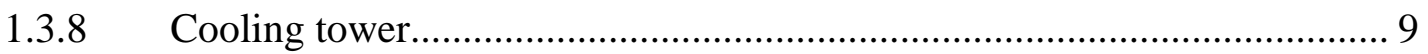

1.3.9 Galvanneal Furnace .......................................................................... 9

1.3.10 Quality Enhancement and Inspection ..................................................... 10

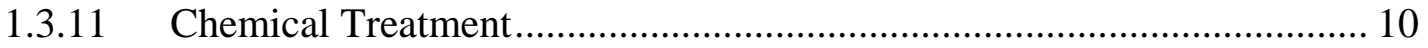

1.3.12 Accumulator Loop Car 2 ..................................................................... 11

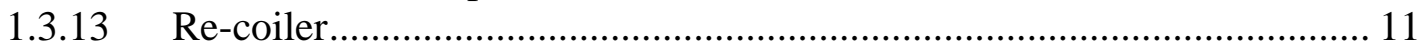

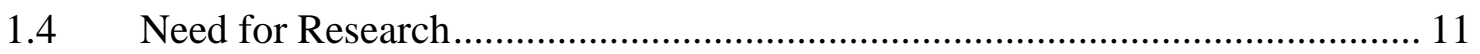

1.4.1 Necessity to know the specific energy consumption ................................. 12

1.4.2 Necessity for Sensitivity Analysis ............................................................ 13

1.4.3 Necessity for Accuracy …………………......................................... 14

$1.5 \quad$ Research Objectives..................................................................................... 14

1.5.1 Galvanizing Energy Profiler Decision Support System (GEPDSS) .......... 14

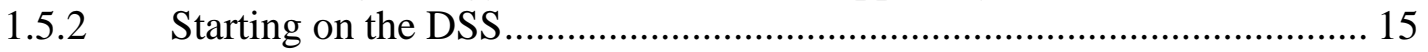

1.5.3 Expectations from the DSS ................................................................ 15

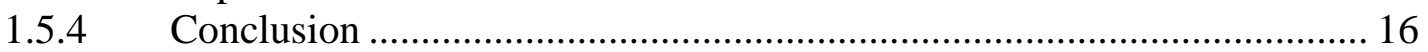

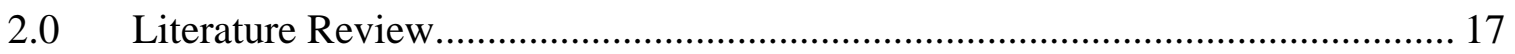

$2.1 \quad$ Energy Measurement and Monitoring .............................................................. 17

2.2 Development in Galvanizing Pot Hardware .................................................... 18

2.3 Development in Galvanizing Bath Management............................................... 20

2.4 Theoretical Calculation for Power Requirement by the Zinc pot ...................... 20

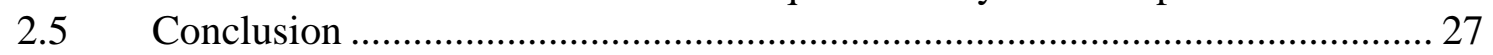

3.0 Research Approach ......................................................................................... 28

3.1 Studying the Continuous Galvanizing Process .............................................. 28

3.2 Preparing Data Collection Sheet...................................................................... 30

3.3 Conducting Measurements and Field Surveys..................................................... 33

3.4 Analysis of Data and Simulation for Savings ................................................... 33 


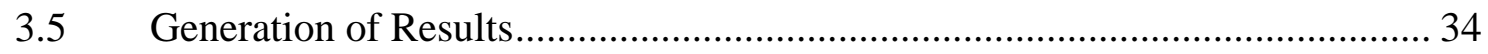

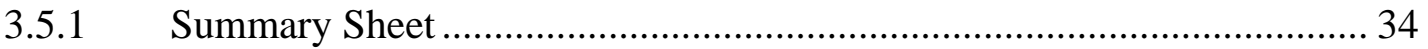

3.5.2 Energy Consumption Details ............................................................... 34

3.5.3 Production and Rejection Details............................................................. 35

3.5.4 Economic Analysis ............................................................................ 35

3.5.5 Graphs ..................................................................................... 35

3.6 Sensitivity Analysis ............................................................................. 35

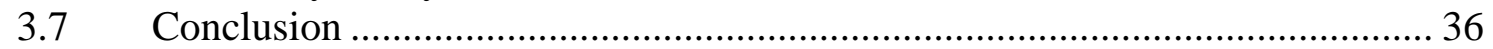

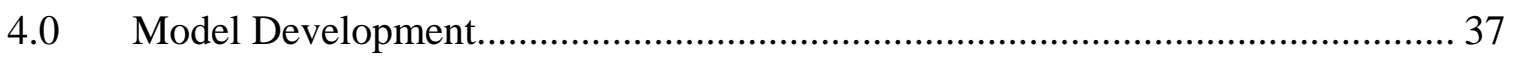

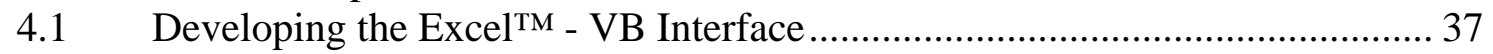

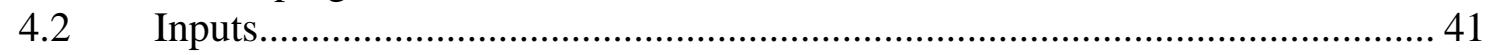

4.2.1 Energy Costs ................................................................................... 41

4.2.2 Process / Products Details ....................................................................... 45

4.2.3 Energy Parameters ............................................................................... 48

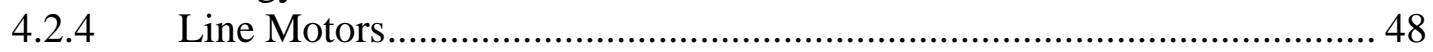

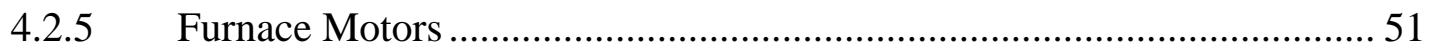

4.2.6 Natural Gas Equipment........................................................................ 51

4.2.7 Nitrogen and Hydrogen Consumption Data .............................................. 55

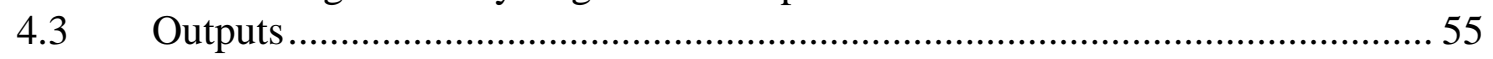

4.3.1 Power and Energy Consumption Details .................................................. 55

4.3.2 Summary Sheet ................................................................................ 57

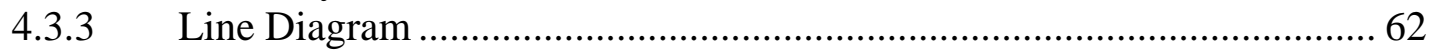

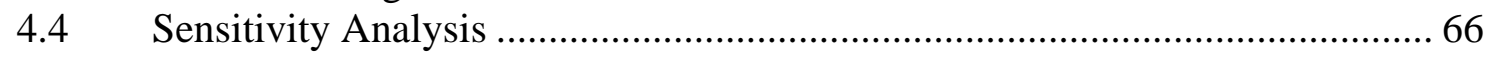

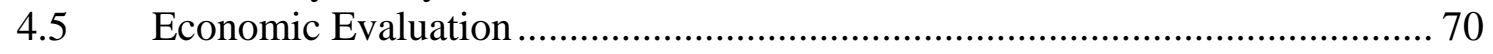

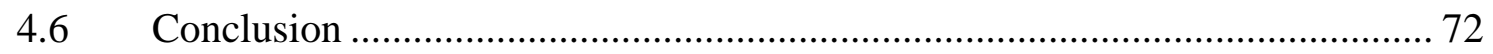

5.0 Validating Results and Future Work................................................................ 73

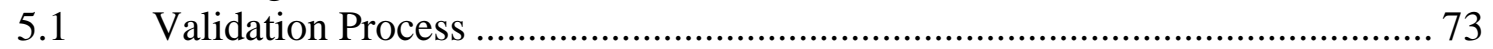

5.2 Results from Sensitivity Analysis................................................................... 75

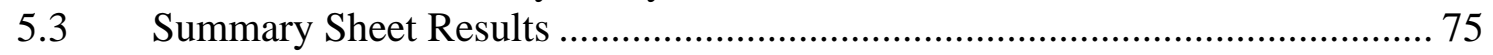

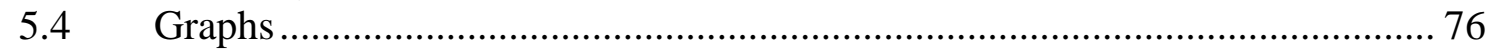

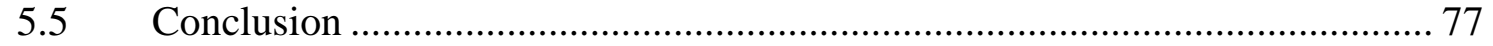

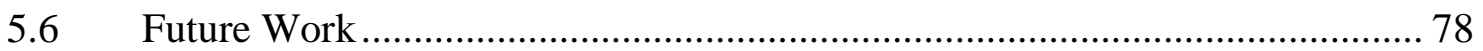

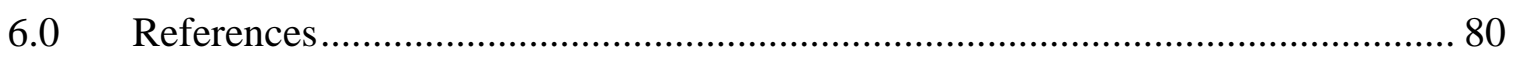




\section{$\underline{\text { List of Figures }}$}

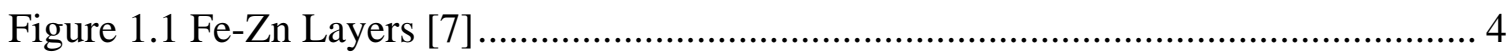

Figure 1.2 Continuous Galvanizing Line..................................................................... 5

Figure 1.3 Schematic of Continuous Galvanizing Pot...................................................... 8

Figure 1.4 Location of the Galvanneal or Holding Furnace .............................................. 9

Figure 3.1: Research Approach................................................................................... 29

Figure 4.1: Architecture of Decision Support System .................................................... 39

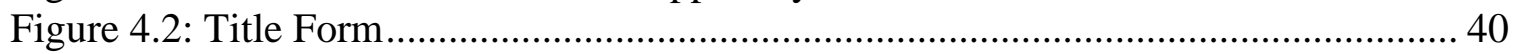

Figure 4.3: Process Selection Form ............................................................................ 41

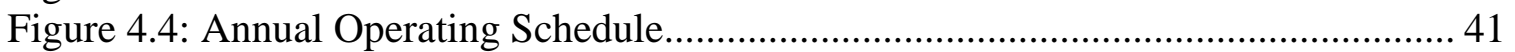

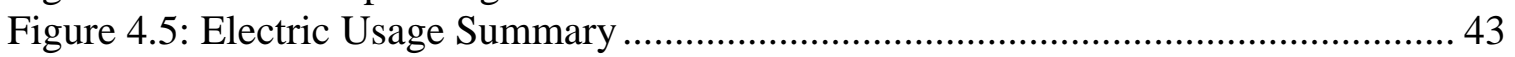

Figure 4.6: Natural Gas Usage Summary …………………............................................. 44

Figure 4.7: Names for different processes ................................................................ 46

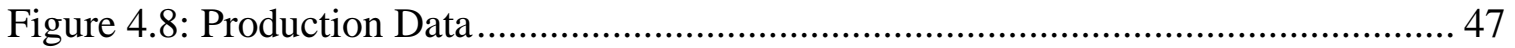

Figure 4.10: Selecting Motor Condition ..................................................................... 48

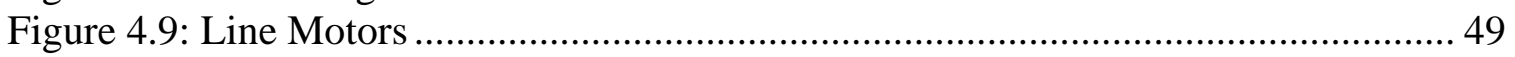

Figure 4.11: Furnace Motors..................................................................................... 50

Figure 4.12: Natural Gas Equipment ........................................................................ 52

Figure 4.13: Load Profile for Annealing Furnace............................................................ 54

Figure 4.14: Recuperator Savings .............................................................................. 54

Figure 4.15: Input section for Nitrogen and Hydrogen Data ............................................ 56

Figure 4.16: Power and Energy Consumption Details for Electrical Equipment............. 56

Figure 4.17: Energy Consumption Details for Natural Gas Equipment and H2-N2 Data 57

Figure 4.18: Monthly Summary Sheet Snapshot 1 ………........................................... 60

Figure 4.19: Monthly Summary Sheet Snapshot 2 ………............................................. 61

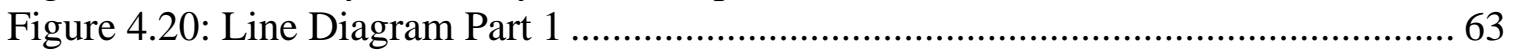

Figure 4.21: Line Diagram Part 2 ........................................................................... 64

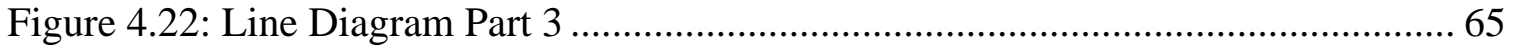

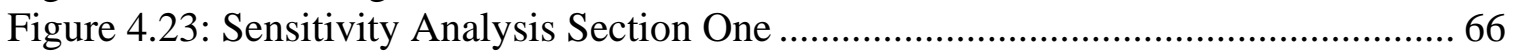

Figure 4.24: Sensitivity Analysis Section Two............................................................... 67

Figure 4.25: Graph of Campaign period Vs MMBtu/ton ................................................... 68

Figure 4.26: Graph of Campaign period Vs Increment in annual production .................... 69

Figure 4.27: Graph of Campaign period Vs Energy savings ............................................ 69

Figure 4.28: Economic Analysis............................................................................... 71

Figure 5.1: Sensitivity Analysis.................................................................................... 74

Figure 5.2: Sensitivity Analysis for Increased Campaign Period...................................... 75

Figure 5.3: Extract from Summary Sheet ………………............................................ 75

Figure 5.4: Overall Energy Consumption ................................................................... 76

Figure 5.5: Natural Gas Energy Consumption................................................................. 76

Figure 5.6: Electrical Energy Consumption....................................................................... 77 


\section{$\underline{\text { List of Tables }}$}

Table 1.1: U.S. Net Shipment of Steel Mill Products .................................................... 2

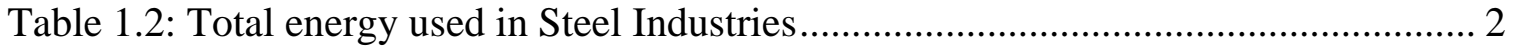

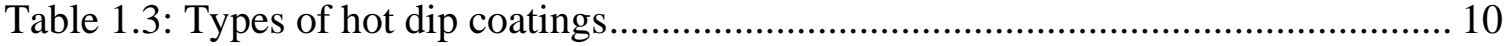

Table 2.1: Energy Savings for IMF Project Calculated by GPRA Spreadsheet............... 18

Table 2.2: Properties of Pure Zinc ............................................................................ 21

Table 2.3: Comparison between actual and theoretical power requirement.................... 26

Table 3.1: Sample list identifying energy intensive equipment, type of fuel and point of

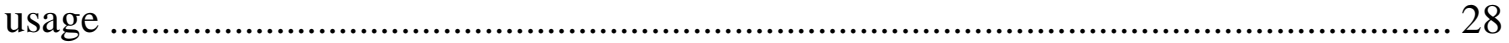

Table 3.2: Example of Data Collection Sheet for Electric Motors ................................. 30

Table 3.3: Example of Survey Form for Different Natural Gas Equipment...................... 32

Table 5.1: Comparison between Actual and Calculated Energy Consumption................. 74 


\subsection{Introduction}

\subsection{Background}

The steel industry accounts for 2-3\% of all energy consumed in the United States [1]. It employs over 150,000 people in well-paying jobs and is among the most productive, efficient, and technologically sophisticated industries in the world [2]. There are more than fifty galvanizing lines in the United States. They produce galvanized steel sheet by pulling it over a roller that is submerged in a molten Zinc, Zinc alloy or Aluminum alloy bath. Although highly competitive, galvanized steel is very lucrative for the steel industry [3]. The coat provides an excellent long term barrier to corrosion thus increasing the service life of steel. Application of galvanized sheet steel consists of a wide spectrum which includes construction, utilities, chemical process, paper and pulp, automobile, structures, machinery and aviation. Approximately half of the zinc produced worldwide is used as a coating in the galvanizing of steel (and iron) for the purpose of corrosion protection [4].

Table 1.1 summarizes the net shipment of various steel products for the year 2000 and 2001 [5]. It can be observed that galvanized steel manufactured with the hot dip process in year 2000 and 2001 accounts for 14,872,000 and 14,293,000 tons respectively. This ranks the production of galvanized sheet steel to be second highest in the steel industry and thus explains the huge demand for galvanized steel products in the US market.

In 1994 the US steel industry consumed 2 quads (quadrillion Btu or $10^{15} \mathrm{Btu}$ ) of energy. This study includes the losses incurred during the distribution, generation, and transmission of electricity. According to the data complied by the American Iron and Steel Institute, in 1997, 1.8 quads of energy were consumed including the electrical losses. This is about $2.5 \%$ of the total domestic energy consumed in the US and about $8 \%$ of the manufacturing energy use. Table 1.2 shows the energy usage in the corresponding years [1]. 
Table 1.1: U.S. Net Shipment of Steel Mill Products

(Thousands of Net Tons)

\begin{tabular}{|l|r|r|r|}
\hline Steel Products & 2001 & \multicolumn{1}{|c|}{2000} & \% Change (00-01) \\
\hline Sheets & 18,287 & 19,770 & $(7.5)$ \\
$\quad$ Hot-rolled & 12,404 & 14,847 & $(16.5)$ \\
Cold-rolled & & & \\
\hline Sheets and Strip & 14,293 & 14,872 & $(3.8)$ \\
$\quad$ Galvanized hot-dipped & 3,012 & 3,496 & $(13.8)$ \\
Galvanized electrolytic & 1,902 & 2,138 & $(9.1)$ \\
All other metallic-coated & 481 & 529 & $(20.6)$ \\
Electrical & & & $(25.6)$ \\
\hline Strip & 690 & 869 & $(9.3)$ \\
Hot-rolled & 1,683 & 2,262 & 109,050 \\
Cold-rolled & 98,940 & & \\
\hline Total & & & \\
\hline
\end{tabular}

Table 1.2: Total energy used in Steel Industries

\begin{tabular}{|c|c|}
\hline Year & $\begin{array}{c}\text { Total Energy used } \\
\text { (Trillion Btu's) }\end{array}$ \\
\hline 1985 & 1,869 \\
\hline 1988 & 2,067 \\
\hline 1991 & 1,673 \\
\hline 1994 & 1,983 \\
\hline
\end{tabular}

\subsection{Process of Galvanizing}

The history of galvanizing dates back to 1742 when a French chemist named P.J. Malouin, in a presentation, described a method of coating iron by dipping it in molten zinc [6]. Galvanizing at its most basic level is dipping steel products into a molten zinc bath. A metallic reaction ensues and a thin coating of zinc is formed, evenly covering all areas of exposed base metal. This simple approach is still used today. Iron and steel components that are required to be galvanized follow a sequence of operations.

\subsubsection{Inspection prior to galvanizing}

The design of the component to be galvanized, any welding present on the component and the surface condition of the material, must be examined to be acceptable for galvanizing. The component must be free of slag from stick welding and of some paints (e.g. enamel) as they are difficult to remove except by abrasive blasting, grinding or the use 
of a paint remover. Water borne paints or appropriate markers should always be used for identification or marking during fabrication of products which are to be galvanized.

\subsubsection{Degreasing}

Components, which are appropriately suspended from materials handling devices, are immersed in a degreasing chemical. This is to ensure that steel surfaces are not masked from the subsequent and most important acid pickling process. If an alkaline caustic soda based degreaser is used, subsequent rinsing in water is essential in order to avoid a neutralizing effect on acid during pickling. Acid degreasers normally contain hydrochloric acid but, phosphoric acid based degreasers are also effective.

\subsubsection{Acid Cleaning (Pickling)}

Either hydrochloric or sulfuric acid is used to prepare steel for galvanizing. Hydrochloric acid is used unheated at a concentration of $15 \%$. Sulfuric acid is heated to a temperature of about $70^{\circ} \mathrm{C}$ with a concentration of $10 \%$. In conventional plants material is rinsed in water before it is transferred to a flux solution. In some plants where hydrochloric acid is used, rinsing is dispensed with. The acid carried over is converted into either ammonium chloride by additions of ammonium hydroxide or zinc chloride by adding zinc dust. Other contaminants are filtered out.

\subsubsection{Flux}

After pickling in acid, the material is transferred to a flux solution, which consists of ammonium chloride and zinc chloride. This solution is normally heated to a temperature of $70^{\circ} \mathrm{C}$. The flux plays an important role in that it provides barrier protection to prevent flash rusting during the period between acid pickling and immersion in zinc. It also has a final cleansing effect on steel surfaces as they enter the zinc. The flux also facilitates the formation of a uniform coating free from discontinuities.

\subsubsection{Hot Dip Galvanizing}

After fluxing and further drying (ideally in a drying oven to avoid excessive splashing of zinc due to the presence of moisture), the products are dipped into the molten

zinc, which is heated to a temperature of about $450^{\circ} \mathrm{C}$. This is $30^{\circ} \mathrm{C}$ above the melting temperature of zinc. In automatic or semi-automatic plants, where products such as small- 
bore tubing are hot dip galvanized, withdrawal speeds are much faster with the ultimate coating thickness and finish controlled by external air wiping and steam jet blasting of the internal bore.

\subsubsection{Quenching}

This process solidifies the zinc coating to ensure easy handling. It also arrests the alloying reaction in the case of reactive steels, which continues well below the melting temperature of zinc. The quench water normally contains a passivating chemical, which retards the formation of white rust (wet storage stain) until such time as when the freshly applied reactive zinc surface has developed a stable and protective basic zinc carbonate film.

Figure 1.1 [7] shows the various layers that are formed due to a reaction between steel and zinc. These consists of base steel as the inner most layer i.e. the alpha ( $\alpha$ ) layer and the top most layer is of pure zinc called the eta $(\eta)$ layer, in between there are three layers containing different Fe-Zn proportions and harnesses. These are called gamma $(\mathrm{Y})$, delta $(\delta)$ and zeta $(\zeta)$ moving in order form base steel to outer Zn layer.

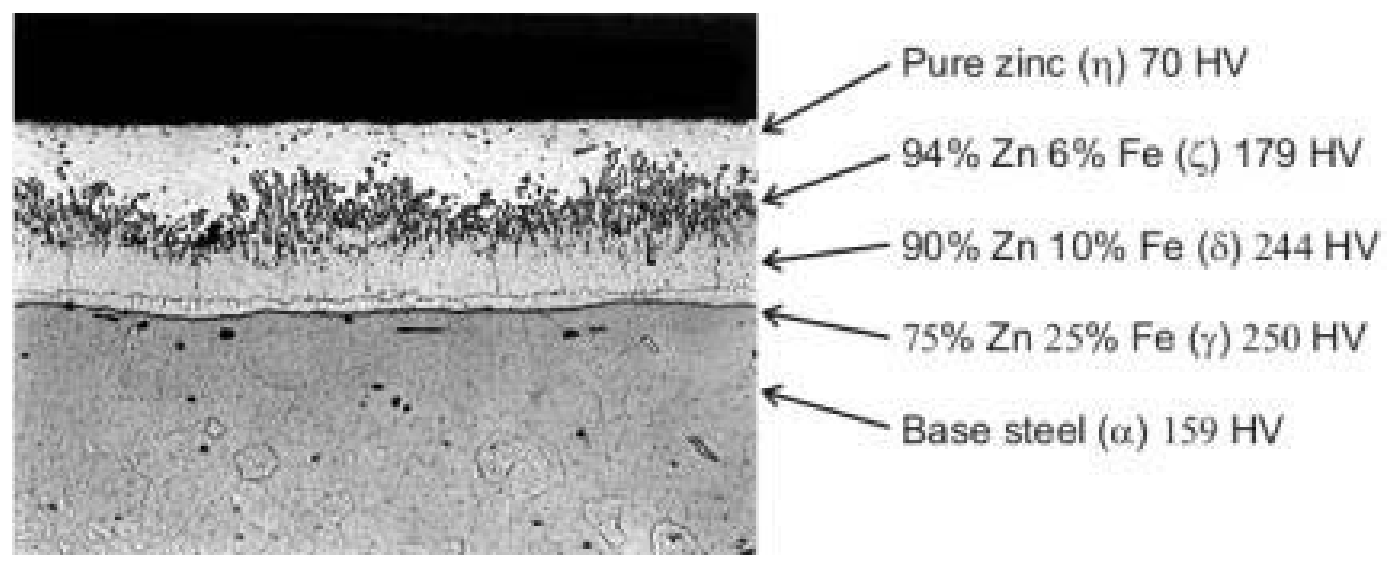

Figure 1.1 Fe-Zn Layers [7]

There are two methods of galvanizing, hot dip galvanizing and continuous galvanizing. In hot dip galvanizing, ferrous components that are to be galvanized are held by an overhead crane and dipped sequentially in tanks containing various liquids for surface preparation before dipping them in to the final molten zinc bath. Hot dip galvanizing is done to steel products like rods, channels, small and medium size machine 
components, steel plates, bolts, nuts and many more, which can be hanged firmly with help of wires.

Continuous galvanizing on the other hand consists of galvanizing sheet steel products of various gauges. The sheet steel strip is fed continuously from a payoff reel and passes through a number of sections, and gets coated with $\mathrm{Zn} / \mathrm{Zn}$ alloy before getting coiled up again. This process runs uninterrupted for weeks, hence it is called continuous galvanizing. The modern continuous galvanizing process was invented by Sendzimir over a half century ago [8].

Detailed description of different sections of continuous galvanizing line is discussed in the following sections.

\subsection{Continuous Galvanizing}

Figure 1.2 shows a flow diagram for a typical continuous galvanizing line.

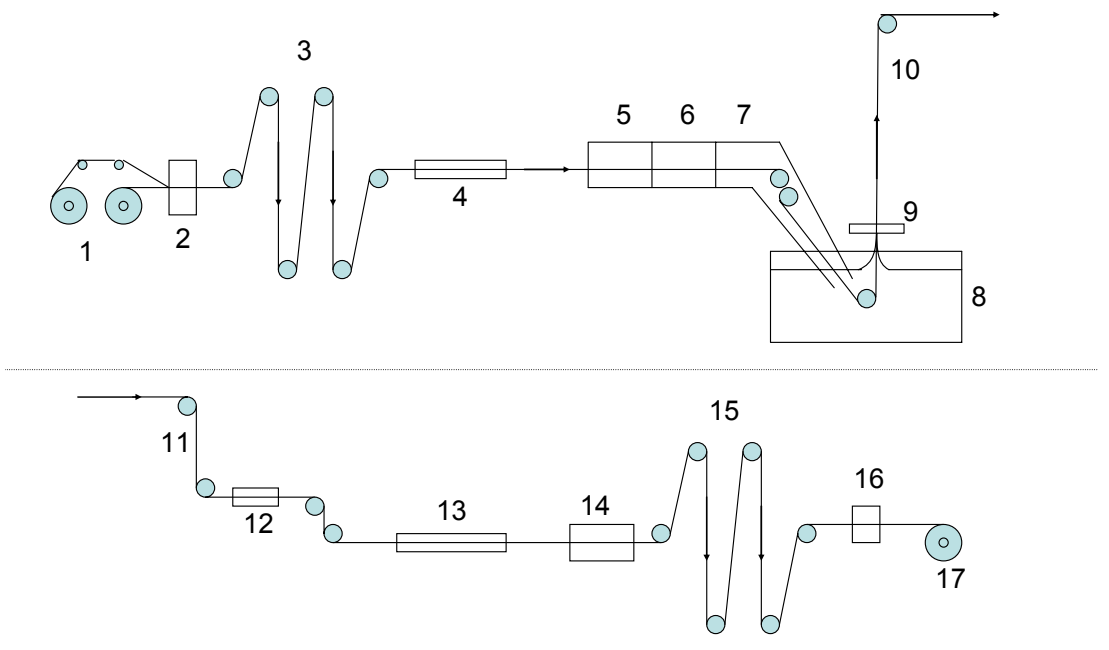

Figure 1.2 Continuous Galvanizing Line

1. Payoff Reels

2. Seam Welder

3. Accumulator loop car 1

4. Degreaser

5. Non Oxidizing Furnace (Annealing)

6. Radiant Tube Section

7. Jet Cooling Section

8. Molten Metal Pot (Zn/Zn Alloy)
9. Air/Gas Knives

10. Up leg Cooling

11. Down leg Cooling

12. Galvanneal Furnace

13. Online Inspection

14. Chemical Treatment

15. Accumulator loop car 2

16. Flying Shear

17. Carrousel Tension Reel 
The equipment listed above consumes either electricity or natural gas. The main electricity consuming devices are large motors used in these equipment and resistance or induction coils used for pre-melt and main zinc pot. In case of natural gas the largest consumers are the annealing and the galvanneal furnaces. Some of the equipment not shown in Figure 1.2 but which also consumes significant energy is the plant air compressors and pot hardware pre-heaters. A brief description of the process and the equipment it transfers through is explained in the following sections.

\subsubsection{Payoff Reel}

Uncoated sheet steel rolls are loaded on the payoff reel for coating. This is the starting point of the continuous galvanizing lines. There are typically two payoff reels. When one roll is about to exhaust, the trailing end of that roll is welded to the leading end of the second roll. Then as the second roll is unwound a new roll is kept ready in place of the first roll for discharge. This helps to keep the process continuous.

\subsubsection{Seam Welder}

The trailing end of the exhausting reel is welded to the leading end of the new reel with the help of the seam welder. During this time, the line is fed through the accumulated sheet steel from the entry end accumulator loop.

\subsubsection{Accumulator Loop Car 1}

The accumulator loop at the entry end is primarily used to maintain the continuity of the process when the payoff reel is getting changed. It is used to cover for the time lag caused by the seam welder. The loop car consists of series of rolls in a zigzag fashion through which the sheet steel passes. The accumulator stores the sheet steel inventory by increasing the distance between the consecutive rolls. Whenever the accumulator is unloading, the rolls start coming closer, thus releasing the sheet steel passing through them. About 700 to 1000 feet of sheet steel can be stored in the accumulator loop car.

\subsubsection{Degreaser}

The steel strip is cleaned of oil and dirt present on the strip surface before it enters the annealing furnace with the help of a degreaser. Sometimes the strip enters the furnace. In furnace the first section has open flames firing directly on the strip to burn out the impurities present on the surface. 


\subsubsection{Annealing Furnace}

Annealing is a heating and cooling operation to induce softness. The furnace has the following sections, pre heat section, non-oxidizing section, radiant tube section, and jet cooling (controlled cooling) section. The annealing furnace is the largest natural gas consuming equipment in the galvanizing facility. The different sections are discussed in detail as below,

a) Pre-heat section: This section comprise of burners firing directly on the strip in order to burn out impurities that may be present on the surface of the strip.

b) Non-Oxidizing section: The non-oxidizing section of the annealing furnace heats the strip in a deoxidizing atmosphere. $\mathrm{N}_{2}$ and $\mathrm{H}_{2}$ are used to replace air in the region. The set point temperature in this section is around $2250{ }^{\circ} \mathrm{F}$ to $2350{ }^{\circ} \mathrm{F}$, but it may vary according to the type of steel. The furnace atmosphere consists of a gas mixture of $13 \%$ hydrogen and $87 \%$ nitrogen [9]. The nitrogen and hydrogen atmosphere is created to prevent oxidation of the strip surface.

c) Radiant Tube section: The radiant tube section has a set point of $1350{ }^{\circ} \mathrm{F}$ to $1450{ }^{\circ} \mathrm{F}$. Again, it varies for different types of steels. The radiant tube section of the furnace helps to maintain the strip temperature in the deoxidizing atmosphere.

d) Controlled cooling (Jet cooling) section: The controlled cooling section of the furnace uses water-cooled heat exchangers and fans to slowly lower the temperature of the steel. The jet-cool furnace plunge cools the steel to roughly $860{ }^{\circ} \mathrm{F}$ to $900{ }^{\circ} \mathrm{F}$. The controlled cooling section is sometimes provided with electric heating elements in case, it is required to raise the temperature of the strip.

\subsubsection{Molten Metal Pot}

The galvanizing line consists of at least two pots containing the molten metal. They are the pre-melt pot and the main pot. The zinc and the compounding alloy metals are mixed and melted in the pre-melt pot to form a proper alloy composition. Then the metal is transferred to the main pot with the help of channels. The main pot is the one which has the sink and stabilizing rolls submerged in it, and over which the steel sheet is passed. Figure 1.3 shows a schematic of the continuous galvanizing pot. Both the pre-melt pots as well as the main pot have heating elements. Heating is done by electric resistance or induction coils or by using natural gas burners. 


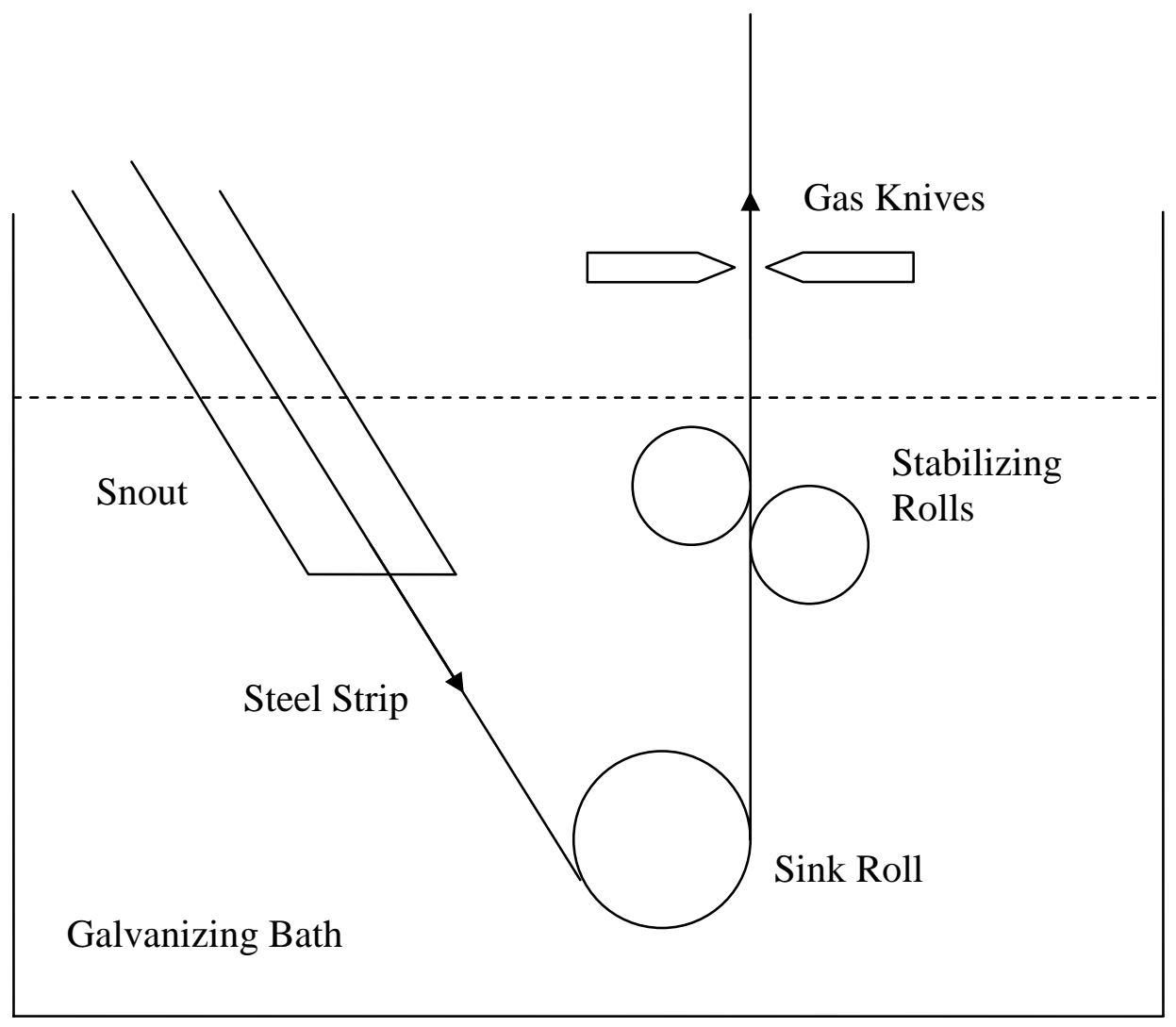

Figure 1.3 Schematic of Continuous Galvanizing Pot

The temperature of the molten metal is maintained at about $850^{\circ} \mathrm{F}$. The temperature varies according to the type of coating and steel strip material. The metal inside the pot is kept molten at all times, even when the line is off production for maintenance or any other reason. The pot is made up of low carbon and low silicon steel. Molten zinc causes erosion of steel walls by creating a zinc iron alloy, some of which adheres to the walls limiting further erosion. This erosion limits the life span of the pot to five to eight years [4].

\subsubsection{Air/Gas Knives}

The steel sheet that comes out of the molten metal pot passes through the air knives. The air or gas knives are used to strip out the excess coating material from the surface of the steel strip. The thickness of the coating can be properly controlled by setting the air pressure on the knives. 


\subsubsection{Cooling tower}

The strip passes through a cooling area where cold air is blown over it. The air is cooled by blowing it through water radiator tubes. The strip is further cooled in an atomized water fog cooler.

\subsubsection{Galvanneal Furnace}

The galvanneal furnace has controlled heating and cooling zones to create a proper finish on the steel. The galvanneal furnace may not be used in case of some types of coating like aluminize or galvalume. Also the furnace may not be present at all if the type of coating that requires the galvanneal furnace is not used in a particular facility. Figure 1.4 shows the schematic of the location of the galvanneal furnace or the holding furnace [30].

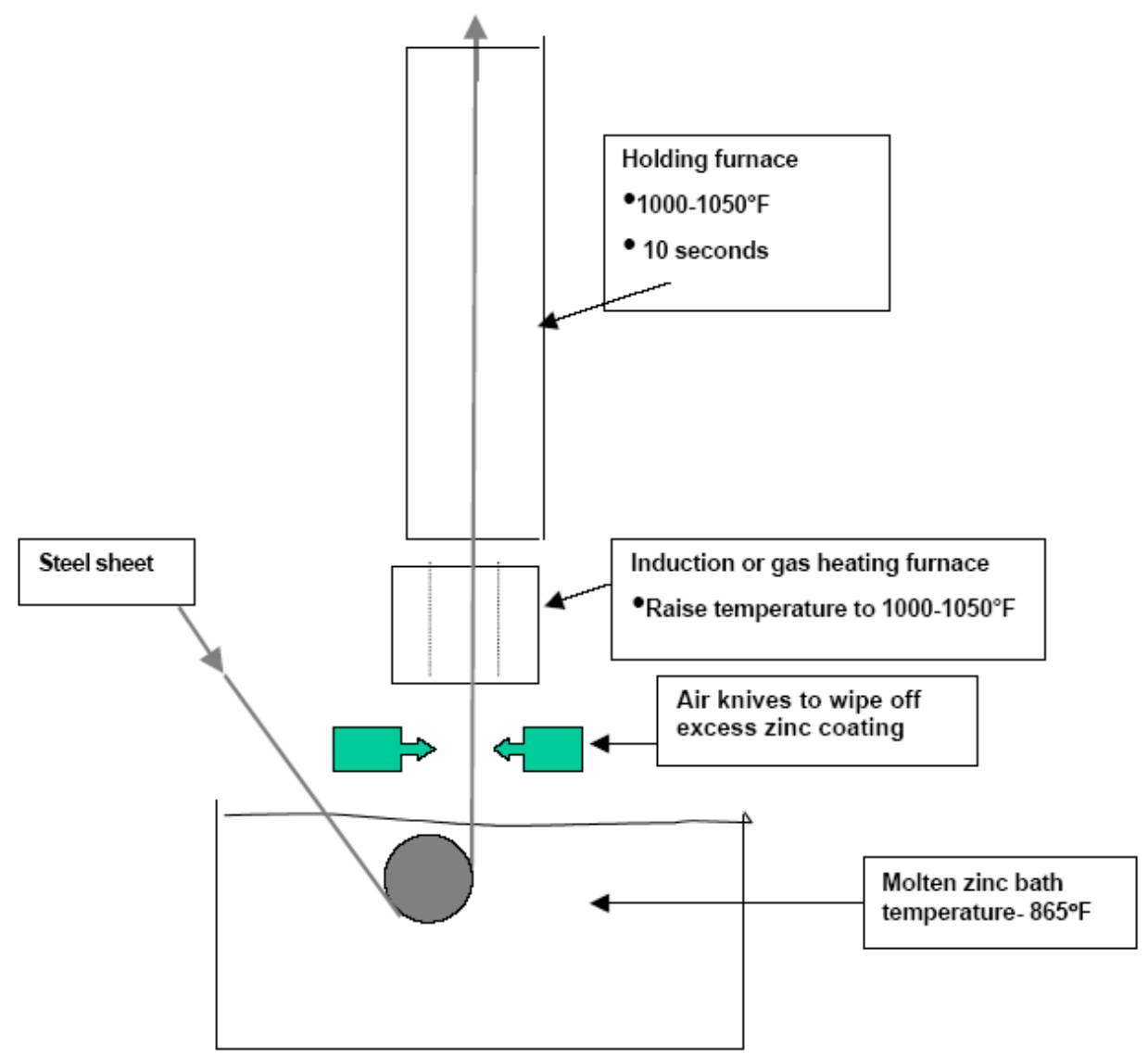

Figure 1.4 Location of the Galvanneal or Holding Furnace

A skim pass mill, and/or a temper mill etc (used to improve the steel surface) may also be present on the line. Every facility has a unique setup to suit its range of products. 


\subsubsection{Quality Enhancement and Inspection}

Surface appearance, mechanical property and shape improvement is accomplished with the help of skin pass rolls and tension leveler. X-ray coating, weight gauge and pin hole detector are used to monitor the quality of the product being rolled. In order to achieve the required coating standards, routine analyses of the various chemicals used in the process are essential. Failure to do so results in substandard coatings and also adds to the processing costs for the galvanizer. A suitably calibrated coating thickness measurement instrument is used to ensure that coating thicknesses conform to the requirements of the relevant specification. Table 1.3 describes the various hot dip coatings, their compositions and ASTM standards describing these products [31].

Table 1.3: Types of hot dip coatings

\begin{tabular}{|c|c|c|c|}
\hline Sr. No. & Types of Coating & Composition & ASTM Standard \\
\hline 1 & Galvanized & Zinc & $\begin{array}{c}\text { ASTM A 653/A 653M } \\
\text { (Wide variety of end uses) }\end{array}$ \\
\hline 2 & Galvanneal & Zinc/10\% Iron & $\begin{array}{c}\text { ASTM A 653/A 653M } \\
\text { (Intended to be painted) }\end{array}$ \\
\hline 3 & Galvalume & $55 \%$ Al/Zinc/1.5\% Si & $\begin{array}{c}\text { ASTM A 792/A 792M } \\
\text { (Metal roofing \& siding) }\end{array}$ \\
\hline 4 & Galfan & Zinc/5\% Al & $\begin{array}{c}\text { ASTM A 875/A 875M } \\
\text { (Prepainted siding) }\end{array}$ \\
\hline 4 & Aluminized & Al or Al/5-11\% Si & $\begin{array}{c}\text { ASTM A 463/A 463 M } \\
\text { (Heat/oxidation resistance) }\end{array}$ \\
\hline 6 & Terne & Lead/8\% Tin & $\begin{array}{c}\text { ASTM A 308/A 308M } \\
\text { (Fuel tanks) }\end{array}$ \\
\hline
\end{tabular}

\subsubsection{Chemical Treatment}

Chemical solution is sprayed on specific products in order to further prevent white rust oxidation. Acrylic coat is sometimes applied on the surface to prevent the surface from physical damage. 


\subsubsection{Accumulator Loop Car 2}

Similar to accumulator loop car 1 , accumulator 2 is used to store the galvanized steel when the carousal reel is being replaced with a new one. Again, similar to loop car 1 , this car also consists of series of rolls in a zigzag fashion through which the sheet steel passes. The accumulator stores the sheet steel inventory by increasing the distance between the consecutive rolls.

\subsubsection{Re-coiler}

Finally, the finished steel strip is oiled, rewound and packed for shipping. Carrousel type tension reel winds the out coming strip. This setup is designed to reduce material handling. The re-coiler is the last equipment in the continuous galvanizing line.

\subsection{Need for Research}

The zinc pot also includes hardware submerged in the molten metal. The submerged hardware consists of a sink roll, two stabilizing rolls and the structure supporting these rolls. Due to the high temperature and the corrosive nature of the molten metal in the pot the bearings and the journal on the rolls have a very short service life. The most frequent cause for line stoppage is the hardware problems in the pot. These issues are related to one or more of the following three issues [26]:

1. Performance of bearings supporting rotating components, such as the sink roll, stabilizer roll and deflector roll.

2. Corrosion of pot hardware in molten zinc, including corrosion of materials subjected to sliding contact.

3. Nucleation and growth of dross (inter metallic particles) on pot hardware, especially roll surfaces causing cosmetic defects in strip coating.

The replacement or repair of the submerged hardware requires a complete stoppage of the production line. Any compromise with the submerged hardware deteriorates the quality of the coat and that is unacceptable. This leads to frequent replacement of the submerged hardware. The average campaign period for a typical galvanizing line is 15 days due to hardware failures.

During the shutdown period much of the equipment needs to be kept operating. For example the coating metal must be kept molten and the annealing furnace is operating on low fire. In addition to this, several systems are left running like air 
compressors and cooling towers. This happens since there is no automatic control to shut down the unnecessary equipment during shutdown. This equipment that needs to be kept operating consumes about 6,000 MMBtu/year during the shutdown period.

In addition, frequent shutdowns raise quality issues, increase scrap and generate inventory. Thus, it is not only the cost of energy that affects the facility but the production side performance also deteriorates due to these frequent changeovers. Just by increasing the campaign period from the current 14 days to a new level of 35 days, decreases production time loss by $50 \%$ and the energy consumption during downtime is reduced to 2,500 MMBtu/year. Assuming a production rate of 40 tons per hour an annual increase of 8,000 tons can be achieved in addition to 3,500 MMBtu of energy savings.

Productivity drives the iron and steel industry. Tons of finished steel produced per hour is monitored carefully. Methodologies suggesting any increment in productivity are appreciated by the manufacturer. Also, improvement in productivity and quality of product has always been a prime focus for any industry especially when it comes to a technology driven, hi-tech, highly competitive industry such as the steel industry. Projects focusing on energy efficiency achieve their goal also by impacting the productivity of the industry. Hence it is necessary to develop a model which will tie the annual production and energy consumption together and provide value for energy per unit production. Various tools are available to measure production and energy consumption independently but none of them consider the joint effect of these two parameters together. Changes of any kind in the energy consumption cannot be projected on the production instantaneously and vice versa with the help of any current available tool. This generated a need for tools that can evaluate energy consumption based on the production instantaneously and can allow simulation and sensitivity analysis.

\subsubsection{Necessity to know the specific energy consumption}

The research performed as a part of this thesis is aimed to quantify the energy benefits obtained from better hardware material, and, to obtain the current energy consumption in MMBtu/ton of galvanized sheet steel produced.

Recently many steel manufacturing and galvanizing facilities have collaborated with facilities from Asia and South America. These firms are purchased by multinationals in order to capture the market share. The corporate level decides on the continuation of 
manufacturing in the purchased facility. It may shut down some or all of the operations in a particular facility if it is found unproductive and may move the operations to sister concerns or overseas. What makes the corporate level take these decisions is the comparison of profit margins among their various national and oversea facilities. Hold of a fraction of market share strengthens their decision policies.

There are various reasons for low profit margins. High energy costs have been identified as one of the reasons for decreasing profit margins of US firms compared to their overseas counterparts. A continuous galvanizing line is an automated process, which uses high tech computer controls and state of the art technology. It is not labor intensive. Also, the chemicals and metals used in the process are not deficient or restricted. Thus, the only variable left that needs to be scrutinized is energy use. This makes energy consumption a high priority issue for survival of the facility. The energy consumption per unit of production is a convenient way to compare performance of various facilities. On the basis of specific energy consumption details the manager can easily identify those areas where money is being wasted on energy compared to similar healthy counterparts.

\subsubsection{Necessity for Sensitivity Analysis}

Once the energy consumption per unit production is obtained, the next step is to identify the opportunities for energy conservation. There are several parameters that can be modified. Equipment capacities, new technology, alternative methods, schedules, best suitable product etc are various means of improving efficiency and increasing productivity of the existing facility. The Department of Energy provides several tools and information to assist in the field of energy conservation, efficiency improvement and waste minimization. One can calculate and enter the savings obtained as a result of implementing one or more of these techniques in order to obtain the revised energy consumption. A simple comparison of the new energy consumption with the existing consumption or with a benchmark will help to filter out the most beneficial alterations that need to be made to the system. With the help of this model it can be easy to obtain the management approval for funds needed to implement the changes. Sensitivity analysis can provide changes in energy consumption and production within minutes without any physical change to the existing system. If one wishes to obtain the energy benefits as a result of application of a better hardware material, the material needs to be 
tested only for a period of few weeks and then the results can be extrapolated to obtain the annual savings. This expedites the decision making process on the shop considerably.

\subsubsection{Necessity for Accuracy}

The model is not only a guideline for energy consumption benchmarking, but also for making substantial decisions for a facility. It can be used to demonstrate the benefits obtained by the implementation of any new technology. This analysis can be demonstrated to sanction a budget for implementation. It can also be used to make significant decisions such as to continue with an existing process or to adopt an alternate process at a particular facility. It may also be used to cease manufacturing a certain type of product all together. These decisions may change life for hundreds of people dependent on the facility. Bearing the importance of this kind of decisions they must be properly backed up with figures obtained from various analyses. This focuses on the importance of the accuracy of the model. Accuracy not only in terms of calculations done by the model but also in the input provided by the user is extremely important.

\subsection{Research Objectives}

The main objectives of the research are as listed:

1. Accurately model a Continuous Galvanizing Line to reflect all the energy points.

2. Enable static simulation of production, rejection and energy consumption.

3. Enable production managers to do sensitivity analysis and evaluate economic benefits of adopting new hardware materials.

4. Enable energy managers to analyze the impact of energy saved if they implement any energy savings or efficiency improvement technique on their equipment.

5. Enable materials researchers to realize the benefits obtained as a result of application of new hardware material developed by them.

\subsubsection{Galvanizing Energy Profiler Decision Support System (GEPDSS)}

A tool was required to validate the energy savings described by researchers in the mentioned projects. One way was to wait for a response from the industries regarding the performance of the new materials. Comparing their previous and current energy bills 
would help to estimate the impact of energy savings. But sometimes it was not practical as it may take years for the materials to get established in the market and lead to results. Hence a computer model was required to approximate the impact of the new hardware materials on the energy consumption of the galvanizing lines. Figure 1.5 shows a system diagram of the proposed decision support system (DSS).

\subsubsection{Starting on the DSS}

The challenge was to identify a basis for comparison and quantification of energy consumption. Options considered were energy consumed per hour, per ton, per unit area of steel galvanized, and so on. The common unit of measurement for the galvanizing industry was tons of galvanized sheet steel produced. The facilities were also interested in learning about any increase in production along with the savings in energy, caused as a result of the project. Thus, the model was designed by keeping the industry's interest in mind.

\subsubsection{Expectations from the DSS}

The vision was not just to develop a tool that will help validate the project results but also something that will trace the production, rejection, downtime, idle and production durations, energy costs associated with production and rejection durations, generate a of log to trace causes for shutdowns etc. The aim was to develop a generic tool for the facility staff to make informed decisions, pin point problem areas and understand energy flow more closely in their facility. This led to the identification all the energy points in the entire continuous galvanizing line and a careful study of the process to tap the energy.

Thus, the research objectives can be summarized to create a model that ties all energy points on a continuous galvanizing line with respect to production and rejection rate, enabling sensitivity analysis and providing decision making information for managers and researchers. 


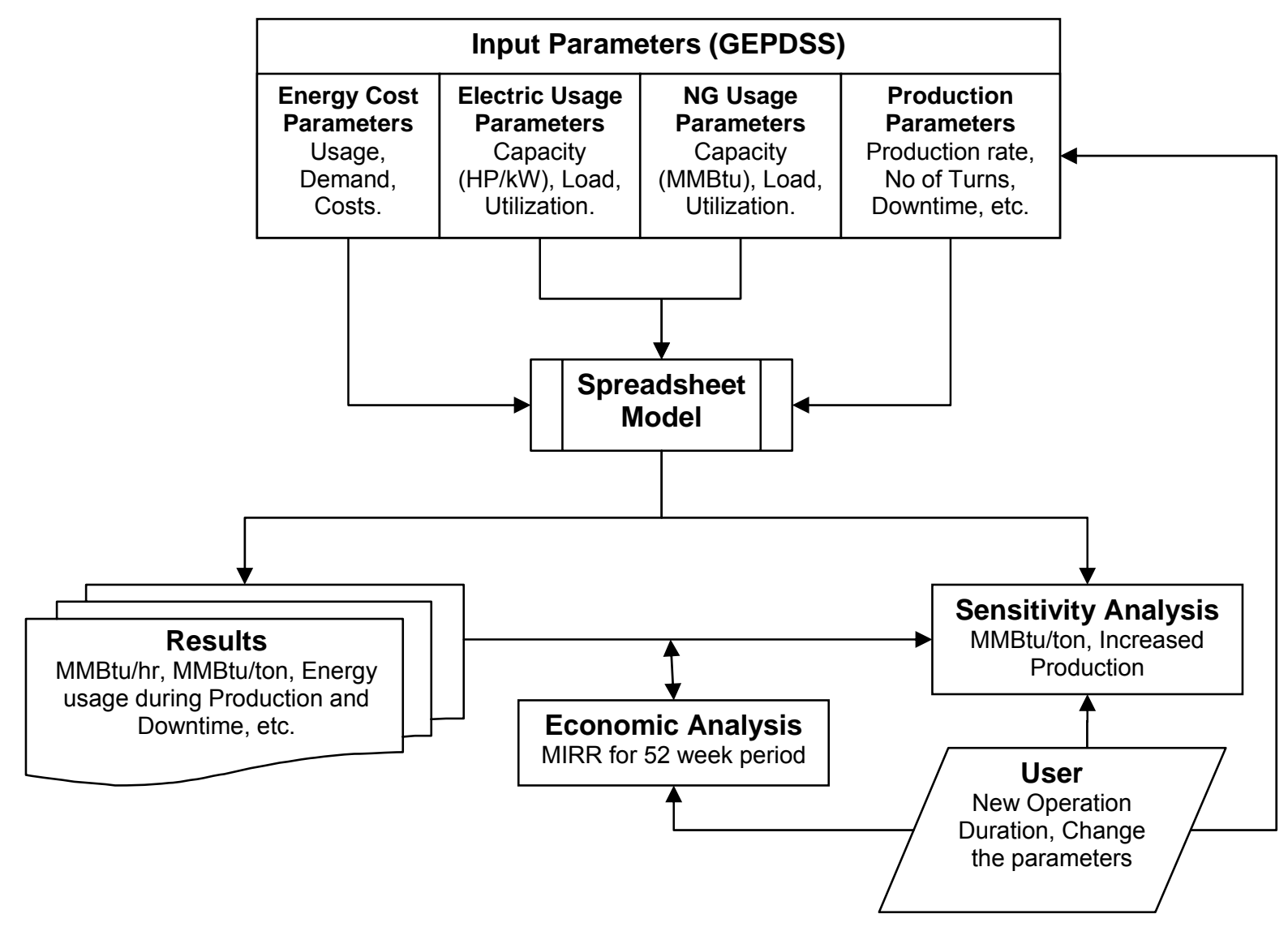

Figure 1.5: System Diagram

\subsubsection{Conclusion}

The galvanizing industry at present faces considerable loss of production and energy as a result of stoppages related with pot hardware failure. The impact of increasing the current campaign period from a 14-day period to a 35-day period is mentioned in section 1.4. The proposed decision support system is expected to analyze and provide results in terms of energy savings and/or increased production obtained as a result of any modification to the existing process. 


\subsection{Literature Review}

\subsection{Energy Measurement and Monitoring}

The modern machinery is very well equipped with controls and meters to administer the required amount of energy based on demand and provide the current energy consumption data for the equipment. This helps to realize the amount of energy being introduced for a particular service in the entire process. Hi-tech sensors provide accurate data to calculate the real time demand and feedback loops transfer this data to computers, which then activates automatic controls based on the analyses of the data.

Several energy management tools are proposed by the United States Department of Energy (DOE). Government funded projects like the Industrial Assessment Center (IAC) provide energy assessment services to several energy intensive facilities. The IAC not only provides them with free assessments but also the DOE decision tools software CD and training. For example, the DOE's decision tool MotorMaster+тм [34] is used to help document motor inventory and to identify/analyze motor driven systems for various energy conservation opportunities. Another similar tool is AirMaster+тм [35], which assists in energy conservation opportunities related to compressed air system in the facility. Also, tools like 3Eplus ${ }^{\mathrm{TM}}$ [37] from North American Insulation Manufacturers Association, and the DOE Process Heating Assessment and Survey Tool (PHAST ${ }^{\text {тм}) ~[36] ~}$ from Industrial Heating Equipment Association, provide data of energy lost as a result of improperly or un-insulated surfaces and calculate efficiency based on air fuel ratio and heat balances for process heating equipment respectively. All these software tools need data input measured from various sensors. The result is fairly accurate information about the energy consumption, energy loss, efficiency measurements, and economics for particular equipment like compressors or boilers.

Some previous studies done in the area of energy consumption associated with the galvanizing industry includes research done by S. G. Blakey and S. B. M. Beck [4]. They came up with a dimensionless equation-demonstrating method for improving furnace efficiency. In their analysis they showed that the current method of burner turndown to reduce energy consumption worsens the thermal efficiency of the furnace (bath furnace) especially at low levels of capacity utilization. The research focused on energy consumption of natural gas fired galvanizing bath furnace. This was the first approach, 
using specific energy consumption from the demand and supply point of view, to describe thermal efficiency. The equations developed are used to compare furnaces of different design and fuel types [4]. However, the equations do not take into account any other equipment present on a galvanizing line. Naoharu Yoshitani, and Akihiko Hasegawa have developed a mathematical model to control the strip temperature in continuous annealing furnace. The model previews the approaching setup change, which is the change of strip size or reference temperature, and optimizes the line speed and the strip temperature trajectory [32].

\subsection{Development in Galvanizing Pot Hardware}

In recent years, research has been conducted to evaluate the performance of materials in galvanizing baths in order to identify "high performance" pot hardware materials $[10,11,12]$. Attempts are being made to develop materials that can withstand the high temperature and corrosive environment of the zinc pot and provide a prolonged service life. Research has progressed on two such projects supported by the United States Department of Energy. The projects are "Development of Improved Materials for Continuous Steel Hot-Dipping Processes." 2001-2005, and “Multifunctional Metallic and Refractory Materials for Energy Efficient Handling of Molten Metals” 2004-2007. The research group consists of West Virginia University Research Corporation, University of Missouri-Rolla, Secat, Oak Ridge National Laboratory, Energy Industries of Ohio and over 23 industrial partners. The benefits resulting from the latter project were calculated using the Government Performance and Results Act 1993 (GPRA) spreadsheet. The energy savings projected using the GPRA spreadsheet is summarized in the Table 2.1. This analysis was done for the project titled, Multifunctional Metallic and Refractory Materials for Energy Efficient Handling of Molten Metals.

Table 2.1: Energy Savings for IMF Project Calculated by GPRA Spreadsheet

\begin{tabular}{|c|c|c|c|c|}
\hline Impact by Year & $\mathbf{2 0 1 0}$ & $\mathbf{2 0 1 5}$ & $\mathbf{2 0 2 0}$ & $\mathbf{2 0 2 5}$ \\
\hline $\mathbf{1 \%}$ Savings (Trillions of BTU) & 0.28 & 2.3 & 9.99 & 16.1 \\
\hline $\mathbf{5 \%}$ Savings (Trillions of BTU) & 1.1 & 9.02 & 39.19 & 63.21 \\
\hline
\end{tabular}

These savings are calculated by subtracting the energy used by primary production sector from the total energy used by the industry. This included energy consumed by three 
different industrial sectors namely aluminum, steel and metal casting industry. The calculations to get the energy associated with these three industries that will be impacted by the ongoing research are given below.

Aluminum: Total Energy used by the industry - Energy used by primary production sector $=\left(4 \times 10^{14}-1.747 \times 10^{14}\right)=2.253 \times 10^{14}$ BTU $[13,14,15]$.

Steel: Total Energy used by the industry - Energy used by primary production sector $=$ $\left(1.8 \times 10^{15}-9.0 \times 10^{14}\right)=9.0 \times 10^{14} \mathrm{BTU}$.

Metal Casting: Energy associated with molten metal containment, transfer and handling related functions $=\left(0.2 \times 2.43 \times 10^{15}=4.86 \times 10^{14}\right.$ BTU (i.e. energy associated with ladles, troughs, etc $\sim 20 \%$ of total value $[13,14,16]$. These savings are obtained from energy associated with molten metal containment and transfer and handling related functions.

Thus the total energy usage for these three industries is $1.6113 \times 10^{15} \mathrm{BTU}$. Assuming that the new hardware material developed by the researchers will recover $1 \%$ of the energy loss, the total energy savings will be $0.0161 \times 10^{15}$ BTU. Total production for the aluminum, steel and metal casting industries is 4, 95 and 13 million metric tons respectively in the United States [13].

The Department of Energy has sponsored several research projects in the field of material science and metallurgy. These projects concentrate on development of new materials and technology, which can realize energy savings and reduce $\mathrm{CO}_{2}$ emissions. John L. Loth proposed a modified zinc pot bearing design for increased bearing life [24]. Different bearing materials were tested using a small scale tester developed by West Virginia University (WVU) Department of Mechanical and Aerospace Engineering (MAE). The results were used for empirical wear rate modeling of zinc pot bearing material [25]. A coating line may incur an economic loss as high as $\$ 500,000 /$ year due to reduction in productivity as a result of bearing failure [13]. Corrosion tests for various hardware materials in liquid metal bath have been carried out by Oak Ridge National Laboratory (ORNL). Since 2001, a more fundamental approach to the improvement of pot hardware materials and designs, aimed at creating an entirely new class of pot hardware materials, has been underway in a cooperative program co-funded by U.S. Department of Energy (U.S. DOE) with a total budget of \$4.6 million [26]. Bruce Kang 
and Venkatesh Parthasarathy carried research to discover the causes of hardware wear and tear in a liquid metal bath under conditions similar to those in galvanizing facilities [27]. K. Zhang and N. Y. Tang carried out experiments to study the reactions of various materials with a galvanizing bath and concluded that Co and Fe based super alloys and cermets coatings react with $\mathrm{Zn}-\mathrm{Al}$ bath reducing bearing life [28].

\subsection{Development in Galvanizing Bath Management}

Extensive research has been carried out and is still going on in the area of galvanizing bath chemistry. Understanding the reactions, its relation with the temperature, composition and metallurgy is a primary area where the International Lead Zinc Research Organization's (ILZRO) efforts are focused. The galvanizing bath itself is perhaps the least understood component of any given galvanizing line, particularly with regard to the chemistry of the contained zinc alloy [17]. The zinc, iron and aluminum crystallographic structure and the properties of intermetallic compounds have been studied extensively $[18,19,20]$. The flow of the molten metal and its behavior during functioning of line is modeled [21]. Sensors are developed that are capable of providing accurate bath composition and temperature [22]. Computer programs for bath managements have been developed; one of them is DEAL ${ }^{\mathrm{TM}}$--Determining Effective Aluminum, which was developed on the fundamentals of thermodynamics [23]. MAPтM - Modeling Aluminum Pickup is another computer tool that calculates the amount of $\mathrm{Al}$ picked up in the interface and the total amount of $\mathrm{Al}$ in the coating [17]. F. Ajersch, F. Ilinca, and J.-F. Hétu, performed a numerical analysis to simulate the velocity and temperature fields in an industrial galvanizing bath for the continuous coating of steel strip. The simulations allow visualization of regions of varying velocity and temperature fields [33].

\subsection{Theoretical Calculation for Power Requirement by the Zinc pot}

The zinc pot is a melting cum holding furnace. It is used to melt the zinc and heat it to the required process temperature. The zinc pot holds the heated zinc at the required temperature and melts the new zinc that is added to substitute the used material. A first principle approach to calculate the power required to melt the zinc, heat it to the required 
temperature, hold the metal and simultaneously heat the new metal added to compensate the used material is demonstrated in the following document.

\section{Properties of Zinc:}

Table 2.2 shows the properties of pure zinc used in the calculations.

Table 2.2: Properties of Pure Zinc

\begin{tabular}{|l|l|l|}
\hline Property & Metric Units & English Units \\
\hline Melting point of zinc & $419.58^{\circ} \mathrm{C}$ & $787.00^{\circ} \mathrm{F}$ \\
\hline Density of Zinc & $7.1 \mathrm{~g} / \mathrm{cc}$ & $0.257 \mathrm{lb} / \mathrm{in}^{3}$ \\
\hline Specific heat capacity (Cp) & $0.3898 \mathrm{~J} / \mathrm{g}-{ }^{\circ} \mathrm{C}$ & $0.0932 \mathrm{BTU} / \mathrm{lb}-{ }^{\circ} \mathrm{F}$ \\
\hline Latent heat of fusion (H) & $110 \mathrm{~J} / \mathrm{g}$ & $47.3 \mathrm{BTU} / \mathrm{lb}$ \\
\hline
\end{tabular}

The melting and holding capacity of the zinc pot considered for the calculation is assumed to be 40 tons or $88,185 \mathrm{lb}$.

\section{Start-up Energy Requirement}

This is the amount of energy required to start the process, i.e. to heat zinc from room temperature to process temperature.

1. Calculation for heat energy required to raise the temperature of the metal to melting point (No change of state).

$\mathrm{Qa}=\mathrm{m} \times \mathrm{Cp} \times(\mathrm{T} 2-\mathrm{T} 1) \ldots \ldots \ldots \ldots \ldots \ldots \mathrm{Eq} 2.1$

Where,

Qa $=$ Heat required to raise the temperature.

$\mathrm{m} \quad=\quad$ Mass of zinc, assumed to be 88,185lbs

$\mathrm{Cp} \quad=\quad$ Specific heat capacity, $0.0932 \mathrm{BTU} / \mathrm{lb}-{ }^{\circ} \mathrm{F}$

$\mathrm{T} 1=$ Initial zinc temperature assumed to be $80^{\circ} \mathrm{F}$

$\mathrm{T} 2=$ Final zinc temperature (melting point), $419.58^{\circ} \mathrm{F}$

Substituting in equation 2.1 we get,

$$
\begin{aligned}
\mathrm{Qa} & =88,185 \mathrm{lb} \times 0.0932 \mathrm{BTU} / \mathrm{lb}-{ }^{\circ} \mathrm{F} \times\left(419.58^{\circ} \mathrm{F}-80^{\circ} \mathrm{F}\right) \\
& =2,790,954 \mathrm{BTU} \\
& =818 \mathrm{kWh} \quad(1 \mathrm{kWh}=3,412 \mathrm{BTU})
\end{aligned}
$$


2. Heat energy required to melt the zinc (change the state of the materials).

$\mathrm{Qb}=\mathrm{mxH} \ldots \ldots \ldots \ldots \ldots . . \mathrm{Eq} 2.2$

Where,

$\mathrm{Qb}=$ Heat required to melt zinc.

$\mathrm{m} \quad=\quad$ Mass of zinc, assumed to be $88,185 \mathrm{lb}$

$\mathrm{H}=\quad$ Latent heat of fusion, $47.3 \mathrm{BTU} / \mathrm{lb}$

Substituting in equation 2.2 we get,

$$
\begin{aligned}
\mathrm{Qa} & =88,185 \mathrm{lb} \times 47.3 \mathrm{TU} / \mathrm{lb} \\
& =4,171,151 \mathrm{BTU} \\
& =1,222 \mathrm{kWh} \quad(1 \mathrm{kWh}=3,412 \mathrm{BTU})
\end{aligned}
$$

3. Heat energy required to raise the temperature of zinc from $419.58^{\circ} \mathrm{F}$ (melting point) to $450{ }^{\circ} \mathrm{F}$ (process temperature).

$\mathrm{Qc}=\quad \mathrm{m} \times \mathrm{Cp} \times(\mathrm{T} 3-\mathrm{T} 2) \ldots \ldots \ldots \ldots \ldots \ldots \mathrm{Eq} 2.3$

Where,

Qc $=$ Heat required to raise the temperature.

$\mathrm{m} \quad=\quad$ Mass of zinc, assumed to be $88,185 \mathrm{lb}$

$\mathrm{Cp}=$ Specific heat capacity, $0.0932 \mathrm{BTU} / \mathrm{lb}-{ }^{\circ} \mathrm{F}$

$\mathrm{T} 3=$ Final zinc temperature assumed to be $450{ }^{\circ} \mathrm{F}$

$\mathrm{T} 2=\quad$ Initial zinc temperature (melting point), $419.58^{\circ} \mathrm{F}$

Substituting in equation 2.3 we get,

$$
\begin{aligned}
\mathrm{Qc} & =88,185 \mathrm{lb} \times 0.0932 \mathrm{BTU} / \mathrm{lb}-{ }^{\circ} \mathrm{F} \times\left(450^{\circ} \mathrm{F}-419.58^{\circ} \mathrm{F}\right) \\
& =250,017 \mathrm{BTU} \\
& =73 \mathrm{kWh} \quad(1 \mathrm{kWh}=3,412 \mathrm{BTU})
\end{aligned}
$$

The total amount of energy required to start up the process $\mathrm{Q}$ is given by

$$
\begin{aligned}
\mathrm{Q}_{1} & =\mathrm{Qa}+\mathrm{Qb}+\mathrm{Qc} \\
& =818 \mathrm{kWh}+1,222 \mathrm{kWh}+73 \mathrm{kWh} \\
& =2,113 \mathrm{kWh}
\end{aligned}
$$


It takes approximately 12 hours to initially charge the molten metal pot. Thus, the power required to perform the work can be calculated as

$$
\mathrm{P}_{1}=\mathrm{kWh} \div \mathrm{T}(\text { Start-up time in hours)............Eq } 2.4
$$

Where,

$$
\begin{array}{lll}
\mathrm{P}_{1} & = & \text { Power required at the start of the process. } \\
\mathrm{kWh}= & \text { Total energy required to start the process. } \\
\mathrm{T} & = & \text { Start-up time in hours. }
\end{array}
$$

Substituting in equation 2.4 we get,

$$
\begin{aligned}
\mathrm{P}_{1} & =2,113 \mathrm{kWh} \div 12 \text { hours } \\
& =176 \mathrm{~kW} .
\end{aligned}
$$

The typical grid rating on the zinc pot varies from $360 \mathrm{~kW}$ to $400 \mathrm{~kW}$. The calculated power is less than the actual grid capacity since no losses or safety factors are considered.

Considering $15 \%$ factor of safety and $10 \%$ heat losses due to conduction and exposed surface, the calculated power requirement will be,

$$
\mathrm{Pm}=\mathrm{P}_{1} \times(1+\mathrm{SF}) \times(1+\mathrm{L}) \ldots \ldots \ldots \ldots . . \mathrm{Eq} 2.5
$$

Where,

$$
\begin{aligned}
& \mathrm{Pm}=\quad \text { Power required after considering losses and safety factor. } \\
& \mathrm{SF}=\quad \text { Factor of safety, assumed to be } 15 \% . \\
& \mathrm{L}=\text { Heat losses from the pot, assumed to be } 10 \% .
\end{aligned}
$$

Substituting in equation 2.5 we get,

$$
\begin{aligned}
\mathrm{Pm} & =176 \mathrm{~kW} \times(1+0.15) \times(1+0.1) \\
& =223 \mathrm{~kW}
\end{aligned}
$$

The calculated theoretical power required to start-up the zinc pot and reach the process temperature is $223 \mathrm{~kW}$, while the actual grid capacity observed in the facilities is from $360 \mathrm{~kW}$ to $400 \mathrm{~kW}$. 


\section{Process Energy Requirement}

This is the amount of energy required to keep the process operating, i.e. to melt the additional zinc from room temperature to process temperature.

The amount of zinc added to the pot is 2 tons $(4,409 \mathrm{lb})$ per hour. It is assumed that there is no separate melting furnace for the zinc and the zinc is directly added to the main pot.

4. Calculation for heat energy required to raise the temperature of the metal to melting point (No change of state).

$$
\mathrm{Qi}=\quad \mathrm{mx} \mathrm{Cp} \times(\mathrm{T} 2-\mathrm{T} 1) \ldots \ldots \ldots \ldots \ldots . . \mathrm{Eq} 2.6
$$

Where,

$$
\begin{array}{lll}
\mathrm{Qi} & = & \text { Heat required to raise the temperature. } \\
\mathrm{m} & = & \text { Mass of zinc added, } 4,409 \mathrm{lb} \\
\mathrm{Cp} & = & \text { Specific heat capacity, } 0.0932 \mathrm{BTU} / \mathrm{lb}-{ }^{\circ} \mathrm{F} \\
\mathrm{T} 1 & = & \text { Initial zinc temperature assumed to be } 80^{\circ} \mathrm{F} \\
\mathrm{T} 2 & = & \text { Final zinc temperature (melting point), } 419.58^{\circ} \mathrm{F}
\end{array}
$$

Substituting in equation 2.6 we get,

$$
\begin{aligned}
\mathrm{Qi} & =4,409 \mathrm{lb} \times 0.0932 \mathrm{BTU} / \mathrm{lb}-{ }^{\circ} \mathrm{F} \times\left(419.58^{\circ} \mathrm{F}-80^{\circ} \mathrm{F}\right) \\
& =139,540 \mathrm{BTU} \\
& =41 \mathrm{kWh} \quad(1 \mathrm{kWh}=3,412 \mathrm{BTU})
\end{aligned}
$$

5. Heat energy required to melt the zinc (change the state of the materials).

$$
\mathrm{Qj} \quad=\quad \mathrm{mxH} \ldots \ldots \ldots \ldots . . . \mathrm{Eq} 2.7
$$

Where,

$$
\begin{array}{lll}
\mathrm{Qj} & = & \text { Heat required to melt zinc. } \\
\mathrm{m} & = & \text { Mass of zinc added, 4,409 } \mathrm{lb} \\
\mathrm{H} & = & \text { Latent heat of fusion, 47.3 BTU/lb }
\end{array}
$$

Substituting in equation 2.7 we get,

$$
\mathrm{Qj} \quad=\quad 4,409 \mathrm{lb} \times 47.3 \mathrm{TU} / \mathrm{lb}
$$




$$
\begin{aligned}
\mathrm{Qj} & =208,546 \mathrm{BTU} \\
& =61 \mathrm{kWh} \quad(1 \mathrm{kWh}=3,412 \mathrm{BTU})
\end{aligned}
$$

6. Heat energy required for raising the temperature of zinc from $419.58{ }^{\circ} \mathrm{F}$ (melting point) to $450{ }^{\circ} \mathrm{F}$ (process temperature).

$$
\mathrm{Qk}=\quad \mathrm{mx} \mathrm{Cp} \times(\mathrm{T} 3-\mathrm{T} 2) \ldots \ldots \ldots \ldots \ldots . . \mathrm{Eq} 2.8
$$

Where,

$$
\begin{array}{lll}
\mathrm{Qk} & = & \text { Heat required to raise the temperature. } \\
\mathrm{m} & = & \text { Mass of zinc added, } 4,409 \mathrm{lb} \\
\mathrm{Cp} & = & \text { Specific heat capacity, } 0.0932 \mathrm{BTU} / \mathrm{lb}-{ }^{\circ} \mathrm{F} \\
\mathrm{T} 3 & = & \text { Final zinc temperature assumed to be } 450{ }^{\circ} \mathrm{F} \\
\mathrm{T} 2 & = & \text { Initial zinc temperature (melting point), } 419.58^{\circ} \mathrm{F}
\end{array}
$$

Substituting in equation 2.8 we get,

$$
\begin{aligned}
\mathrm{Qk} & =4,409 \mathrm{lb} \times 0.0932 \mathrm{BTU} / \mathrm{lb}-{ }^{\circ} \mathrm{F} \times\left(450^{\circ} \mathrm{F}-419.58^{\circ} \mathrm{F}\right) \\
& =12,500 \mathrm{BTU} \\
& =4 \mathrm{kWh}(1 \mathrm{kWh}=3,412 \mathrm{BTU})
\end{aligned}
$$

The total amount of energy required for starting the process $Q$ is given by

$$
\begin{aligned}
\mathrm{Q}_{2} & = & \mathrm{Qi}+\mathrm{Qj}+\mathrm{Qk} \\
& = & 51 \mathrm{kWh}+61 \mathrm{kWh}+4 \mathrm{kWh} \\
& = & 106 \mathrm{kWh}
\end{aligned}
$$

The process of melting and raising the temperature of the new metal added to the pot takes approximately one hour, thus the power required to perform this process is,

$$
\mathrm{P}_{2}=\mathrm{kWh} \div \mathrm{T} \text { (time in hours) } \ldots \ldots \ldots \ldots \ldots \text {. } 2.9
$$

Where,

$$
\begin{array}{lll}
\mathrm{P}_{2} & = & \text { Power required to maintain the process. } \\
\mathrm{kWh}= & \text { Total energy required to maintain the process operating. } \\
\mathrm{T} & = & \text { Time in hours. }
\end{array}
$$


Substituting in equation 2.9 we get,

$$
\begin{aligned}
\mathrm{P}_{2} & =106 \mathrm{kWh} \div 1 \text { hours } \\
& =106 \mathrm{~kW} .
\end{aligned}
$$

Considering $15 \%$ factor of safety and $10 \%$ heat losses due to conduction and exposed surface, the calculated power requirement will be,

$$
\mathrm{Pn}=\mathrm{P}_{2} \mathrm{x}(1+\mathrm{SF}) \mathrm{x}(1+\mathrm{L}) \ldots \ldots \ldots \ldots \ldots \text {..Eq } 2.10
$$

Where,

$$
\begin{aligned}
& \mathrm{Pm}=\quad \text { Power required after considering losses and safety factor. } \\
& \mathrm{SF}=\quad \text { Factor of safety, assumed to be } 15 \% . \\
& \mathrm{L}=\quad \text { Heat losses from the pot, assumed to be } 10 \% .
\end{aligned}
$$

Substituting in equation 2.10 we get,

$$
\begin{aligned}
\mathrm{Pm} & =106 \mathrm{~kW} \times(1+0.15) \times(1+0.1) \\
& =134 \mathrm{~kW}
\end{aligned}
$$

It is observed that the grid is $40 \% \sim 45 \%$ loaded during the process. Assuming that the grid is rated for $360 \mathrm{~kW}$ and is $45 \%$ loaded, then, the proportion of actual capacity used is,

$$
\begin{aligned}
& =\quad 360 \mathrm{~kW} \times 0.45 \\
& =\quad 162 \mathrm{~kW}
\end{aligned}
$$

Thus, $162 \mathrm{~kW}$ is the proportion of actual capacity utilized. This is close to the theoretically calculated value of $134 \mathrm{~kW}$.

The results of the above calculations can be summarized as follows:

Table 2.3: Comparison between actual and theoretical power requirement.

\begin{tabular}{|l|c|c|}
\hline \multicolumn{1}{|c|}{ Process Status } & $\begin{array}{c}\text { Actual Power Measured } \\
\text { from the Industry }\end{array}$ & $\begin{array}{c}\text { Calculated Power } \\
\text { Required for the Process }\end{array}$ \\
\hline At Start-up & $360 \mathrm{~kW} \sim 400 \mathrm{~kW}$ & $223 \mathrm{~kW}$ \\
\hline To maintain the Process & $144 \mathrm{~kW} \sim 162 \mathrm{~kW}$ & $134 \mathrm{~kW}$ \\
\hline
\end{tabular}


Thus, it can be concluded that the values for actual power requirement are very close to the calculated power required for the given process. The excess amount of power (or rated capacity) observed in the actual practical scenario can be defined to account for the various losses in energy that occur in an industrial setup.

\subsection{Conclusion}

There is no source available at present to compute the amount of energy consumed to produce coated sheet steel by continuous galvanizing process. Even though there is great potential for energy conservation opportunities in this arena, there is no commercial tool available to measure the existing energy consumption and no established benchmark for comparison. 


\subsection{Research Approach}

\subsection{Studying the Continuous Galvanizing Process}

Initial visits were conducted in leading galvanizing facilities. The entire process and the basics of the continuous galvanizing process were studied thoroughly. A list of all the common equipment was made. The energy intensive equipment and energy consumption points were noted. Table 3.1 shows an example of the list of equipment and energy points generated from the initial shop visit. The plant personnel were interviewed to get details of general shop floor practices, production schedules and maintenance plans. Also, information regarding bath hardware, bath chemistry and issues relating to the service life of the hardware were discussed. Using all the data collected from visits, and referring to books describing continuous galvanizing practices, a list was prepared, which consisted of all of the different equipment that is used in continuous galvanizing in the order of the process flow. Figure 3.1 summarizes the research approach.

Table 3.1: Sample list identifying energy intensive equipment, type of fuel and point of usage

\begin{tabular}{|c|c|c|c|}
\hline $\begin{array}{c}\text { Sr. } \\
\text { No }\end{array}$ & Equipment & Fuel Type & Point of Usage \\
\hline 1 & Payoff reel mandrel & Electric & Motor \\
\hline 2 & Welding m/c & Electric & Welder \\
\hline 3 & Accumulator & Electric & Several DC Motors \\
\hline 4 & Annealing Furnace & $\begin{array}{c}\text { Natural Gas } \\
\text { (Supporting } \\
\text { gases: N2, H2) }\end{array}$ & N.G. Burners \\
\hline 5 & Cooling Tower & Electric & Fan Motor \\
\hline 6 & Zn pot & Electric & Induction pot \\
\hline 7 & Line motors to pull strip & Electric & DC Motors \\
\hline 8 & Air knifes & Electric & 150 HP Blower \\
\hline 9 & Temper Mill & Electric & Motors \\
\hline 10 & Miscellaneous pull motors / & Electric & Motors \\
$\vdots$ & equipment & $\vdots$ & $\vdots$ \\
\hline
\end{tabular}




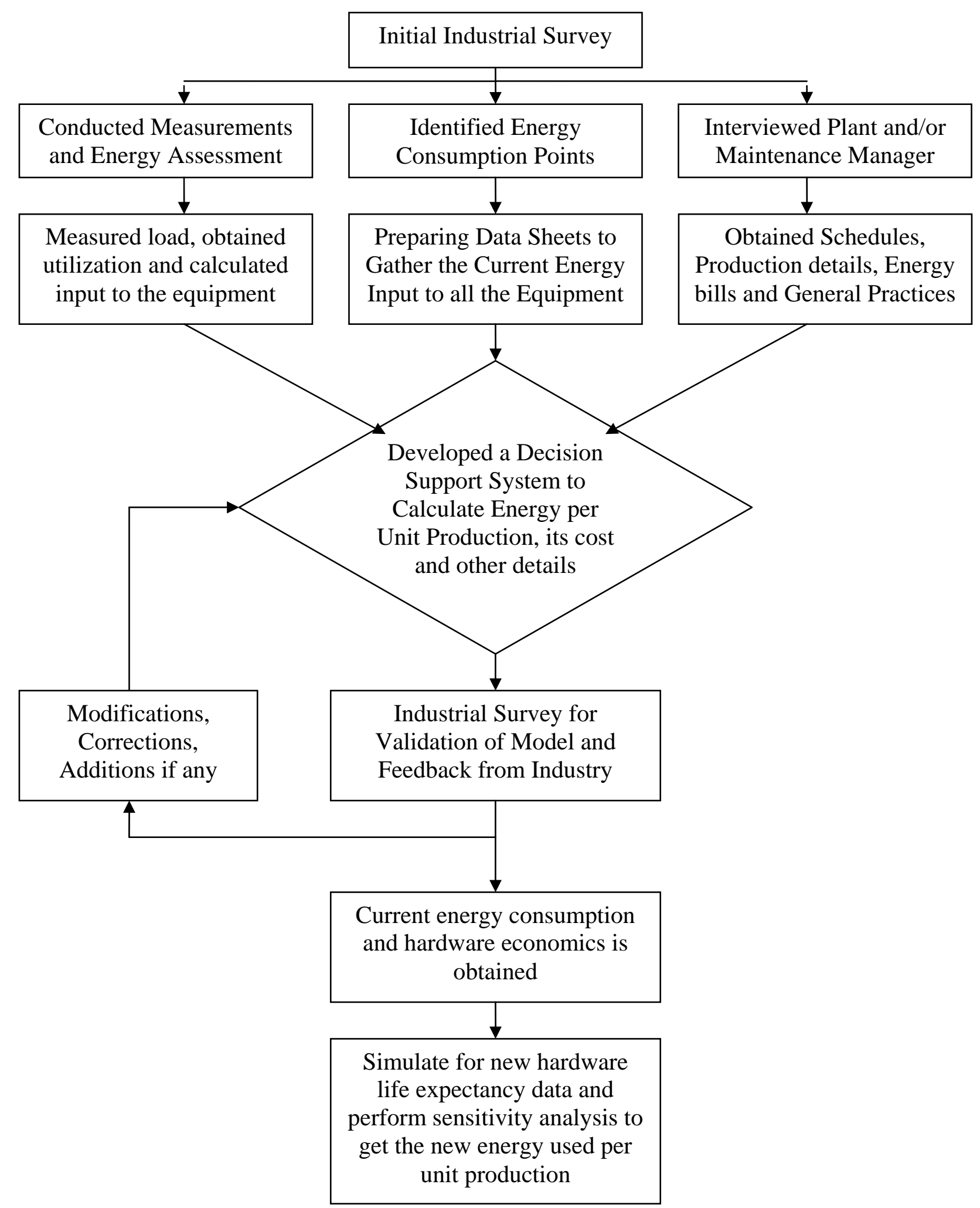

Figure 3.1: Research Approach 


\subsection{Preparing Data Collection Sheet}

The equipment list prepared from the information was referred and each piece of equipment was carefully studied. For example, Payoff Reel was considered, its application was noted and the major energy-consuming component of the equipment was identified, in this case it will be an electric motor. Similarly, the second equipmentannealing furnace was selected, its application noted and the energy consumption point identified i.e. natural gas burner. The process was repeated for all the equipment present in the list.

After identifying all the energy consumption points at various positions in the process, a survey form was prepared so that all the energy related information for the particular energy points could be gathered precisely. The survey form was designed to be in the form of tables so that it is easy to fill in the data. Table 3.2 shows an example of the data collection form for various electric motors. Table 3.3 shows an example of data collection form for natural gas equipment.

Table 3.2: Example of Data Collection Sheet for Electric Motors

\begin{tabular}{|c|c|c|c|c|c|c|c|}
\hline \multicolumn{9}{|c|}{ Equipment Name Containing the Motor } \\
\hline HP & $\begin{array}{c}\text { No. of } \\
\text { Motors } \\
\text { of Same } \\
\text { HP }\end{array}$ & $\begin{array}{c}\text { Load } \\
\text { Factor } \\
(\%)\end{array}$ & $\begin{array}{c}\text { Utilization } \\
\text { Factor } \\
(\%)\end{array}$ & $\begin{array}{c}\text { \# of } \\
\text { Standby } \\
\text { Motors }\end{array}$ & $\begin{array}{c}\text { Are the } \\
\text { motors } \\
\text { running } \\
\text { during } \\
\text { Shutdowns } \\
\text { (YES/NO) }\end{array}$ & $\begin{array}{c}\text { Load } \\
\text { Factor } \\
\text { During } \\
\text { Shutdown } \\
\mathbf{( \% )}\end{array}$ & Eff \\
\hline 60 & 2 & 60 & 80 & 1 & NO & 60 & 91 \\
\hline
\end{tabular}

The basic formula to calculate the input energy is,

$$
M M B t u / h r=\Sigma\{H P \times(N-n) \times L F \times U F \times C\} / E f f .
$$

Where,

$$
\begin{array}{ll}
H P & =\text { Horsepower of the motor } \\
N & =\text { Total number of motors of same horsepower } \\
n & =\text { Number of standby motors } \\
L F & =\text { Load Factor } \\
U F & =\text { Utilization Factor } \\
C & =\text { Conversion Factor HP to MMBtu/hr (0.002547) } \\
E f f & =\text { Efficiency }
\end{array}
$$


The summation of MMBtu/hr for all the motors entered by the user will provide the total energy consumed by the motors. Additional variables such as life-span of the motor and their load during shutdown period are also built in the model.

An example of calculation based on Eq 3.1 for the data provided in Table 3.2 is shown below,

$M M B t u / h r=\{60 h p \times(2-1) \times 0.6 \times 0.8 \times 0.002547 M M B t u / h r\} \div 0.91$

$$
=0.0806 \mathrm{MMBtu} / \mathrm{hr}
$$

Now if the motor is assumed to be running for 8,000 hrs annually, total annual energy consumed by the motor will be,

MMBtu $=0.0806 \mathrm{MMBtu} / \mathrm{hr} \times 8,000 \mathrm{hrs}$

$$
=645 \mathrm{MMBtu} / \mathrm{yr}
$$

Assuming average electricity rate to be $16 \$ / M M B t u(0.05 \$ / k W h)$, the annual energy cost of operating the motor can be given as,

$\$$ lyr $=645$ MMBtu x $7 \$$ MMBtu

$=\$ 4,515.00 /$ year

Similarly, the input energy consumed by other electric equipment and the natural gas equipment can be calculated. The energy consumed by the natural gas equipment is calculated as shown below,

$$
M M B t u / h r=\Sigma\{M \times N \times L F \times U F\} / E f f \ldots . . \text { (without recuperators)...(Eq 3.2) }
$$

or $\quad M M B t u / h r=\sum\{(M \times r) \times N \times L F \times U F\} / E f f \ldots .($ with recuperators) ...(Eq 3.3)

Where,

$$
\begin{array}{ll}
M & =\text { Burner rating (MMBtu/hr) } \\
N & =\text { Number of burners of same capacity } \\
L F & =\text { Load Factor } \\
U F & =\text { Utilization Factor } \\
r & =\text { Reduction in gas consumption as a result of recuperators }
\end{array}
$$

If the input for the gas burners is given in terms of SCFH, then the above formula is multiplied by a conversion factor $\mathrm{K}(0.001)$ to convert the units to MMBtu/hr. The formula with input given in SCFH is shown in equation 3.4 and equation 3.5. 


$$
M M B t u / h r=\Sigma\{S \times N \times L F \times U F \times K\} / E f f \ldots . . \text { (without recuperators)...(Eq 3.4) }
$$

or

$$
M M B t u / h r=\Sigma\{(S \times r) \times N \times L F \times U F \times K\} / E f f \ldots . . \text { (with recuperators) (Eq 3.5) }
$$

Where,

$\mathrm{S} \quad=$ Capacity of burner in SCFH

$\mathrm{K}=$ Conversion factor form SCFH to MMBtu/hr (0.001)

The energy consumption points were classified based on the equipment that are used. This classification ensures that all the energy consumption points in the equipment are covered. This also makes it easy for the person filling in the data to identify exactly what motor or energy consumption point is been referred. These kinds of data sheets were required to obtain the required information for calculating input energy. The capacities of different equipment are described in different units. The data sheet asks for the input capacity in most suitable unit for the facility person to fill in. These data sheets will act as input for the benchmarking calculations. In addition to the equipment data other sheets were designed to obtain steel production and rejection data, production and down times, electric and natural gas consumption, energy costs and hardware related information for the concerned facility.

\begin{tabular}{|c|c|c|c|c|c|c|c|}
\hline $\begin{array}{l}\text { Equipment } \\
\text { Name }\end{array}$ & $\begin{array}{c}\text { MMBtu/Hr } \\
\text { or SCFH } \\
\text { for each } \\
\text { Burner }\end{array}$ & $\begin{array}{c}\text { Number } \\
\text { of } \\
\text { Burners } \\
\text { with } \\
\text { same } \\
\text { capacity }\end{array}$ & $\begin{array}{c}\text { Load } \\
\text { Factor } \\
(\%)\end{array}$ & $\begin{array}{l}\text { Utilization } \\
\text { Factor (\%) }\end{array}$ & $\begin{array}{l}\text { Recuperator } \\
\text { (Yes/No) }\end{array}$ & $\begin{array}{c}\text { Status } \\
\text { during } \\
\text { downtime } \\
\text { (On/Pilot/ } \\
\text { Low Fire) }\end{array}$ & $\begin{array}{c}\text { Load } \\
\text { Factor } \\
\text { During } \\
\text { Shutdown } \\
\quad(\%)\end{array}$ \\
\hline $\begin{array}{c}\text { Pre-Heat } \\
\text { Section }\end{array}$ & 0.24 & 24 & 80 & 100 & Yes & ON & 20 \\
\hline
\end{tabular}

Table 3.3: Example of Survey Form for Different Natural Gas Equipment

The survey form was developed as an aid to obtain the necessary information required for the model. This survey form has different sections on motors, furnaces, Zn pot, other natural gas and electric consumption equipment, production data and pot hardware material data. This survey form uses terms containing common shop floor language that can be easily understood by shop floor maintenance personnel. Thus, relevant and accurate information is obtained for the decision support system.

These survey forms are the part of the DSS (Decision Support System) and comprise the input section of the model. The plant staff can take a printout of the input 
sheet and go to various locations in the facility in order to collect the required data to fill in the survey form. In this way, the user neither has to bother about carrying a portable computer around the facility, nor has to guess things while filling the survey form in the office.

\subsection{Conducting Measurements and Field Surveys}

The survey forms are filled with the information obtained from the visits conducted at three different galvanizing facilities. Additional visits are conducted to ensure the accuracy of the data used for trial analysis. During these visits the survey forms were further refined and also measurements were performed to obtain loads on various equipment. Some of the instruments used to conduct the measurements are Amprobe, Stroboscope, Infrared Temperature Gun, Thermal Camera and Combustion Gas Stack Analyzer. In addition to this, onboard data available from computers controlling the galvanizing line was also referred. The online controllers provided information like load factors on the electric grids for the zinc pots, natural gas consumption in different sections of the annealing furnace and the set point and current temperatures at different points in the process. The data that was measured as well as that obtained from the facility was used to refine the DSS. Any equipment that may have been missed was added later. The data collection fields were simplified and aimed to obtain the most accurate information possible. These visits resulted in promising information for analysis and further study.

\subsection{Analysis of Data and Simulation for Savings}

The analysis of the data will be performed with the help of the decision support system. The initial pages of the survey form consist of input sections. The subsequent sections consist of various results in form of tables and charts. The data can be gathered from the field by printing out the data collection sheets. The collected data is then entered into the DSS. The input section of the DSS consists of two different type of data set. The first type of data set corresponds to the energy input supplied to different equipment in the plant. This includes the rating, load and utilization of various energy points. This data set entry is one-time work for a given galvanizing line and may vary a little for different 
product types manufactured on the same line. The second type of data set consists of monthly energy costs and its consumption, production, production time, downtime and pot hardware data. The second data set is updated as monthly energy bills and production related data is filled. This data set is in real time.

The DSS analyzes the input data and provides results in term of energy required per unit production for different products, its cost and hardware economics. These results will reflect the current scenario in the concerned continuous galvanizing line. The results depend on the production, production time and downtime. Now, if any new pot hardware is used, its performance will impact the production and reduce downtime. This increase in production or number of turns can be obtained for the first few months of service for the new hardware. Based on the performance, the data can be extrapolated for the whole year and filled in the DSS. This will provide information about the energy consumption per unit production and other production details when the new hardware is used. Comparing these results with the previous results, one can evaluate the energy savings and other benefits resulting from the use of the new hardware. Also, the production can be completely assumed based on the manufacturers' claim about the hardware life. Consider an example where the current hardware gives 330 hours of service life. If the manufacturer claims that the new hardware would provide 500 hours of service life, then the increased number of turns can be entered in the DSS and results will be simulated.

\subsection{Generation of Results}

\subsubsection{Summary Sheet}

A comprehensive table providing monthly details of total production of different coating products, time required for production and downtime, electrical and natural gas energy consumed, and cost of energy during production as well as downtime is summarized. This will provide a value for MMBtu/ton for every month and for every product.

\subsubsection{Energy Consumption Details}

The energy consumption sheet provides energy consumed per hour by various motors, electric grids on the Zn metal pot, natural gas equipment like furnaces and boilers and other miscellaneous equipment for production as well as for non-production periods. 
Energy consumed will be given in MMBtu/hr classified according to the equipment type. Also per unit energy cost for natural gas, electricity kWh and demand calculated from utility bills will be provided.

\subsubsection{Production and Rejection Details}

The total production and rejection of different products in tons, total production and downtime, and the percentages of productive time, downtime and idle time with respect to annual operation hours is summarized in one table. Another table provides the $\log$ of any rejection or stoppages that occurred due to either the failure of pot hardware or any other reason. This table shows the date and month the rejection occurred and the amount of rejection. It also shows what caused the rejection i.e. which hardware component failed and the material of the hardware.

\subsubsection{Economic Analysis}

A simple economic analysis is performed for the pot hardware material. The cost of any new hardware can be entered in the DSS. The hardware failure log provides the service life of the hardware installed in the pot. By dividing the total capital cost by the service life in days we can get how much it costs the plant per day for a particular hardware. This per-day cost when new hardware is implemented should be equal or lower than the existing cost. Also from sensitivity analysis, the annual projected savings will be obtained. The ratio of these savings to annual investment on pot hardware should be greater than unity.

\subsubsection{Graphs}

The results of energy consumption details will be represented in the form of bar charts for quick evaluation of the energy consumption profile. The energy consumed by different equipment during production as well as during downtimes will be graphed. Also, the energy consumption by equipment based of fuel type will be shown for different periods.

\subsection{Sensitivity Analysis}

The DSS has a quick sensitivity analysis module to analyze the effect of the increased up time on production and energy consumption. The sensitivity analysis will be based on constant production rate and production schedule. It will have an average value 
for energy consumption per hour and will calculate the current work schedule from the production data provided. The user can input the new schedule and quickly compare the results for the new production and energy consumption. It is expected that using this analysis the user can make a decision as to how long a particular product should be scheduled to minimize the energy consumption and allocate preventive maintenance shutdowns.

\subsection{Conclusion}

1) A systematic study of the equipment in galvanizing facilities is conducted. 2) Major energy consuming equipment is identified and focus is drawn over collecting data pertaining to that equipment. 3) Variables affecting energy consumption are identified and measured. 4) Preliminary analysis is conducted in Excel ${ }^{\mathrm{TM}}$ and formulas are developed for calculating energy consumption, and 5) As discussed in section 3.5, the output expected from the decision support system is established. 


\subsection{Model Development}

\subsection{Developing the Excel ${ }^{\mathrm{TM}}$ - VB Interface}

The model is developed to handle up to three different processes performed on the same galvanizing line. This resulted in development of four independent Excel ${ }^{\mathrm{TM}}$ files, each consisting of a number of Excel ${ }^{\mathrm{TM}}$ sheets. One file represents one particular process and each file consists of multiple spreadsheets called modules. These modules are interconnected with formulas and share data within the four Excel ${ }^{\mathrm{TM}}$ files. The handling of these four files was out of the scope of Visual Basic Application (VBA) in Excel ${ }^{\mathrm{TM}}$. Thus, an independent VB DOT NET program was developed that was capable of handling and accessing these Excel ${ }^{\mathrm{TM}}$ sheets while working out of $\mathrm{Excel}^{\mathrm{TM}}$ environment. This makes it necessary for the model to be installed on a computer. The VB program enables access to any specific spreadsheet of any one of the Excel ${ }^{\mathrm{TM}}$ files, for example, if the monthly summary button is clicked, the following code runs and enables access to the file.

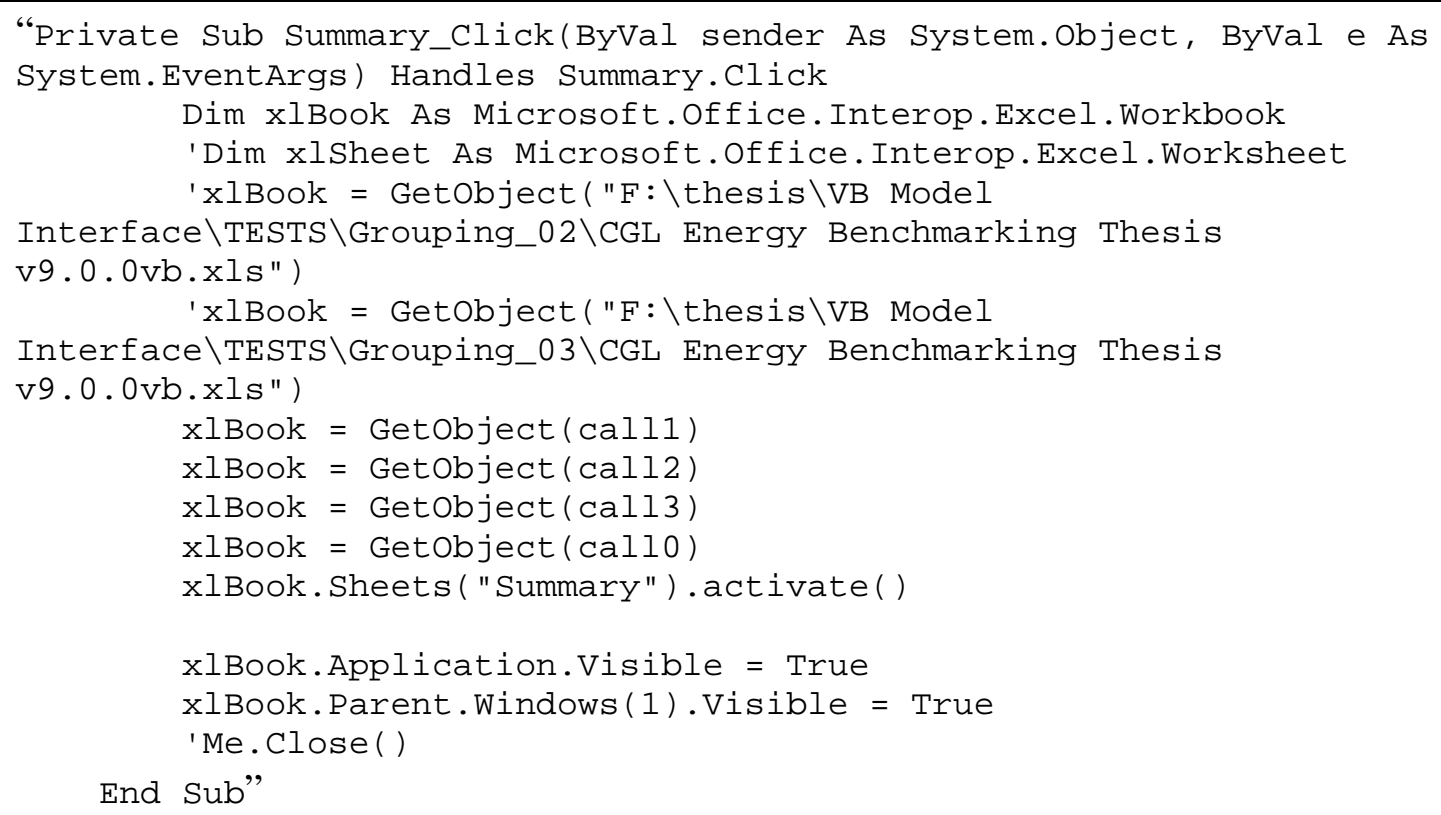

Similarly, several such codes enables access to Excel ${ }^{\mathrm{TM}}$ sheets pertaining to the required process as selected by the user. The entered data is stored on the hard drive in these Excel $^{\mathrm{TM}}$ files. Since there are individual files dedicated to individual processes, data once 
entered for a particular process will be stored in memory unless altered by the user. The files are stored in a location on $\mathrm{C}$ drive specified during installation of the program. 


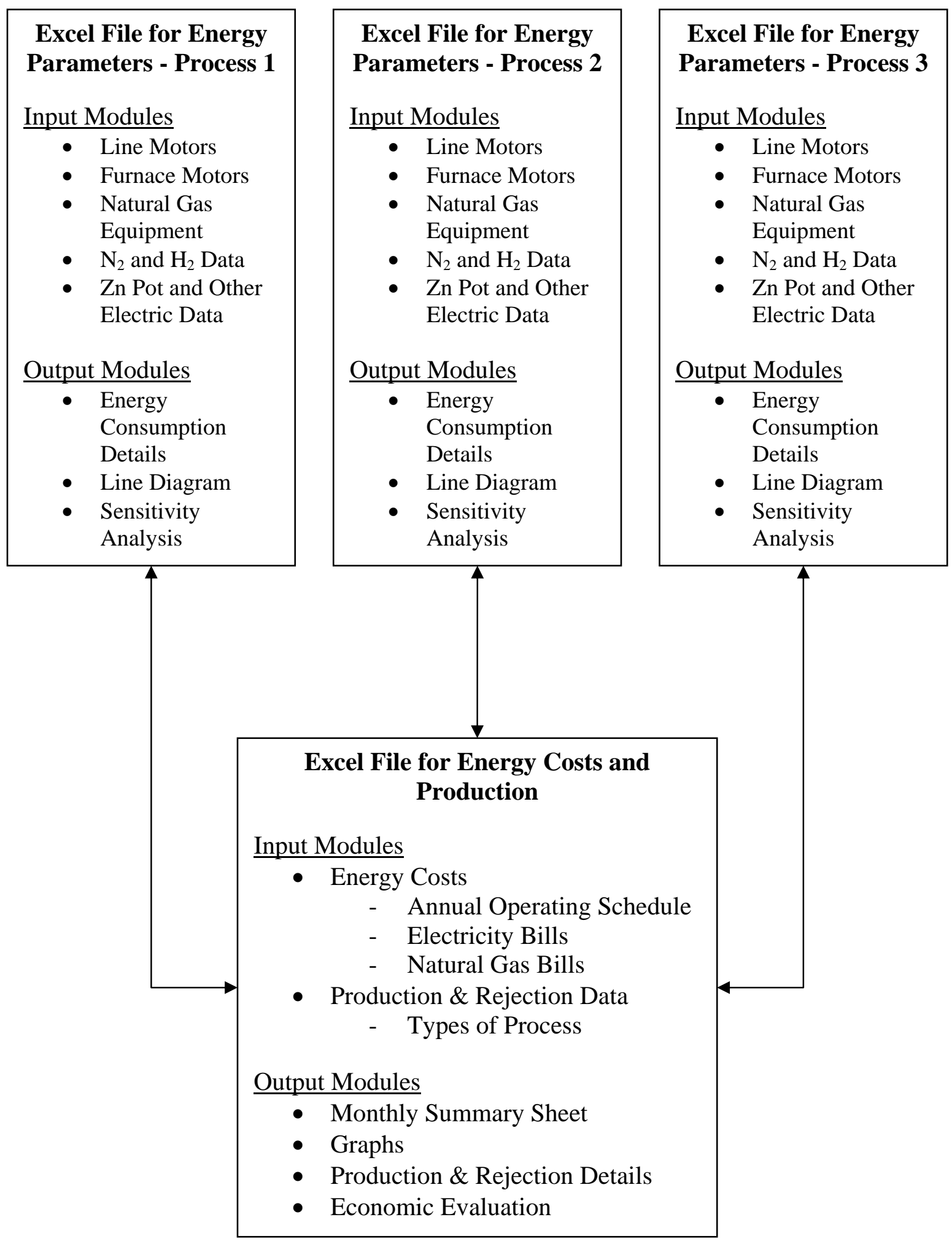

Figure 4.1: Architecture of Decision Support System 
Figure 4.1 shows the architecture of the decision support system. The boxes represent the four different files. The input and output modules are specified in the boxes. The arrows represent the flow of information from one file to another. One or multiple modules may use the information. Each Excel ${ }^{\mathrm{TM}}$ file has a separate calculation module at the end of the file; this arrangement prevents damage to the modules by mistaken deletion of the data. All the input values are exported to the calculation module and only the results are shown in the output modules. Also, data sharing within the files is done from the calculation modules only.

Figure 4.2 shows the VB form that user will see as soon as the program is run.

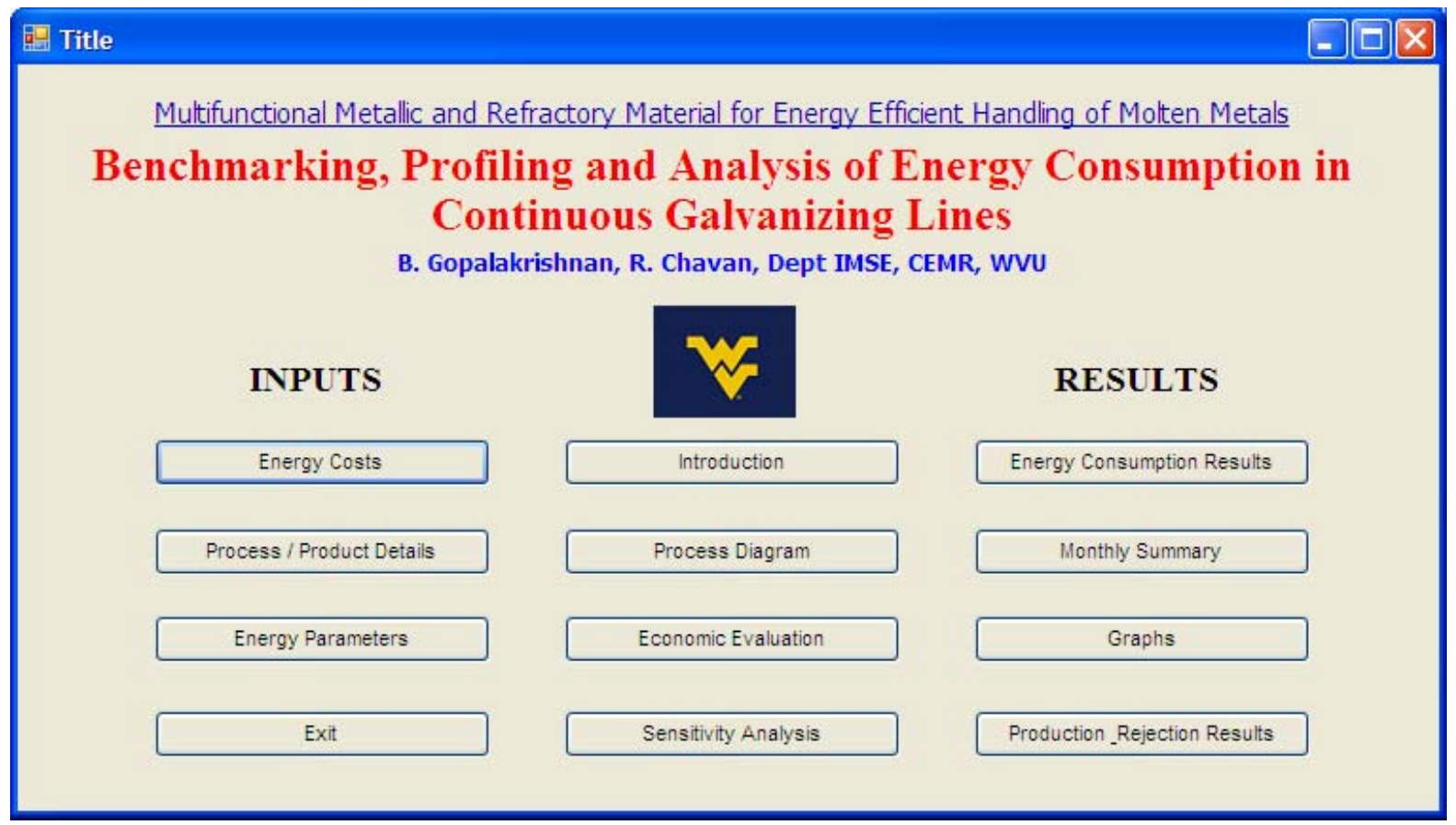

Figure 4.2: Title Form

This page helps the user navigate through the different sections of the model. Based on the user selection a particular module of a particular file will be opened or further options will be provided to the user. This not only facilitates the handling of multiple files and modules, but also makes the model more rigid and stable. If the user chooses to fill in data relating to a particular process, a pop up screen will prompt the selection of the process for which the data is to be entered / modified. Various buttons on Figure 4.2 are discussed in detail on section 4.2 and section 4.3 . 
Figure 4.3 shows the form where the user is prompted to select the process, which he wishes to alter. This will ensure that the proper process is selected by the user and keeps the other two processes unaltered.

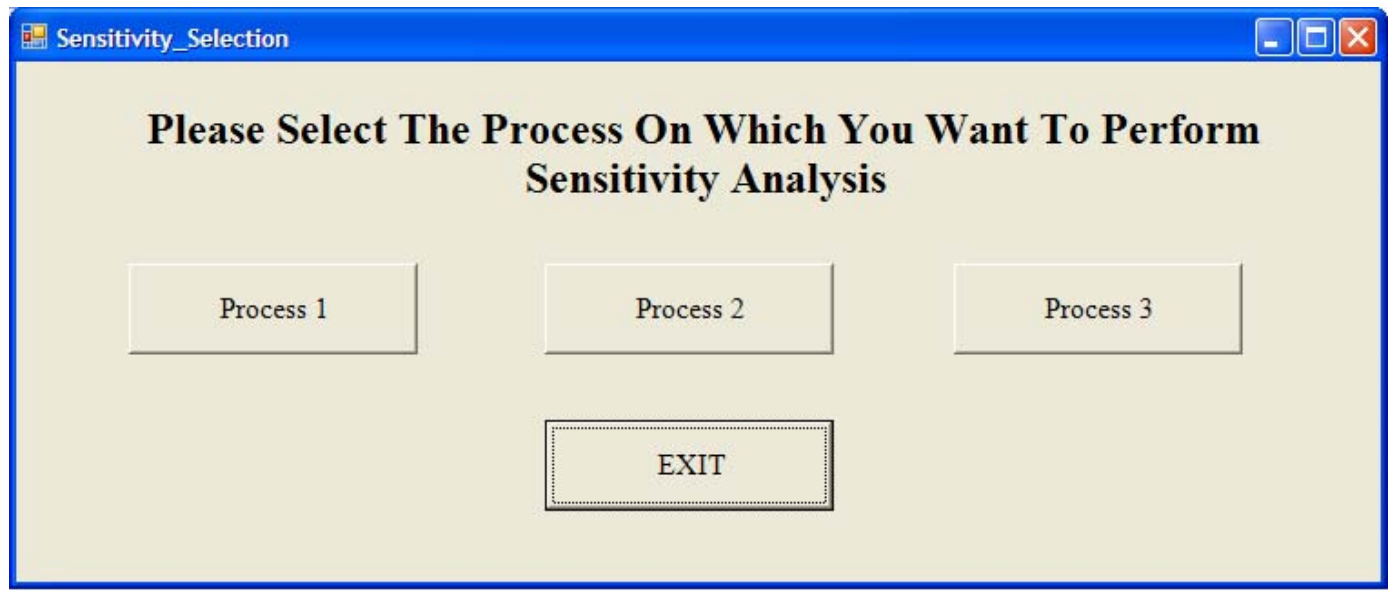

Figure 4.3: Process Selection Form

\subsection{Inputs}

The input sections links those modules where the user is required to fill in data pertaining to electricity and natural gas costs, details of processes, production and equipment capacity and utilization for each process selected. The input section is discussed in detail in the subsequent sections.

\subsubsection{Energy Costs}

As soon as the module for energy costs is accessed, a pop-up window, shown in Figure 4.4, opens. The user is prompted to fill in the information which is used to calculate the annual operating hours for the galvanizing line.

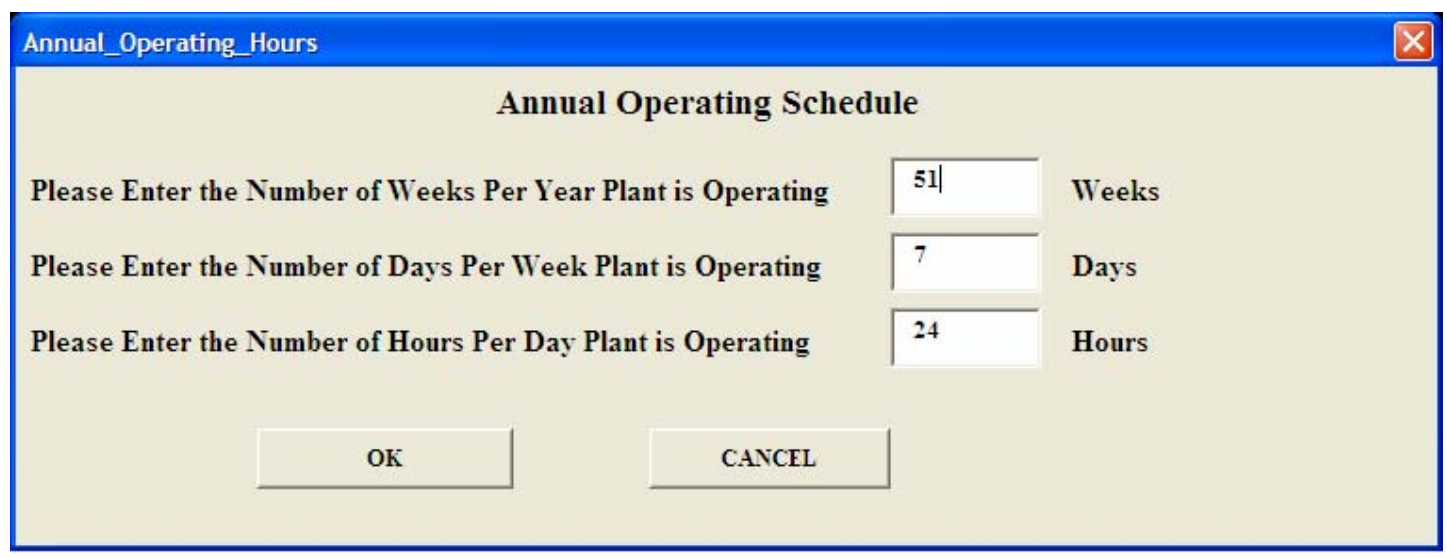

Figure 4.4: Annual Operating Schedule 
The default values for annual operating schedule are shown in Figure 4.4. The input fields for electric and natural gas usage and rates are shown in Figure 4.5 and 4.6 respectively. 


\begin{tabular}{|c|c|c|c|c|c|c|c|c|c|}
\hline \multicolumn{10}{|c|}{ Electrical Usage Summary } \\
\hline & & Energy & Billed * & Energy & Usage & Demand & Other & Total & \\
\hline & & Usage & Demand & Cost & Cost & Cost & Charges & Cost & \\
\hline Year & Month & $(\mathrm{kWh})$ & $(\mathrm{kVA})$ & $(\mathrm{S} / \mathrm{kWh})$ & (\$) & (\$) & $(\$)$ & (\$) & MMBtu \\
\hline \multirow{12}{*}{2004} & January & $5,082,604.00$ & $10,048.00$ & 0.0233 & $118,323.02$ & $71,740.69$ & $1,085.73$ & $191,149.44$ & $17,346.77$ \\
\hline & February & $4,902,055.00$ & $9,922.00$ & 0.0233 & $114,119.84$ & $70,853.03$ & $1,124.63$ & $186,097.50$ & $16,730.56$ \\
\hline & March & $5,431,957.00$ & $9,754.00$ & 0.0233 & $126,455.96$ & $69,681.63$ & 877.07 & $197,014.66$ & $18,539.10$ \\
\hline & April & $5,075,874.00$ & $9,282.00$ & 0.0233 & $118,166.35$ & $66,373.39$ & 898.78 & $185,438.52$ & $17,323.80$ \\
\hline & May & $5,353,923.00$ & $9,781.00$ & 0.0233 & $124,639.33$ & $69,865.18$ & 913.93 & $195,418.44$ & $18,272.77$ \\
\hline & June & $4,836,108.00$ & $10,329.00$ & 0.0233 & $112,584.59$ & $73,708.67$ & $1,251.15$ & $187,544.41$ & $16,505.49$ \\
\hline & July & & & & 0.00 & & 0.00 & & 0.00 \\
\hline & August & & & & 0.00 & & 0.00 & & 0.00 \\
\hline & September & & & & 0.00 & & 0.00 & & 0.00 \\
\hline & October & & & & 0.00 & & 0.00 & & 0.00 \\
\hline & November & & & & 0.00 & & 0.00 & & 0.00 \\
\hline & December & & & & 0.00 & & 0.00 & & 0.00 \\
\hline \multirow[t]{7}{*}{ Total } & & $30,682,521.00$ & $59,116.00$ & & $714,289.09$ & $422,222.59$ & $6,151.29$ & $1,142,662.97$ & $104,718.50$ \\
\hline & \multicolumn{3}{|c|}{ Average Power Factor } & $=$ & 0.9875 & & \multirow{6}{*}{\multicolumn{3}{|c|}{$\begin{array}{c}\text { SCROLL DOWN FOR GAS USAGE } \\
\text { SUMMARY }\end{array}$}} \\
\hline & \multicolumn{3}{|c|}{ Average kWH Cost } & $=$ & $\$ 0.03724$ & & & & \\
\hline & \multicolumn{3}{|c|}{ Average MMBtu Cost } & $=$ & $\$ 10.91$ & & & & \\
\hline & \multicolumn{3}{|c|}{ Marginal Cost of kWH (\$/kWh) } & $=$ & $\$ 0.02348$ & & & & \\
\hline & \multicolumn{3}{|c|}{ Marginal Cost of MMBtu (S/MMBtu) } & $=$ & $\$ 6.88$ & & & & \\
\hline & \multicolumn{3}{|c|}{ Demand Cost $(\$ / \mathrm{kW})$} & $=$ & $\$ 7.23$ & & & & \\
\hline
\end{tabular}

Figure 4.5: Electric Usage Summary 


\begin{tabular}{|c|c|c|c|c|c|c|c|c|}
\hline \multicolumn{9}{|c|}{ Natural Gas Summary } \\
\hline Year & Month & MCF & Dth & MMBtu & Gas Cost(\$) & Transport cost(\$) & Total Cost & S/MMBtu \\
\hline \multirow{12}{*}{2004} & January & $68,067.00$ & 66297.258 & $68,067.00$ & $423,454.92$ & $68,336.51$ & $491,791.43$ & 7.23 \\
\hline & Febuary & $65,659.00$ & 63951.866 & $65,659.00$ & $381,870.93$ & $52,273.82$ & $434,144.75$ & 6.61 \\
\hline & March & $70,263.00$ & 68436.162 & $70,263.00$ & $403,693.16$ & $23,680.73$ & $427,373.89$ & 6.08 \\
\hline & April & $62,744.00$ & 61112.656 & $62,744.00$ & $380,004.10$ & $22,671.39$ & $402,675.49$ & 6.42 \\
\hline & May & $57,734.00$ & 56232.916 & $57,734.00$ & $382,729.55$ & $22,950.13$ & $405,679.68$ & 7.03 \\
\hline & June & $50,953.00$ & 49628.222 & $50,953.00$ & $383,896.25$ & $20,412.87$ & $404,309.12$ & 7.93 \\
\hline & July & & 0 & 0.00 & & & 0.00 & \\
\hline & August & & 0 & 0.00 & & & 0.00 & \\
\hline & September & & 0 & 0.00 & & & 0.00 & \\
\hline & October & & 0 & 0.00 & & & 0.00 & \\
\hline & November & & 0 & 0.00 & & & 0.00 & \\
\hline & December & & 0 & 0.00 & & & 0.00 & \\
\hline \multirow[t]{3}{*}{ Total } & & $375,420.00$ & & $375,420.00$ & $2,355,648.91$ & $210,325.45$ & $2,565,974.36$ & \\
\hline & & & & & & & & \\
\hline & $1 \mathrm{Dth}=$ & 0.974 & MCF & & & & & \\
\hline & & Por MORtu = & & & & & & \\
\hline \multicolumn{3}{|c|}{ Average Gas Cost Per MMBtu = } & 6.83 & \$MMBtu & & & & \\
\hline
\end{tabular}

Figure 4.6: Natural Gas Usage Summary 
The first two columns in Figure 4.5 are for the year and month of the utility bills being entered. In the third column the total electricity used during a particular month in $\mathrm{kWh}$ is to be entered. The fourth column is the electrical demand in $\mathrm{kVA}$ or $\mathrm{kW}$ as provided by the utility company. If there is no demand reported on the utility bill, the user should enter 1 in the field. The energy rate in $\$ / k W h$ has to be entered. The demand cost and the total cost on the utility bills must be entered in column 7 and 9. The other charges constitute discounts, penalties, or other fees included in the total charge. The other charges will be calculated automatically. Finally, the average power factor also needs to be entered. The marginal energy cost in $\$ / \mathrm{MMBtu}$ and the demand cost in $\$ / \mathrm{kW}$ is used by the model to calculate and report dollars spent on electricity. All this information can be obtained from the utility bills or by calling the utility supplier. Various average and marginal costs are calculated as follows.

Average $\mathrm{kWh}$ Cost $(\$ / \mathrm{kWh})=$ Total Cost $(\$) /$ Energy Usage $(\mathrm{kWh})$

Average MMBtu Cost $(\$ / M M B t u)=$ Total Cost $(\$) / M M B t u(k W h / 293)$

$(1 \mathrm{MMBtu}=293 \mathrm{kWh})$

Marginal Cost of $k W h(\$ / k W h)=($ Usage Cost + Other Charges $)(\$) /$ Energy Usage $(\mathrm{kWh})$

Marginal Cost of MMBtu (\$/MMBtu) = Marginal Cost of kWh (\$/kWh) x 293

Demand Cost $(\$ / k W)=($ Demand Cost $) /($ Billed Demand $(k V A) x$ Average Power Factor $)$

Similarly, the details for natural gas usage and transportation costs can be obtained from the utility bills provided to calculate the average $\$ / M M B t u$ cost for natural gas. Figure 4.6 shows the fields where natural gas consumption data is to be entered. The monthly consumption of natural gas in MCF, the money paid for usage of the gas and the money paid to the transportation company must be provided. These fields must be entered monthly, as soon as the utility bills are received in order to keep the energy costs updated and induce more accuracy in the dollar values calculated.

\subsubsection{Process / Products Details}

The first item the user is prompted is to enter the names for three different processes that the user wishes to enter data on. Also user is required to provide hours per 
turn. Figure 4.7 shows the pop-up window to enter the names for different processes and the number of hours per turn.

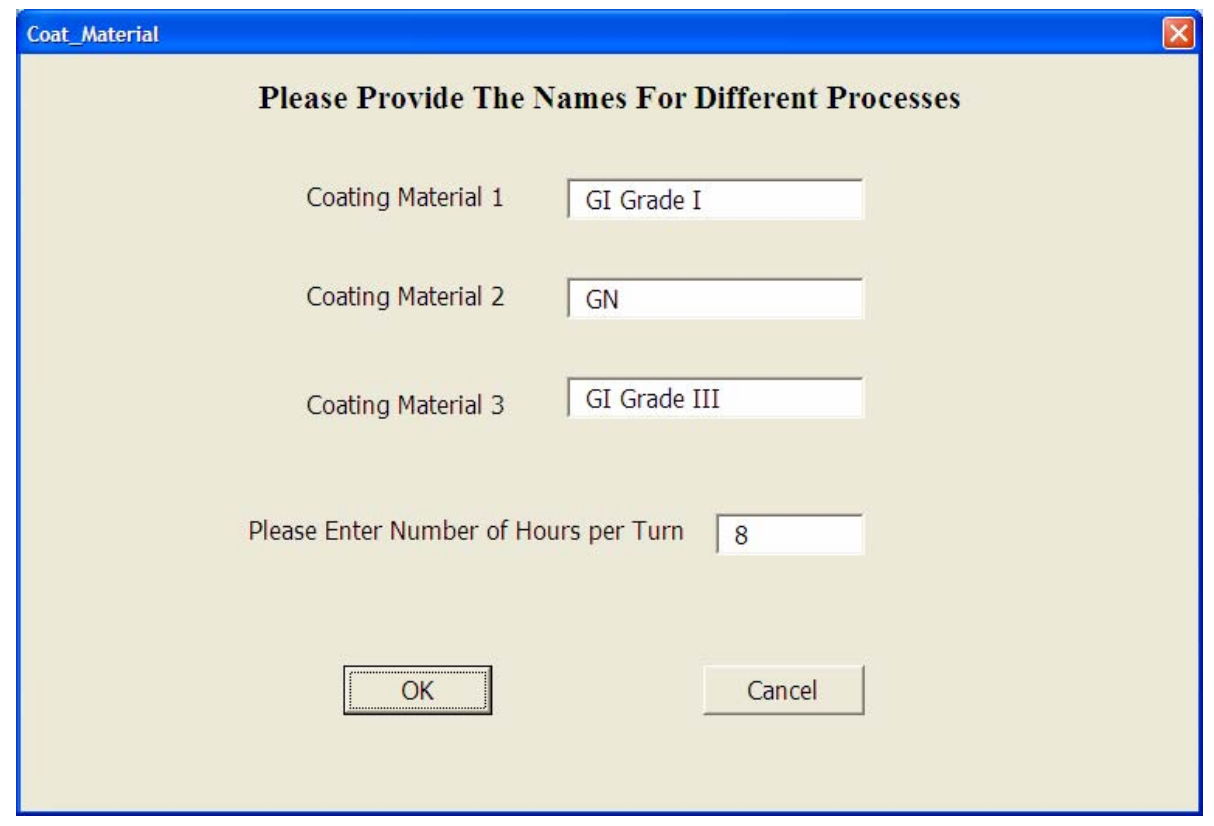

Figure 4.7: Names for different processes

If the user wishes to enter only one or two processes, one can leave the remaining fields blank. The default value for hours per turn is eight hours. Once the user has filled the data in the pop-up window one can proceed to enter the information about the production.

Figure 4.8 shows example of production data input fields for the month of January. All the data that is entered by the user will be involved on the calculations of energy consumption, production, downtimes and uptimes under the process selected by the user. Also, a log will be generated of all the failures that occurred. The user is required to fill all the fields in the form. The best way to fill in the details is to enter the date, select the process and the production rate at the start of a campaign. The form should be revisited whenever a failure occurs.

Consider Figure 4.8, the user enters the start date of the campaign as the $1^{\text {st }}$ of January and selects the process that is being performed. The production rate is also specified at this moment. Now, suppose the line is shutdown for some reason after six days, the user revisits this section and enters the number of turns that has passed since the last stoppage. Also, the amount of time the line was not producing is to be provided. Also, the amount of material rejected if any, along with the reason for the stoppage should be entered. 


\begin{tabular}{|c|c|c|c|c|c|c|c|c|c|c|c|c|}
\hline $\mathrm{A}$ & $\mathrm{B}$ & & $\mathrm{C}$ & $\mathrm{D}$ & $E$ & $F$ & $G$ & \multicolumn{2}{|l|}{$\mathrm{H}$} & \multicolumn{2}{|c|}{1} & $J$ \\
\hline Month & \multicolumn{2}{|l|}{$\begin{array}{l}\text { Line Type } \\
\text { (Coating) }\end{array}$} & $\begin{array}{c}\text { Production Rate } \\
\text { (Tons } / \mathrm{Hr})\end{array}$ & $\begin{array}{l}\text { Number of } \\
\text { Turns }\end{array}$ & $\begin{array}{c}\text { Number of Line } \\
\text { Stoppages }{ }^{\star} \text { due } \\
\text { to Pot Hardware } \\
\text { Failure }\end{array}$ & $\begin{array}{l}\text { Total Time for All } \\
\text { Stoppages } \\
\text { Including End of } \\
\text { Production } \\
\text { (Downtime Hours) }\end{array}$ & $\begin{array}{l}\text { Amount of material } \\
\text { Rejected due to } \\
\text { Hardware Failure } \\
\text { (Tons) }\end{array}$ & \multicolumn{5}{|c|}{$\begin{array}{l}\text { Select Pot Hardware Material that Failed if } \\
\text { Applicable }\end{array}$} \\
\hline \multicolumn{8}{|c|}{$\begin{array}{c}\text { Jan } \\
\text { Start Date }\end{array}$} & \multicolumn{2}{|c|}{$\begin{array}{l}\text { Select Roll } \\
\text { Type if } \\
\text { Applicable } \\
\end{array}$} & \multicolumn{2}{|c|}{$\begin{array}{c}\text { Select } \\
\text { Component if } \\
\text { Applicable } \\
\end{array}$} & \multirow{2}{*}{\begin{tabular}{|c|}
$\begin{array}{c}\text { Specify Material if } \\
\text { Applicable }\end{array}$ \\
Strip Breakdown
\end{tabular}} \\
\hline 1 & Structural Steel & $\nabla$ & 43 & 14 & 1 & 6 & 200 & None & $\nabla$ & None & $\nabla$ & \\
\hline 8 & Structural Steel & $\nabla$ & 43 & 14 & 1 & 6 & 200 & None & $\nabla$ & None & $\nabla$ & Strip Breakdown \\
\hline 15 & Structural Steel & $\nabla$ & 43 & 14 & 1 & 10 & 50 & Stabilizing Roll & $\nabla$ & Bearing & $\nabla$ & Stellite / PM \\
\hline 23 & Soft Steel & $\nabla$ & 43 & 14 & 1 & 6 & 175 & None & $\nabla$ & \begin{tabular}{|l|} 
None \\
\end{tabular} & $\nabla$ & Strip Breakdown \\
\hline \multirow[t]{4}{*}{30} & Soft Steel & $\nabla$ & 43 & 14 & 1 & 6 & 200 & None & $\nabla$ & Other & $\nabla$ & Strip Breakdown \\
\hline & Soft Steel & $\nabla$ & & & & & & Stabilizing Roll & $\nabla$ & \begin{tabular}{|l|} 
Journal \\
\end{tabular} & $\nabla$ & \\
\hline & Non-Anneal & $\nabla$ & & & & & & None & $\nabla$ & \begin{tabular}{|l} 
None \\
\end{tabular} & $\nabla$ & \\
\hline & Non-Anneal & $\nabla$ & & & & & & None & $\nabla$ & \begin{tabular}{|l} 
None \\
\end{tabular} & $\nabla$ & \\
\hline \multicolumn{13}{|l|}{ Feb } \\
\hline 6 & Soft Steel & $\nabla$ & 43 & 14 & 1 & 10 & 80 & Sink Roll & $\nabla$ & Bearing & $\nabla$ & Stellite / PM \\
\hline 13 & Non-Anneal & $\nabla$ & 43 & 14 & 1 & 6 & 206 & None & $\nabla$ & \begin{tabular}{|l|} 
Other \\
\end{tabular} & $\nabla$ & Strip Breakdown \\
\hline 20 & Non-Anneal & $\nabla$ & 43 & 14 & 1 & 6 & 200 & None & $\nabla$ & None & $\nabla$ & Strip Breakdown \\
\hline \multirow[t]{2}{*}{27} & Non-Anneal & $\nabla$ & 43 & 14 & 1 & 10 & 100 & Stabilizing Roll & $\nabla$ & Other & $\nabla$ & CF3M \\
\hline & Non-Anneal & $\nabla$ & & & & & & Sink Roll & $\nabla$ & Bearing & $\nabla$ & \\
\hline
\end{tabular}

Figure 4.8: Production Data 


\subsubsection{Energy Parameters}

The energy parameters section of the input field will let the user enter the data pertaining to all the equipment, capacities, utilization and load factors, and information about the status of the equipment during downtimes. This section consists of multiple modules. The equipment is broadly classified according to the type of fuel used and energy consumption point as described previously in Section 3.1. Each module is dedicated to a particular category of equipment and the input fields are customized accordingly. The accuracy of the results depends largely on the accuracy of the data provided in these fields. The following sections discuss the various modules in detail.

\subsubsection{Line Motors}

Figure 4.9 shows a sample snapshot of input section for line motors. This spreadsheet contains motors present on equipment that are commonly found in the galvanizing facility. The various motors covered under this0 spreadsheet are-Pay-off reel, Hydraulic unit motors, Bridle rolls, Accumulator loop motors, Temper mill motors, Leveler cassette unit, Air knife compressor/blower, Plant air compressor, Chemical treatment section, Cooling tower motors and miscellaneous motors section that will cover all the pumps, blowers and drives present on the line or on the supporting equipment.

The input fields are designed to be very user friendly. Drop down menus are provided at various places. The model will calculate the motor efficiency based on the horsepower, load factor and the motor condition entered by the user. The motor condition selection filed is shown in Figure 4.10.

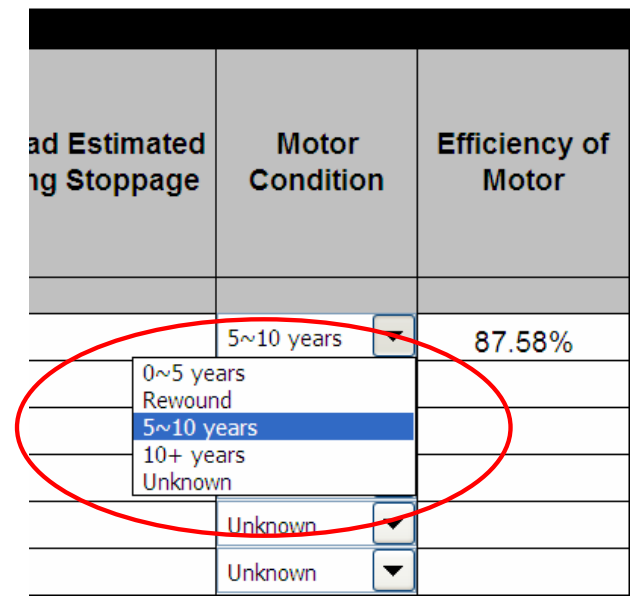

Figure 4.10: Selecting Motor Condition 


\begin{tabular}{|c|c|c|c|c|c|c|c|c|c|c|c|c|c|}
\hline \multicolumn{14}{|c|}{ Hydraulic Unit Motors } \\
\hline \multirow{2}{*}{$\begin{array}{l}2 \\
\mathrm{i}\end{array}$} & \multirow{2}{*}{$\begin{array}{l}\text { HP } \\
60 \\
\end{array}$} & \multirow{2}{*}{\begin{tabular}{|c|} 
\# of motors of \\
same HP
\end{tabular}} & \multirow{2}{*}{$\begin{array}{c}\mathrm{AC} / \mathrm{DC} \\
\text { Drive } \\
\mathrm{AC} \\
\end{array}$} & \multirow{2}{*}{\begin{tabular}{|c|}
$\begin{array}{c}\% \text { loaded } \\
\text { estimate } \\
\text { (Load factor) }\end{array}$ \\
$80.00 \%$ \\
\end{tabular}} & \multirow{2}{*}{$\begin{array}{c}\begin{array}{c}\% \text { of time used } \\
\text { (Utilization } \\
\text { factor) }\end{array} \\
100.00 \% \\
\end{array}$} & \multirow{2}{*}{\begin{tabular}{|c|} 
\# of motors \\
Standby
\end{tabular}} & \multicolumn{2}{|c|}{$\begin{array}{c}\text { Are the Motors } \\
\text { Running During Line } \\
\text { Stoppage }{ }^{\star} \text { YES/NO }\end{array}$} & \multirow{2}{*}{\begin{tabular}{|c|}
$\begin{array}{c}\% \text { Load Estimated } \\
\text { During Stoppage }\end{array}$ \\
$40.00 \%$ \\
\end{tabular}} & \multicolumn{2}{|c|}{$\begin{array}{c}\text { Motor } \\
\text { Condition }\end{array}$} & \multirow{2}{*}{$\begin{array}{c}\begin{array}{c}\text { Efficiency of } \\
\text { Motor }\end{array} \\
83.52 \% \\
\end{array}$} & \multirow{2}{*}{$\begin{array}{c}\begin{array}{c}\text { Estimated } \\
\text { Savings }\end{array} \\
2.00 \% \\
\end{array}$} \\
\hline & & & & & & & YES & $\nabla$ & & Rewound & $\nabla$ & & \\
\hline ii & 40 & 2 & $\mathrm{AC}$ & \begin{tabular}{|l|}
$80.00 \%$ \\
\end{tabular} & $100.00 \%$ & 1 & no & $\nabla$ & & $5^{\sim 10}$ years & $\nabla$ & $87.48 \%$ & \\
\hline iii & & & & & & & YES & $\nabla$ & & Unknown & $\nabla$ & & \\
\hline iv & & & & & & & YES & $\nabla$ & & Unknown & $\nabla$ & & \\
\hline $\mathrm{v}$ & & & & & & & YES & $\nabla$ & & Unknown & $\nabla$ & & \\
\hline $\mathrm{vi}$ & & & & & & & YES & $\nabla$ & & Unknown & $\nabla$ & & \\
\hline \multicolumn{14}{|c|}{ Bridle Roll Motors } \\
\hline 3 & HP & $\begin{array}{c}\# \text { of motors of } \\
\text { same HP }\end{array}$ & $\begin{array}{l}\mathrm{AC} / \mathrm{DC} \\
\text { Drive }\end{array}$ & $\mid \begin{array}{c}\% \text { loaded } \\
\text { estimate } \\
\text { (Load factor) }\end{array}$ & $\begin{array}{l}\text { \% of time used } \\
\text { (Utilization } \\
\text { factor) }\end{array}$ & $\begin{array}{c}\text { \# of motors } \\
\text { Standby }\end{array}$ & \multicolumn{2}{|c|}{$\begin{array}{c}\text { Are the Motors } \\
\text { Running During Line } \\
{\text { Stoppage }{ }^{\star} \text { YES/NO }}^{\text {Y }}\end{array}$} & $\begin{array}{l}\% \text { Load Estimated } \\
\text { During Stoppage }\end{array}$ & \multicolumn{2}{|c|}{$\begin{array}{c}\text { Motor } \\
\text { Condition }\end{array}$} & $\begin{array}{l}\text { Efficiency of } \\
\text { Motor }\end{array}$ & $\begin{array}{c}\text { Estimated } \\
\text { Savings }\end{array}$ \\
\hline $\mathrm{i}$ & 75 & 2 & $\mathrm{AC}$ & $60.00 \%$ & $100.00 \%$ & 0 & No & $\nabla$ & & $10+$ years & $\nabla$ & $87.40 \%$ & \\
\hline ii & 50 & 2 & $\mathrm{AC}$ & $60.00 \%$ & $100.00 \%$ & 0 & YES & $\nabla$ & $30.00 \%$ & $5^{N 10}$ years & $\nabla$ & $87.58 \%$ & \\
\hline iii & 20 & 3 & $\mathrm{AC}$ & $60.00 \%$ & $100.00 \%$ & 0 & YES & $\nabla$ & $30.00 \%$ & $0^{\circ} 5$ years & $\nabla$ & $87.70 \%$ & \\
\hline iv & 30 & 2 & $\mathrm{AC}$ & $60.00 \%$ & $100.00 \%$ & 0 & YES & $\nabla$ & $30.00 \%$ & 5 "10 years & $\nabla$ & $87.37 \%$ & \\
\hline v & 50 & 2 & $\mathrm{AC}$ & $60.00 \%$ & $100.00 \%$ & 0 & No & $\nabla$ & & $0^{\infty} 5$ years & $\nabla$ & $88.02 \%$ & \\
\hline vi & 355 & 1 & $A C$ & $60.00 \%$ & $100.00 \%$ & 0 & No & $\nabla$ & & $0^{\sim} 5$ years & $\nabla$ & $91.21 \%$ & $2.00 \%$ \\
\hline vii & & & & & & & YES & $\nabla$ & & Unknown & $\nabla$ & & \\
\hline
\end{tabular}

Figure 4.9: Line Motors 


\section{Data for Different Motors in the Furnace}

* Line Stoppage means the coating line is stopped due to hardware failure in the bath (OR) due to preventive maintenance.

\begin{tabular}{|c|c|c|c|c|c|c|c|c|c|c|c|c|c|c|}
\hline \multirow{3}{*}{$\begin{array}{c}12 \\
12 a \\
\mathrm{i} \\
\end{array}$} & \multirow{3}{*}{$\begin{array}{c}\begin{array}{c}\text { Motors on different } \\
\text { sections of Annealing } \\
\text { Furnace }\end{array} \\
\begin{array}{c}\text { Motors in Pre Heat } \\
\text { Section (Name) }\end{array} \\
\text { Combustion Air Exhaust } \\
\end{array}$} & \multicolumn{13}{|c|}{$\begin{array}{c}\text { (Combustion Blower Motors, Exhaust Blower Motors, Dilution Air Blower Motor, Furnace Pilot Air, Radient Tube Air Blower Motor, Controlled Cooling/Jet Cooling Air } \\
\text { Blower Motors, etc) }\end{array}$} \\
\hline & & \multirow{2}{*}{$\begin{array}{l}\text { HP } \\
100 \\
\end{array}$} & \multirow{2}{*}{\begin{tabular}{|c}
$\begin{array}{l}\text { \# of motors } \\
\text { of same HP }\end{array}$ \\
1 \\
\end{tabular}} & \multirow{2}{*}{$\begin{array}{c}\mathrm{AC} / \mathrm{DC} \text { Drive } \\
\mathrm{AC} \\
\end{array}$} & \multirow{2}{*}{$\begin{array}{l}\begin{array}{c}\% \text { Loaded } \\
\text { estimate }\end{array} \\
75.00 \% \\
\end{array}$} & \multirow{2}{*}{$\begin{array}{c}\% \text { of time } \\
\text { used } \\
\text { (Utilization } \\
\text { factor) }\end{array}$} & \multirow[t]{2}{*}{$\begin{array}{l}\text { \# of motors } \\
\text { Standby }\end{array}$} & \multicolumn{2}{|c|}{$\begin{array}{c}\text { Are the Motors } \\
\text { Running During Line } \\
\text { Stoppage* YES/NO }\end{array}$} & \multirow[t]{2}{*}{$\begin{array}{l}\text { \% Load Estimated } \\
\text { During Stoppage }\end{array}$} & \multicolumn{2}{|c|}{$\begin{array}{l}\text { Motor } \\
\text { Condition }\end{array}$} & \multirow{2}{*}{\begin{tabular}{|c}
$\begin{array}{c}\text { Efficiency } \\
\text { of Motor }\end{array}$ \\
$88.55 \%$ \\
\end{tabular}} & \multirow[t]{2}{*}{$\begin{array}{c}\text { Savings from } \\
\text { Implementing } \\
\text { Energy } \\
\text { Efficiency } \\
\text { Measures } \\
\end{array}$} \\
\hline & & & & & & & & No & $\nabla$ & & $0 \sim 5$ years & $\nabla$ & & \\
\hline ii & Dilution air fan & 15 & \begin{tabular}{|l}
1 \\
\end{tabular} & $A C$ & $75.00 \%$ & $100.00 \%$ & & YES & $\nabla$ & $30.00 \%$ & $5 * 10$ years & $\nabla$ & $87.22 \%$ & \\
\hline iii & Dilution air fan 2 & 50 & 1 & $A C$ & $75.00 \%$ & $100.00 \%$ & & YES & $\nabla$ & $30.00 \%$ & Unknown & $\nabla$ & $87.59 \%$ & \\
\hline iv & Rolls & 20 & 1 & $A C$ & $75.00 \%$ & $100.00 \%$ & & No & - & & Unknown & $\nabla$ & $87.27 \%$ & \\
\hline$v$ & & & & & & & & YES & $\nabla$ & & Unknown & $\nabla$ & & \\
\hline vi & & & & & & & & YES & $\nabla$ & & Unknown & $\nabla$ & & \\
\hline vii & & & & & & & & YES & $\nabla$ & & Unknown & $\nabla$ & & \\
\hline viii & & & & & & & & YES & $\nabla$ & & Unknown & $\nabla$ & & \\
\hline ix & & & & & & & & YES & $\nabla$ & & Unknown & $\nabla$ & & \\
\hline$x$ & & & & & & & & No & $\nabla$ & & Unknown & $\nabla$ & & \\
\hline $\mathrm{xi}$ & & & & & & & & No & $\nabla$ & & Unknown & $\nabla$ & & \\
\hline xii & & & & & & & & no & $\nabla$ & & Unknown & $\nabla$ & & \\
\hline $12 b$ & $\begin{array}{l}\text { Motors in Non Oxidizing } \\
\text { Furnace Section (Name) }\end{array}$ & HP & $\begin{array}{l}\text { \# of motors } \\
\text { of same HP }\end{array}$ & $\mathrm{AC} / \mathrm{DC}$ Drive & $\begin{array}{l}\% \text { loaded } \\
\text { estimate }\end{array}$ & $\begin{array}{l}\% \text { of time } \\
\text { used } \\
\text { (Utilization } \\
\text { factor) }\end{array}$ & $\begin{array}{l}\text { \# of motors } \\
\text { Standby }\end{array}$ & $\begin{array}{r}\text { A } \\
\text { Run } \\
\text { Sto }\end{array}$ & & $\begin{array}{l}\% \text { Load Estimated } \\
\text { During Stoppage }\end{array}$ & $\begin{array}{r}\text { Motor } \\
\text { Conditio }\end{array}$ & & $\begin{array}{c}\text { Efficiency } \\
\text { of Motor }\end{array}$ & $\begin{array}{l}\text { Savings from } \\
\text { Implementing } \\
\text { Energy } \\
\text { Efficiency }\end{array}$ \\
\hline
\end{tabular}

Figure 4.11: Furnace Motors 
Also, the user must specify the status of the motor during downtimes. If the motor is running during downtimes then, a separate load factor for that period must be provided. If the user decides to implement some efficiency improvement technique on the existing equipment and wishes to see the effect of doing so on the overall system, one can fill in the estimated percentage savings that will be achieved in the "Estimated Savings" column. Consider an example of the user replacing the drive with a variable frequency drive and he estimates that there will be $2 \%$ savings. The user will enter $2 \%$ in the estimated savings column against the corresponding drive. The user can also put a small note in the adjacent row regarding the changes that has been made.

\subsubsection{Furnace Motors}

Figure 4.11 shows a sample snapshot of input section for the motors present in or associated with the annealing and galvanneal furnace. The combustion blower, exhaust blowers, pilot air blowers etc in all the different sections of the furnace are covered on this spreadsheet. All the input fields are similar to those in the previous line motor module. Referring again to Figure 4.11, the name of the motor in the preheat section is to be entered, (example the combustion air exhaust). The horsepower, number of motors, and the load and utilization factor for the motors has to be entered. Status of the motor during shutdown must be selected. If the motor is running during downtime, its load during the downtime needs to be specified. Further, the condition of the motor, i.e. the approximate amount of time the motor has been in service must be specified. The efficiency of the motor is calculated based on the motor condition, load and capacity.

\subsubsection{Natural Gas Equipment}

The galvanizing line typically consists of two large natural gas fired furnaces. The first furnace is located prior to the zinc pot and is know as the annealing furnace. The second furnace is located immediately after the zinc pot and is known as the galvanneal furnace. Both these furnaces constitute more than $70 \%$ of the natural gas consumption in the facility. In addition to these furnaces there may be other equipment like natural gas boiler, sink hardware preheat furnace, etc. Figure 4.12 shows a sample snapshot of the input section for natural gas equipment. 


\section{Data for Different Natural Gas Equipment \\ Structural Steel}

Please select the unit used to specity the natural gas burners capacity

\begin{tabular}{|c|c|c|c|c|c|c|c|c|c|c|c|}
\hline \multicolumn{6}{|c|}{ Please select the unit used to specity the natural gas burners capacity } & $\begin{array}{c}\text { Recuperator } \\
\text { Savings }\end{array}$ & & & \multirow{4}{*}{$\begin{array}{l}\text { \% Load During Low } \\
\text { Fire }\end{array}$} & \multirow{4}{*}{$\begin{array}{l}\text { Burner } \\
\text { Efficiency }\end{array}$} & \multirow{4}{*}{\begin{tabular}{|c|} 
Savings from \\
Implementing \\
Energy \\
Efficiency \\
Measures \\
\end{tabular}} \\
\hline Sr. No & Name & \multirow{3}{*}{$\begin{array}{l}\text { Burner Capacity in } \\
\text { MMMBtu/hr or Gas } \\
\text { usage SCFH }\end{array}$} & \multirow{3}{*}{$\begin{array}{c}\text { Number of } \\
\text { Burners with } \\
\text { same capacity }\end{array}$} & \multirow{3}{*}{$\%$ Load Factor } & \multirow{3}{*}{$\begin{array}{l}\% \text { Time used } \\
\text { (Utilization factor) }\end{array}$} & \multirow{3}{*}{$\begin{array}{l}\text { Recuperator } \\
\text { YES/NO }\end{array}$} & \multirow{3}{*}{\multicolumn{2}{|c|}{$\begin{array}{c}\text { During Line Stoppage } \\
\text { the Burner is } \\
\text { ON/OFFILOW FIRE }\end{array}$}} & & & \\
\hline 1 & Furnace & & & & & & & & & & \\
\hline $1 \mathrm{a}$ & Pre Heat Section & & & & & & & & & & \\
\hline$i$ & Pre heat & 1.62 & 36 & $70.00 \%$ & $100.00 \%$ & YES & LOWFIRE & $\nabla$ & $20.00 \%$ & $95.00 \%$ & \\
\hline ii & & & & & & NO & Don & $\nabla$ & & & \\
\hline iii & & & & & & No & ON & - & & & \\
\hline iv & & & & & & YES & ON & - & & & \\
\hline$v$ & & & & & & No & ON & - & & & \\
\hline vi & & & & & & NO & ON & $\nabla$ & & & \\
\hline vii & & & & & & No & ON & - & & & \\
\hline viii & & & & & & No & ON & $\nabla$ & ferente & & \\
\hline $1 \mathrm{~b}$ & Non Oxidizing Furnace & $\begin{array}{l}\text { Burner Capacity in } \\
\text { MMMBtu/hr or Gas } \\
\text { usage SCFH }\end{array}$ & $\begin{array}{c}\text { Number of } \\
\text { Burners with } \\
\text { same capacity }\end{array}$ & $\%$ Load Factor & $\begin{array}{c}\% \text { Time used } \\
\text { (Utilization factor) }\end{array}$ & $\begin{array}{l}\text { Recuperator } \\
\text { YES/NO }\end{array}$ & $\begin{array}{r}\text { During L } \\
\text { is th } \\
\text { ON/OF }\end{array}$ & & $\begin{array}{l}\text { General: } \\
\text { Line Stoppage means the } \\
\text { stopped due to hardware } \\
\text { (OR) due to preventive mai }\end{array}$ & $\begin{array}{l}\text { ating line is } \\
\text { ure in the bath } \\
\text { tenance. }\end{array}$ & $\begin{array}{c}\text { Savings from } \\
\text { Implementing } \\
\text { Energy } \\
\text { Efficiency } \\
\text { Measures }\end{array}$ \\
\hline$i$ & & & & & & No & LOWFIRE & $\nabla$ & & & \\
\hline ii & & & & & & No & ON & - & & & \\
\hline $\mathrm{iii}$ & & & & & & No & ON & - & & & \\
\hline iv & & & & & & YES & ON & $\nabla$ & & & \\
\hline 19 & Index / Motors / Furnac & Motors $\lambda$ NG Equipm & t/ N2-H2 Data, & ther Electric $\not C$ & umption / Diagram & / Sensitivity $\overline{\overline{\alpha b}}$ & ackstage & & & & \\
\hline
\end{tabular}

Figure 4.12: Natural Gas Equipment 
The user has the provision to enter the burner capacity either in MMBtu/hr or SCFH. The module is designed in such a way that data for every section of the furnaces can be entered independently. The first column identifies the section of the furnace followed by burner rating, number of burners, load and utilization. It is recommended to enter the burners according to the zones. The load on the burners may vary from zone to zone, even though they belong to the same section. If there is recuperator on the burners then, proper selection must be done. By clicking on recuperator savings button the savings obtained from recuperators can be changed. This will open the window shown in Figure 4.14. During downtimes the annealing furnace is often set to a low fire setting. The user must properly identify what is the status of the furnace burners during shutdown period. If the burners are on low fire then, the low fire load should be entered. If the user selects the burners to be off then, the pilot consumption only will be considered. The efficiency on the burner in this case is to be provided by the user unlike in motors where it is automatically calculated.

The annealing furnace has a ramp-up and steady state rate that varies in a small range. This range is typical for a particular type of process. The user can easily obtain an average firing factor for each section of the furnace. This firing factor will vary from process to process. The firing factor depends on many factors like the process temperatures, dew point, gauge etc. Figure 4.13 shows how the load on burners varies for different processes.

Consider process A and process B as galvanizing two different gauge of steel. Process $\mathrm{A}$ is a thick gauge and it can be seen from Figure 4.13 that it takes 0.55 hours to reach the set point temperature. At set point temperature burners are loaded to $75 \%$ of their capacity. Once the set point is reached, the load profile keeps swinging between $70 \%$ and $100 \%$ to maintain the furnace temperature. This continues till the same product is running through the line. Thus, it can be said that during process $\mathrm{A}$, the furnace has an average load factor of $87.5 \%$. Similarly, when process B is carried out, i.e. thin gauge, the furnace reaches the set point in 0.45 hours and the burners are loaded up to $50 \%$. The load varies from $50 \%$ to $60 \%$ during the entire process B production. The average load profile for this process is $55 \%$. 


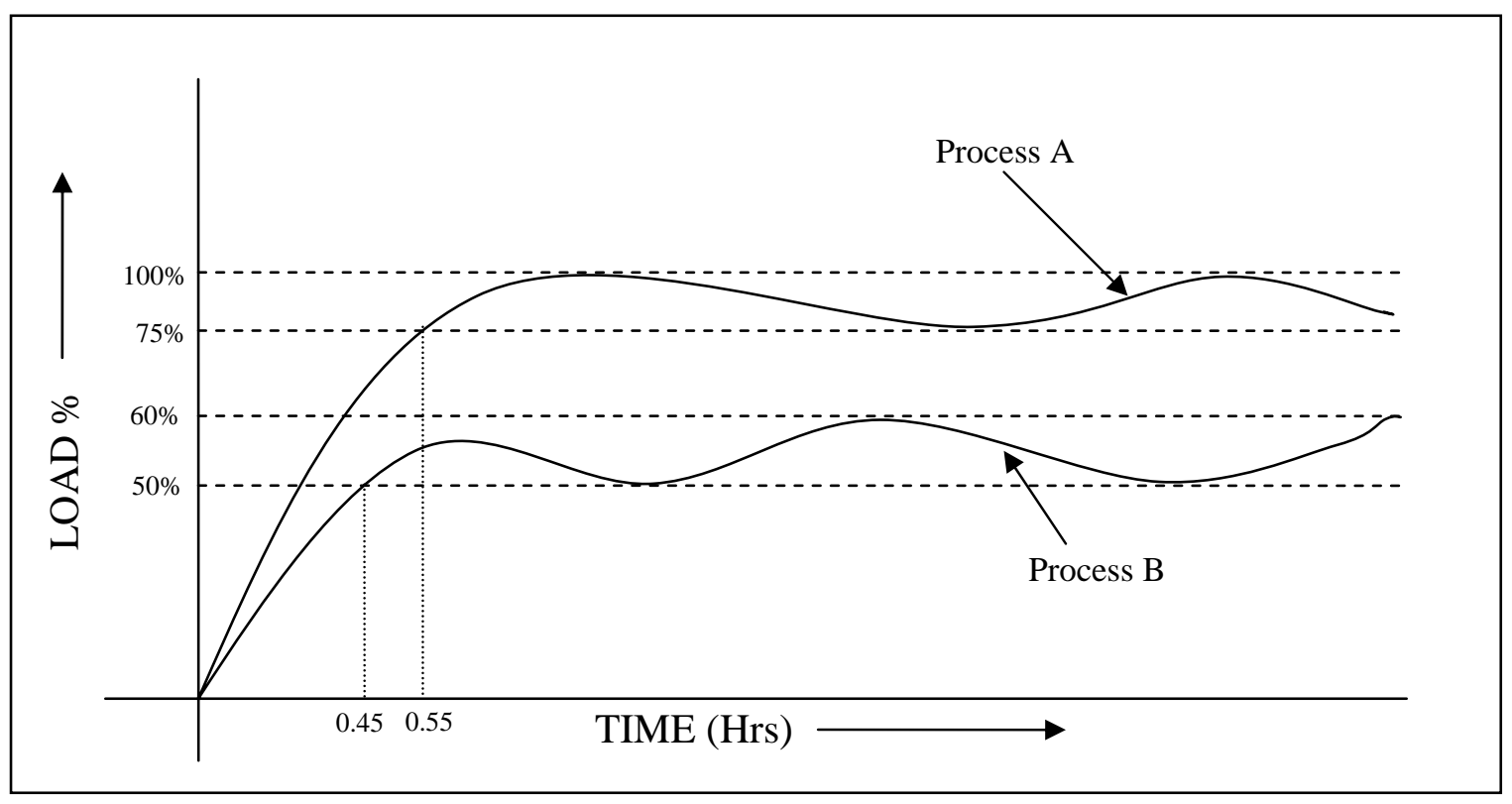

Figure 4.13: Load Profile for Annealing Furnace

Thus the user has the liberty to enter a different firing factor for all different sections of the furnace for all the three processes. Most of the newly installed furnaces have recuperative burners. The user can select if the burners have recuperators on them. Also, the user can enter the savings obtained as a result of the recuperators. The default value of the savings is $6 \%$. Figure 4.14 shows the data entry form for recuperator savings. If the user implements any efficiency improvement technique on the furnace and wishes to see the effect of doing so on the overall system, the user can fill in the estimated percentage savings that will be achieved in the "Estimated Savings" column. For example if the facility proposes to insulate the entire furnace or a section of it and estimate 5\% energy savings, this $5 \%$ can be directly entered in this column.

Enter the energy savings in percentage obtained as a result of recuperator

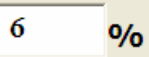

$\mathrm{OK}$

EXIT

Figure 4.14: Recuperator Savings 


\subsubsection{Nitrogen and Hydrogen Consumption Data}

A reducing atmosphere must be maintained in the entire annealing furnace. This is important, as the steel is prone to oxidation at elevated temperatures. To avoid oxidation and remove any oxygen present in the furnace, hydrogen and nitrogen is pumped to displace the air inside the furnace. Hydrogen reacts with any oxygen present in the furnace or steel surface to form vapor. Nitrogen is used as a carrier gas and does not take part in any chemical reaction. The proportion of the gases varies from process to process. The amount of hydrogen can vary from $13 \%$ to $40 \%$ from process to process, remaining being the nitrogen. Figure 4.15 shows a snapshot for the input section for nitrogen and hydrogen data for a particular process. The usage in SCFH as well as the cost of hydrogen and nitrogen in \$/MCF should be provided.

\subsection{Outputs}

\subsubsection{Power and Energy Consumption Details}

The energy consumption details spreadsheet provides the per hour consumption of energy by the particular process. Natural gas consumption is given in MMBtu/hr. Also, consumption for all the major natural gas consuming equipment is shown separately. Similarly, electricity consumption is shown in $\mathrm{kW}$ for different equipment. Based on the production data, the total cost of natural gas, electricity and demand for the particular

process is also obtained. In addition to this, the consumption and cost of hydrogen and nitrogen is also obtained. Figure 4.16 and 4.17 shows snapshots of the energy consumption details spreadsheet. Figure 4.16 show the total horsepower of all motors i.e. 4,058 hp. Also, it shows the energy consumption of $8.23 \mathrm{MMBtu} / \mathrm{hr}$ during production, and 1.33 MMBtu/hr during downtime. Figure 4.16 shows the MMBtu/hr for various natural gas operated equipment such as the annealing furnace, natural gas fired boiler, and other miscellaneous equipment. Also the total energy consumption reported for natural gas equipment is 51.16 MMBtu/hr during production and 17.51 MMBtu/hr during downtime. The total consumption of hydrogen and nitrogen, as well as the consumption cost for these two gases, is reported. The rates for electricity and natural gas in \$/MMBtu and electrical demand in $\$ / \mathrm{kW}$ calculated by the Energy costs spreadsheet are also shown on this spreadsheet. 


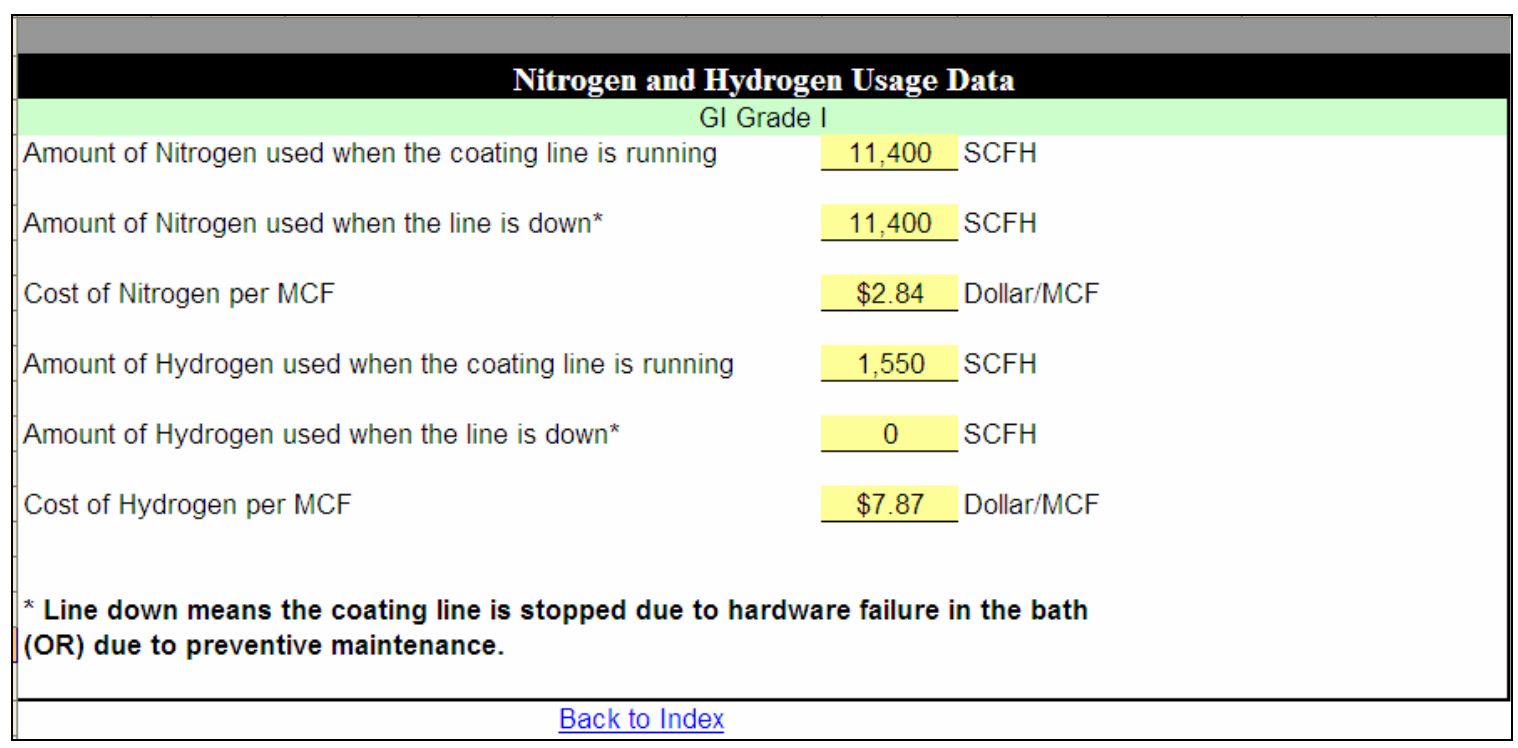

Figure 4.15: Input section for Nitrogen and Hydrogen Data

\begin{tabular}{|c|c|c|c|}
\hline \multicolumn{4}{|c|}{ Power \& Energy Consumption Details } \\
\hline \multicolumn{4}{|c|}{ GL - Structural Steel } \\
\hline \multicolumn{4}{|c|}{ Electric Motors } \\
\hline & Production & Downtime & Units \\
\hline Total Horsepower & $4,085.00$ & $4,085.00$ & $\mathrm{HP}$ \\
\hline Total Power of line motors & $2,142.07$ & 318.76 & $\mathrm{~kW}$ \\
\hline Total Power of furnace motors & 268.22 & 70.44 & $\mathrm{~kW}$ \\
\hline Percentage of total power used & $44.02 \%$ & $7.11 \%$ & $\%$ \\
\hline Total Motor Power & $2,410.29$ & 389.20 & $\mathrm{~kW}$ \\
\hline Total Energy Consumption by motors & 8.23 & 1.33 & MMBtu/hr \\
\hline Cost for running the motors & $\$ 38,733$ & $\$ 893$ & Dollars \\
\hline Demand Cost for Motors & $\$ 0$ & $\$ 0$ & Dollars \\
\hline Total Cost for running the motors & $\$ 38,733$ & $\$ 893$ & Dollars \\
\hline \multicolumn{4}{|c|}{ Other Electric Equipment } \\
\hline & Production & Downtime & Units \\
\hline Power of Main Pot in kW & 350 & 350 & kW \\
\hline Power of Pre-melt Pot in kW & 0 & 0 & kW \\
\hline Total Power of Miscellaneous equipment in $\mathrm{kW}$ & 139 & 46 & $\mathrm{~kW}$ \\
\hline Energy Consumption in MMBtu/hr & 1.67 & 1.35 & MMBtu/hr \\
\hline Cost of running other Electric Equipment & $\$ 7,852$ & $\$ 910$ & Dollars \\
\hline Demand Cost for other Electric Equipment & $\$ 0$ & $\$ 0$ & Dollars \\
\hline
\end{tabular}

Figure 4.16: Power and Energy Consumption Details for Electrical Equipment 


\begin{tabular}{|c|c|c|c|}
\hline \multicolumn{4}{|c|}{ Natural Gas Equipment } \\
\hline & Production & Downtime & Units \\
\hline Energy Consumed by Annealing Furnace & 48.71 & 17.43 & MMBtu/hr \\
\hline Energy Consumed by NG Boiler & 0.00 & 0.00 & MMBtu/hr \\
\hline Energy Consumed by misc NG equipment & 2.45 & 0.08 & MMBtu/hr \\
\hline Energy Consumed by Galvaneal furnace & 0.00 & 0.00 & MMBtu/hr \\
\hline $\begin{array}{l}\text { Total Energy Consumed by all NG } \\
\text { Equipment }\end{array}$ & 51.16 & 17.51 & MMBtu/hr \\
\hline Cost for running Natural Gas Equipment & $\$ 179,842$ & $\$ 8,793$ & Dollars \\
\hline \multicolumn{4}{|c|}{ Cost of Energy } \\
\hline Marginal Cost of Electricity & \multicolumn{2}{|c|}{$\$ 9.34$} & \$/MMBtu \\
\hline Demand Cost & \multicolumn{2}{|c|}{$\$ 0.00$} & $\$ / \mathrm{kW}$ \\
\hline Cost of Natural Gas & \multicolumn{2}{|c|}{$\$ 6.97$} & \$/MMBtu \\
\hline \multicolumn{4}{|c|}{ Nitrogen and Hydrogen } \\
\hline & Production & Downtime & Units \\
\hline Total Hydrogen Consumption & 781,200 & 0 & SCF \\
\hline Total Hydrogen Consumption Cost & $\$ 6,148$ & $\$ 0$ & Dollars \\
\hline Total Nitrogen Consumption & $5,745,600$ & 820,800 & SCF \\
\hline Total Nitrogen Consumption Cost & $\$ 16,318$ & $\$ 2,331$ & Dollars \\
\hline
\end{tabular}

Figure 4.17: Energy Consumption Details for Natural Gas Equipment and $\mathrm{H}_{2}-\mathrm{N}_{2}$ Data

\subsubsection{Summary Sheet}

The summary sheet is a comprehensive chart providing monthly data for all the three processes. This information gets filled as the user adds on the production data. Figure 4.18 and 4.19 show small portions of the summary sheet snapshot. The snapshot is divided to obtain better viewing. The various columns starting from left to right are as follows:

Month: The different months and the processes are shown in the first column.

Production in Tons: The monthly production for each process is reported.

Total hours of operation: The total time per month spent on each process is reported.

Rejection in tons: Any rejection that occurred during the month is reported for each process.

Total hours of downtime: The total shutdown time including preventive maintenance shutdowns is reported. 
Natural gas consumed during production (MMBtu): The total natural gas energy in MMBtu consumed during production for the month is reported.

Electrical energy consumed during production (kWh): The total electrical energy in $\mathrm{kWh}$ consumed during production for the month is reported.

Hydrogen consumed during production (SCF): The total hydrogen consumed by each process during production is reported in SCF.

Cost of hydrogen during production (\$): The total cost of hydrogen consumed during production for the given month is reported.

Nitrogen consumed during production (SCF): The total nitrogen consumed by each process during production is reported in SCF.

Cost of nitrogen during production (\$): The total cost of nitrogen consumed during production for the given month is reported.

Cost of energy during production (\$): The total money spent on electrical and natural gas energy during production for the given processes is reported.

Natural gas consumed during downtime (MMBtu): The total natural gas energy in MMBtu consumed during downtime for the month is reported.

Electrical energy consumed during downtime (kWh): The total electrical energy in $\mathrm{kWh}$ consumed during downtime for the month is reported.

Hydrogen consumed during downtime (SCF): The total hydrogen consumed by each process during downtime is reported in SCF.

Cost of hydrogen during downtime (\$): The total cost of hydrogen consumed during downtime for the given month is reported.

Nitrogen consumed during downtime (SCF): The total nitrogen consumed by each process during downtime is reported in SCF.

Cost of nitrogen during downtime (\$): The total cost of nitrogen consumed during downtime for the given month is reported.

Cost of energy during downtime (\$): The total money spent on electrical and natural gas energy during downtime for the given processes are reported.

Total money spent on Energy (\$): Total money spent on electrical and natural gas energy during production as well as downtime is reported. 
MMBtu/ton: The specific energy consumption for various processes performed during each month is reported.

The total for all these values for each process as well as the grand total for the entire line is also obtained. 


\begin{tabular}{|c|c|c|c|c|c|c|c|c|c|c|c|c|}
\hline \multirow{2}{*}{\multicolumn{2}{|c|}{ Month }} & \multirow[b]{2}{*}{$\begin{array}{l}\text { Production } \\
\text { in Tons }\end{array}$} & \multirow[b]{2}{*}{$\begin{array}{l}\text { Total Hours } \\
\text { of Operation }\end{array}$} & \multirow[b]{2}{*}{$\begin{array}{c}\text { Rejection in } \\
\text { Tons }\end{array}$} & \multirow[b]{2}{*}{$\begin{array}{c}\text { Total Hours of } \\
\text { Downtime }\end{array}$} & \multirow[b]{2}{*}{$\begin{array}{l}\text { NG Energy } \\
\text { Consumed } \\
\text { during } \\
\text { Production } \\
\text { (MMBtu) }\end{array}$} & \multirow[b]{2}{*}{$\begin{array}{l}\text { Electrical } \\
\text { Energy } \\
\text { Consumed } \\
\text { during } \\
\text { Production } \\
\text { (kWh) }\end{array}$} & \multirow[b]{2}{*}{$\begin{array}{l}\text { Hydrogen } \\
\text { Consumed } \\
\text { During } \\
\text { Production } \\
\text { (SCF) }\end{array}$} & \multirow[b]{2}{*}{$\begin{array}{l}\text { Cost of } \\
\text { Hydrogen } \\
\text { During } \\
\text { Production (\$) }\end{array}$} & \multirow[b]{2}{*}{$\begin{array}{l}\text { Nitrogen } \\
\text { Consumed } \\
\text { During } \\
\text { Production } \\
\text { (SCF) }\end{array}$} & \multicolumn{2}{|c|}{ Monthly Summary } \\
\hline & & & & & & & & & & & $\begin{array}{l}\text { Cost of } \\
\text { Nitrogen } \\
\text { During } \\
\text { Production (\$) }\end{array}$ & $\begin{array}{l}\text { Cost of Energy } \\
\text { During } \\
\text { Production (\$) }\end{array}$ \\
\hline \multirow{4}{*}{\begin{tabular}{|l|} 
January \\
\\
\end{tabular}} & & & & & & & & & & & & \\
\hline & GI Grade I & 17,280 & 432 & 0 & 92 & 25,433 & $1,783,286$ & 669,600 & $\$ 5,270$ & $4,924,800$ & $\$ 13,986$ & $\$ 264,816$ \\
\hline & GN & 0 & 0 & 0 & 0 & 0 & 0 & 0 & so & 0 & so & so \\
\hline & GI Grade I|| & 8,320 & 208 & 70 & 48 & 7,386 & 863,460 & 322,400 & $\$ 2,537$ & $2,371,200$ & $\$ 6,734$ & $\$ 110,056$ \\
\hline \multirow{4}{*}{ February } & & & & & & & & & & & & \\
\hline & GI Grade I & 13,440 & 336 & 60 & 110 & 19,781 & $1,387,000$ & 520,800 & $\$ 4,099$ & $3,830,400$ & $\$ 10,878$ & $\$ 212,603$ \\
\hline & GN & 16,320 & 408 & 0 & 48 & 13,843 & $1,647,815$ & 632,400 & $\$ 4,977$ & $4,651,200$ & $\$ 13,209$ & $\$ 180,705$ \\
\hline & GI Grade I|| & 0 & 0 & 0 & 0 & 0 & 0 & 0 & so & 0 & so & so \\
\hline \multirow{4}{*}{ March } & & & & & & & & & & & & \\
\hline & GI Grade I & 9,600 & 240 & 20 & 24 & 14,129 & 990,714 & 372,000 & $\$ 2,928$ & $2,736,000$ & $\$ 7,770$ & $\$ 149,692$ \\
\hline & GN & 0 & 0 & 0 & 0 & 0 & 0 & 0 & so & 0 & so & so \\
\hline & GI Grade II & 18,240 & 456 & 30 & 96 & 16,193 & $1,892,970$ & 706,800 & $\$ 5,563$ & $5,198,400$ & $\$ 14,763$ & $\$ 185,152$ \\
\hline \multirow[t]{4}{*}{ April } & & & & & & & & & & & & \\
\hline & GI Grade I & 19,200 & 480 & 60 & 96 & 28,259 & $1,981,428$ & 744,000 & $\$ 5,855$ & $5,472,000$ & $\$ 15,540$ & $\$ 290,923$ \\
\hline & GN & 0 & 0 & 0 & 0 & 0 & 0 & 0 & so & 0 & so & so \\
\hline & G| Grade II| & 0 & 0 & 0 & 0 & 0 & 0 & 0 & so & 0 & so & so \\
\hline \multirow[t]{4}{*}{ May } & & & & & & & & & & & & \\
\hline & GI Grade | & 17,280 & 432 & 30 & 96 & 25,433 & $1,783,286$ & 669,600 & $\$ 5,270$ & $4,924,800$ & $\$ 13,986$ & $\$ 264,816$ \\
\hline & GN & 0 & 0 & 0 & 0 & 0 & 0 & 0 & so & 0 & so & so \\
\hline & GI Grade I|| & 0 & 0 & 0 & 0 & 0 & 0 & 0 & so & 0 & so & so \\
\hline \multirow[t]{4}{*}{ June } & & & & & & & & & & & & \\
\hline & G| Grade | & 17,280 & 432 & 40 & 60 & 25,433 & $1,783,286$ & 669,600 & $\$ 5,270$ & $4,924,800$ & $\$ 13,986$ & $\$ 264,816$ \\
\hline & GN & 13.440 & 336 & 0 & 72 & 11.400 & $1,357,024$ & 520,800 & $\$ 4,099$ & $3,830,400$ & $\$ 10,878$ & $\$ 153,971$ \\
\hline & GI Grade III & 0 & 0 & 0 & 0 & 0 & 0 & 0 & So & $\frac{0,400}{0}$ & so & so \\
\hline
\end{tabular}

Figure 4.18: Monthly Summary Sheet Snapshot 1 


\begin{tabular}{|c|c|c|c|c|c|c|c|c|c|c|}
\hline Sept & & & & & & & & & & \\
\hline & GI Grade I & 2,516 & 157,672 & 0 & So & $1,094,400$ & $\$ 3,108$ & $\$ 35,884$ & $\$ 365,967$ & 1.96 \\
\hline & GN & 0 & 0 & 0 & SO & 0 & so & so & so & \\
\hline & GI Grade III & 0 & 0 & 0 & So & 0 & So & So & So & \\
\hline \multicolumn{11}{|l|}{ Oct } \\
\hline & GI Grade I & 2,516 & 157,672 & 0 & So & $1,094,400$ & $\$ 3,108$ & $\$ 35,884$ & $\$ 287,647$ & 2.01 \\
\hline & GN & 1,203 & 140,060 & 0 & So & 820,800 & $\$ 2,331$ & $\$ 27,915$ & $\$ 208,620$ & 1.30 \\
\hline & GI Grade III & 0 & 0 & 0 & So & 0 & So & so & so & \\
\hline \multicolumn{11}{|l|}{ Nov } \\
\hline & Gl Grade I & 0 & 0 & 0 & So & 0 & So & So & So & \\
\hline & GN & 0 & 0 & 0 & So & 0 & So & so & So & \\
\hline & GI Grade III & 0 & 0 & 0 & So & 0 & So & so & So & \\
\hline \multicolumn{11}{|l|}{ Dec } \\
\hline & G| Grade I & 0 & 0 & 0 & So & 0 & So & So & So & \\
\hline & GN & 0 & 0 & 0 & So & 0 & So & So & So & \\
\hline & GI Grade III & 0 & 0 & 0 & So & 0 & So & So & So & \\
\hline \multirow{4}{*}{ Total } & GIGradel & & & & 50 & & & & & \\
\hline & $\begin{array}{l}\text { GI Grade } \\
\text { GN }\end{array}$ & $\frac{20,702}{3,200}$ & $\frac{1,297,508}{372,105}$ & 0 & So & $9,006,000$ & $\$ 25,577$ & $\$ 304,451$ & $\$ 2,781,527$ & 1.98 \\
\hline & $\mid$\begin{tabular}{|l|l|} 
GI Grade || \\
\end{tabular} & $\frac{3,209}{4,178}$ & $\begin{array}{r}373,495 \\
466808\end{array}$ & $\frac{0}{120,000}$ & SO & $2,188,800$ & $\$ 6,216$ & $\$ 79,130$ & $\$ 594,511$ & 1.29 \\
\hline & & $4,1 / 8$ & 466,898 & 120,000 & $\$ 944$ & $2,736,000$ & $\$ 7,770$ & $\$ 90,443$ & $\$ 600,364$ & 1.37 \\
\hline \multirow{3}{*}{ G. Total } & & & & & & & & & & \\
\hline & & 28,089 & $2,137,900$ & 120,000 & $\$ 944$ & $13,930,800$ & $\$ 39,563$ & $\$ 474,024$ & $\$ 3,976,402$ & 1.74 \\
\hline & & $\begin{array}{l}\text { NG Enengy } \\
\text { Consumed } \\
\text { during } \\
\text { Downtime } \\
\text { (MMBtu) }\end{array}$ & $\begin{array}{l}\text { Electrical } \\
\text { Energy } \\
\text { Consumed } \\
\text { during } \\
\text { Downtime } \\
\text { (kWh) }\end{array}$ & $\begin{array}{c}\text { Hydrogen } \\
\text { Consumed } \\
\text { During } \\
\text { Downtime (SCF) }\end{array}$ & $\begin{array}{c}\text { Cost of } \\
\text { Hydrogen During } \\
\text { Downtime (\$) }\end{array}$ & $\begin{array}{l}\text { Nitrogen } \\
\text { Consumed } \\
\text { During } \\
\text { Downtime (SCF) }\end{array}$ & $\begin{array}{c}\text { Cost of Nitrogen } \\
\text { During } \\
\text { Downtime (\$) }\end{array}$ & $\begin{array}{l}\text { Cost of Energy } \\
\text { During Downtime } \\
\text { (\$) }\end{array}$ & $\begin{array}{c}\text { Total Money } \\
\text { Spent on } \\
\text { Energy (\$) }\end{array}$ & MMBtu/ton \\
\hline
\end{tabular}

Figure 4.19: Monthly Summary Sheet Snapshot 2 


\subsubsection{Line Diagram}

A line diagram of the entire line is produced for every process. The diagram represents the major energy consuming equipment of the line as well as supporting equipment. The energy consumed by each piece of equipment or a set of similar equipment is shown on the diagram. The user can select to view the amount of energy consumed by each piece of equipment during production as well as during downtime. In this way it is easy for one to identify which piece of equipment is running during downtime and how much energy it is consuming. The line diagram is shown in Figure $4.20,4.21$ and 4.22 . Figure 4.20 shows the entry end of the line. The utilized capacity of electrical equipment is provided in $\mathrm{kW}$ and that of natural gas equipment is provided in MMBtu/hr. For example the payoff roll motors require $120.33 \mathrm{~kW}$ of electrical power and the annealing furnace require 45.39 MMBtu/hr of natural gas energy. These values can also be observed during the downtime. Figure 4.21 shows the exit end of the galvanizing line. Figure 4.22 shows the supporting equipment such as boilers, plant air compressors, sink hardware pre-heat oven etc. The $\mathrm{kW}$ and $\mathrm{MMBtu} / \mathrm{hr}$ required by this equipment during production or downtime is also reported. 


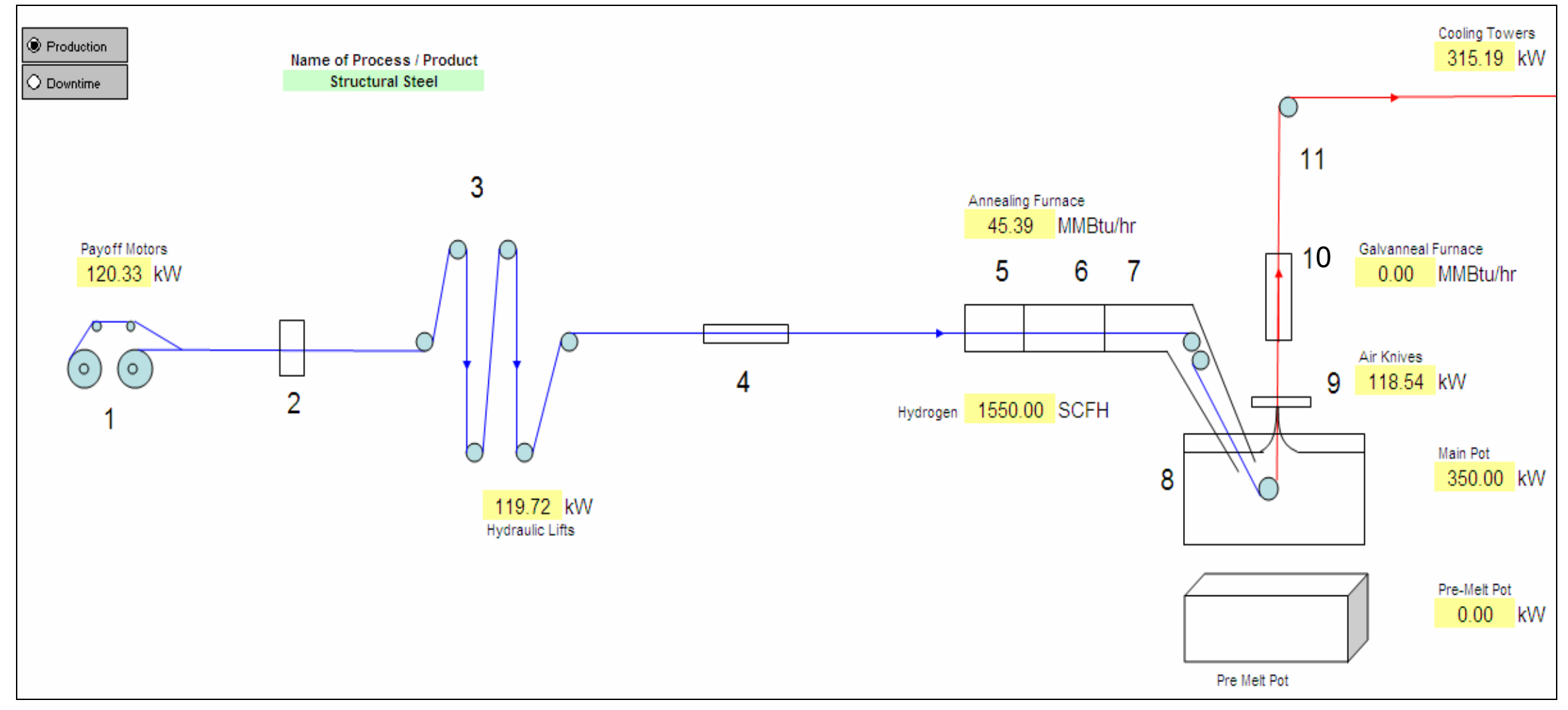

Figure 4.20: Line Diagram Part 1 


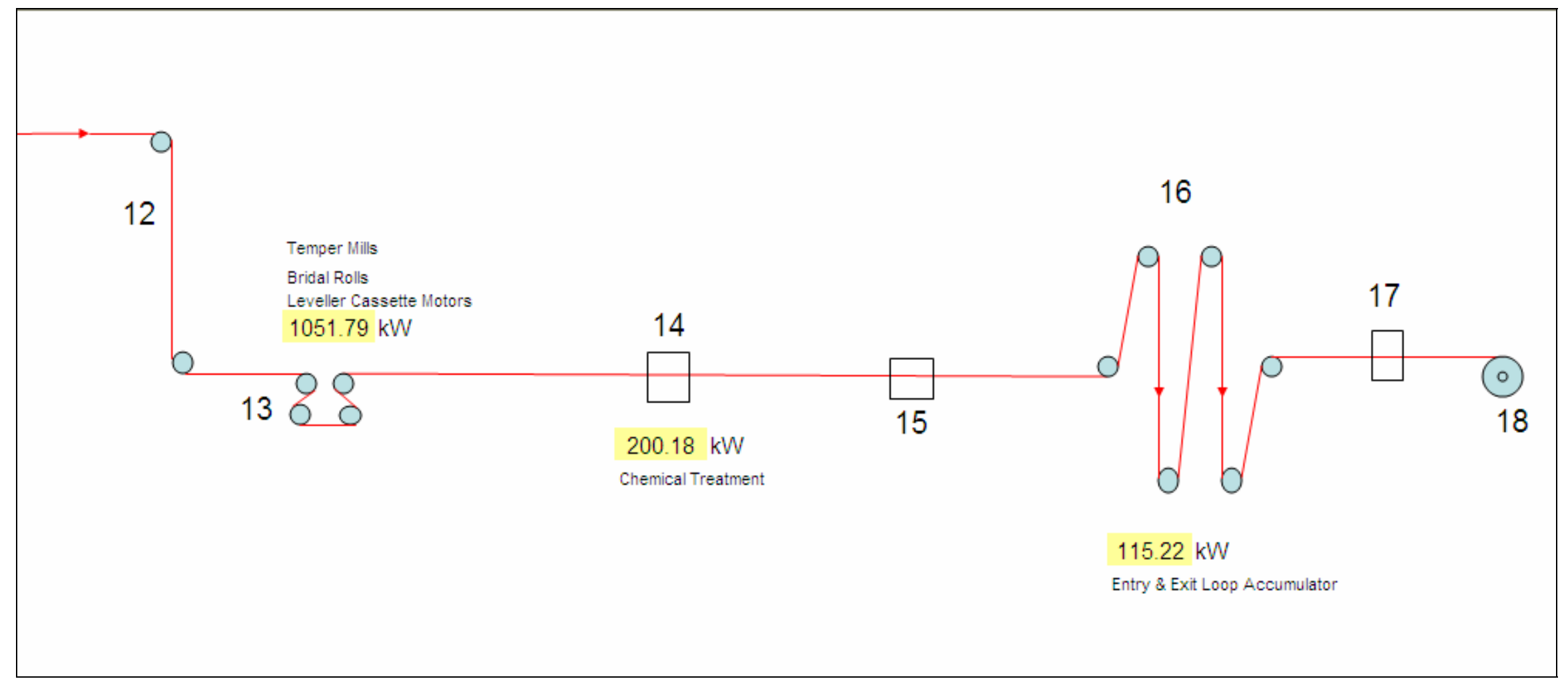

Figure 4.21: Line Diagram Part 2 
1. Payoff Reels and Re-coiler Motors

2. Seam Welder

3. Accumulator loop car 1

4. Degreaser

5. Non Oxidizing Furnace (Annealing)

6. Radiant Tube Section

7. Jet Cooling Section

8. Molten Metal Pot ( $\mathrm{Zn} / \mathrm{Zn}$ Alloy)

9. Air/Gas Knives

10. Galvaneal Furnace

11. Up leg Cooling

12. Down leg Cooling

13. Roll Mills

14. Chemical Treatment

15. Online Inspection

16. Accumulator loop car 2

17. Flying Shear

18. Carrousel Tension Reel
$120.33 \mathrm{~kW}$

$115.22 \mathrm{~kW}$

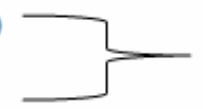

45.39 MMBtu/hr

$350 \mathrm{~kW}$

$118.54 \mathrm{~kW}$

$0 \mathrm{~kW}$

$315.19 \mathrm{~kW}$

$1051.79 \mathrm{~kW}$

$200.18 \mathrm{~kW}$

Included in accumulator loop car 1

Included in Payoff Reel

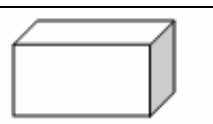

Air Compressors

$354.27 \mathrm{~kW}$

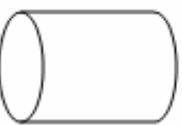

Biolers

$12.02 \mathrm{MMBtu} / \mathrm{hr}$

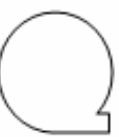

Misc Natural Gas Equipmen

$0.05 \mathrm{MMBtu} / \mathrm{hr}$

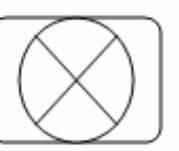

Misc Electric Equipment

$493.00 \mathrm{~kW}$

Figure 4.22: Line Diagram Part 3 


\subsection{Sensitivity Analysis}

This tool helps the user to realize the benefits obtained as a result of increased production and energy savings. Figure 4.23 and 4.24 shows the snapshots of sensitivity analysis spreadsheet. Figure 4.23 is also the first part of the two sections of sensitivity sheet. In this section all the data pertaining to energy, production hours and downtimes is obtained or calculated from the data provided by the user when filling the different input fields. Thus, the current campaign period for the line is calculated and based on the average production rate and average downtime the annual production is estimated. Also the consumption of energy to produce the calculated galvanized steel is also obtained. Now, in the second section of the spreadsheet i.e. Figure 4.24, the user enters the new campaign period, which he expects to obtain as a result of implementation of new pot hardware or for any other reason.

\begin{tabular}{|c|c|}
\hline \multicolumn{2}{|c|}{ Sensitivity Analysis } \\
\hline Week/s Campaign & Day Cycle \\
\hline Average No. of weeks operated before shutdown & \begin{tabular}{|l|l|l|}
2.67 & weeks \\
\end{tabular} \\
\hline Production in given weeks & \begin{tabular}{l|l|l}
17,920 & tons \\
\end{tabular} \\
\hline Furnace energy consumption for production weeks & $26374.71 \mid$ MMBtu \\
\hline Misc motor energy consumption for production weeks & \begin{tabular}{|l|l|l}
4063.95 & MMBtu \\
\end{tabular} \\
\hline Zn Pot energy consumption for production weeks & 2247.45|MMBtu \\
\hline Operating weeks per year & \begin{tabular}{r|l}
51 & weeks/year \\
\end{tabular} \\
\hline Average Shutdown duration in hours & 75.3 hours \\
\hline Total operating hours & \begin{tabular}{l|l|l}
8,568 & hours/year \\
\end{tabular} \\
\hline The number of maintenance shutdowns per year & \begin{tabular}{l|l|l}
16 & shutdowns/year \\
\end{tabular} \\
\hline Total Production time & 7,335 hours/year \\
\hline Total down time (during shutoff) & 1,233 hours/year \\
\hline Energy consumed by plant during production & \begin{tabular}{l|l}
535,170 & MMBtu/year \\
\end{tabular} \\
\hline Energy consumed by plant during shutoff & 39,218 MMBtu/year \\
\hline Total Annual energy consumption & \begin{tabular}{|l|l|}
574,388 & MMBtu/year \\
\end{tabular} \\
\hline Total Annual Production & 293,404 tons/year \\
\hline Energy consumption per ton of steel produces & \begin{tabular}{l|l|l}
1.96 & MMBtu/ton \\
\end{tabular} \\
\hline
\end{tabular}

Figure 4.23: Sensitivity Analysis Section One

Also, the user can change and reduce the average downtime, which by default is the same as for the current scenario. By applying these two changes the user will realize the new value of production in ton of galvanized steel and also the amount of energy required to produce this quantity. Now, the dual benefits of increasing the campaign period can be expressed as increased annual production and the amount of energy saved. The energy 
savings can be calculated by comparing the new production volume and energy consumption to the old production volume and energy consumption. For example, from Figure 4.23 the current 19 days campaign yields an annual production of 293,404 tons and consumes 574,388 MMBtu of energy. Now, from Figure 4.24, the new campaign period is increased to 28 days. This yields an annual production of 308,187 tons with annual energy consumption of 589,596 MMBtu. With the old campaign the energy required to produce 308,187 tons would have been;

$(308,187$ Tons $\times$ 574,388 MMBtu $) \div 293,404$ Tons $=603,328$ MMBtu

Thus the energy savings obtained are 603,328 - 589,596 = 13,732 MMBtu.

\begin{tabular}{|c|c|c|}
\hline $4.00 \quad$ Week/s Campaign & 28 & Day Cycle \\
\hline Average No. of weeks operated before shutdown & 4 & weeks \\
\hline Production in given weeks & 26880 & tons \\
\hline Furnace energy consumption for production weeks & 39562.06308 & MMBtu \\
\hline Misc motor energy consumption for production weeks & 6095.920944 & MMBtu \\
\hline Zn Pot energy consumption for production weeks & 3371.17872 & MMBtu \\
\hline Operating weeks per year & 51 & weeks/year \\
\hline Average Shutdown duration in hours & 75.3 & hours \\
\hline Total operating hours & 8,568 & hours/year \\
\hline The number of maintenance shutdowns per year & 11 & shutdowns/year \\
\hline Total Production time & 7,705 & hours/year \\
\hline Total down time (during shutoff) & 863 & hours/year \\
\hline Energy consumed by plant during production & 562,133 & MMBtu/year \\
\hline Energy consumed by plant during shutoff & 27,463 & MMBtu/year \\
\hline Total Annual energy consumption & 589,596 & MMBtu/year \\
\hline Total Annual Production & 308,187 & tons/year \\
\hline Energy consumption per ton of steel produces & 1.91 & MMBtu/ton \\
\hline Increased annual production & 14,782 & tons \\
\hline Energy Savings per ton & 0.04 & MMBtu/ton \\
\hline Total Energy Savings due to increased production & 13,731 & MMBtu \\
\hline
\end{tabular}

Figure 4.24: Sensitivity Analysis Section Two

Figure 4.25 is plotted with campaign period on the X-axis and the specific energy consumption in MMBtu/ton on the Y-axis. It can be observed that the specific energy consumption drops down considerably in initial weeks. After 5 weeks of campaign period the slope of the curve is reduced. 


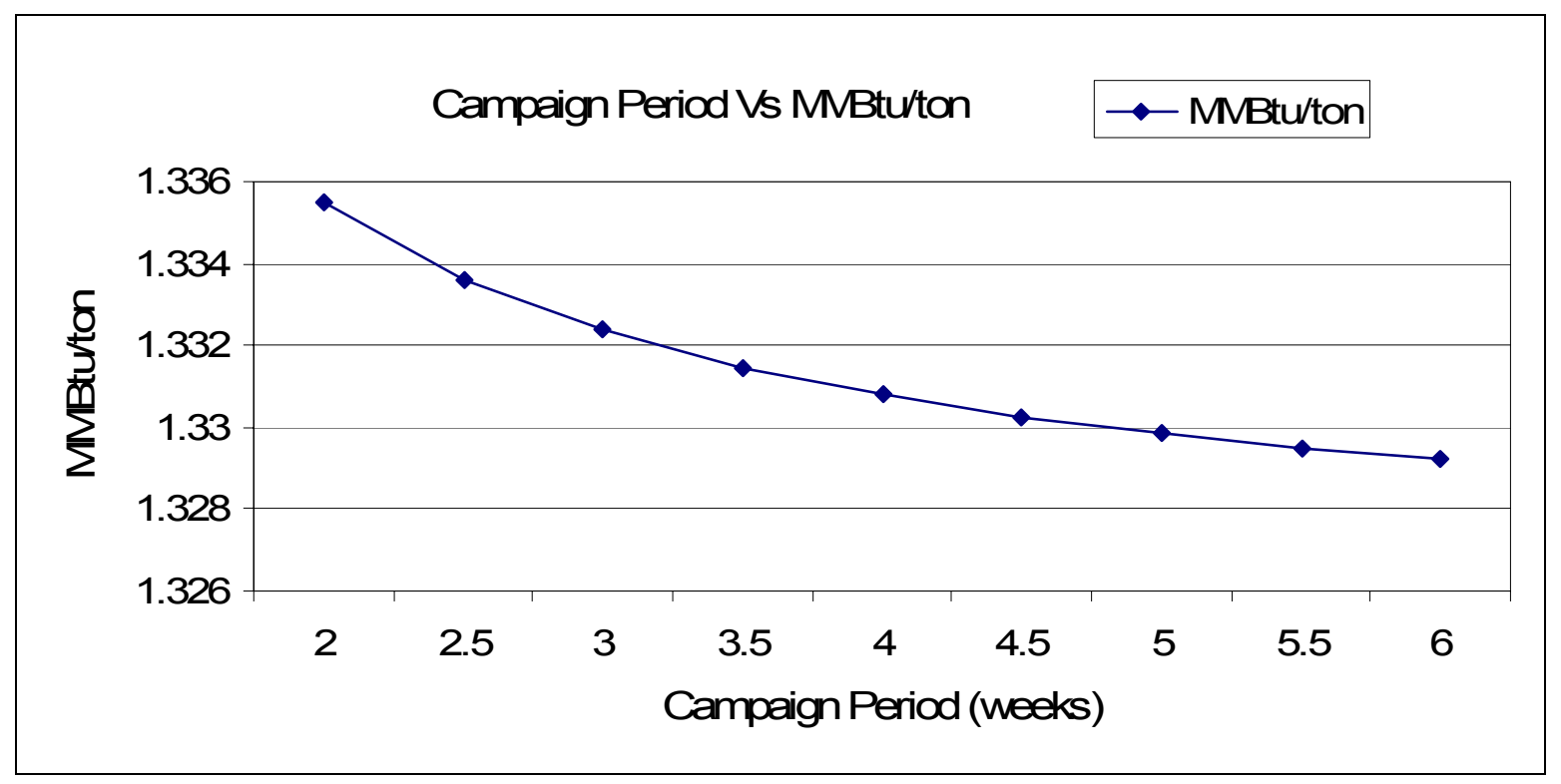

Figure 4.25: Graph of Campaign period Vs MMBtu/ton

Figure 4.26 is plotted with campaign period on the $\mathrm{X}$-axis and the increased annual production in tons on the Y-axis. The increased annual production is the additional production obtained as a result of increased campaign period. It can be observed that the production increases from 8,500 tons in a two-week campaign to 14,000 tons in a 5-week campaign. However, the increase in production after from the 5week campaign is not significant. As seen from the graph, the production in the 6-week campaign is less than 15,000 tons. 


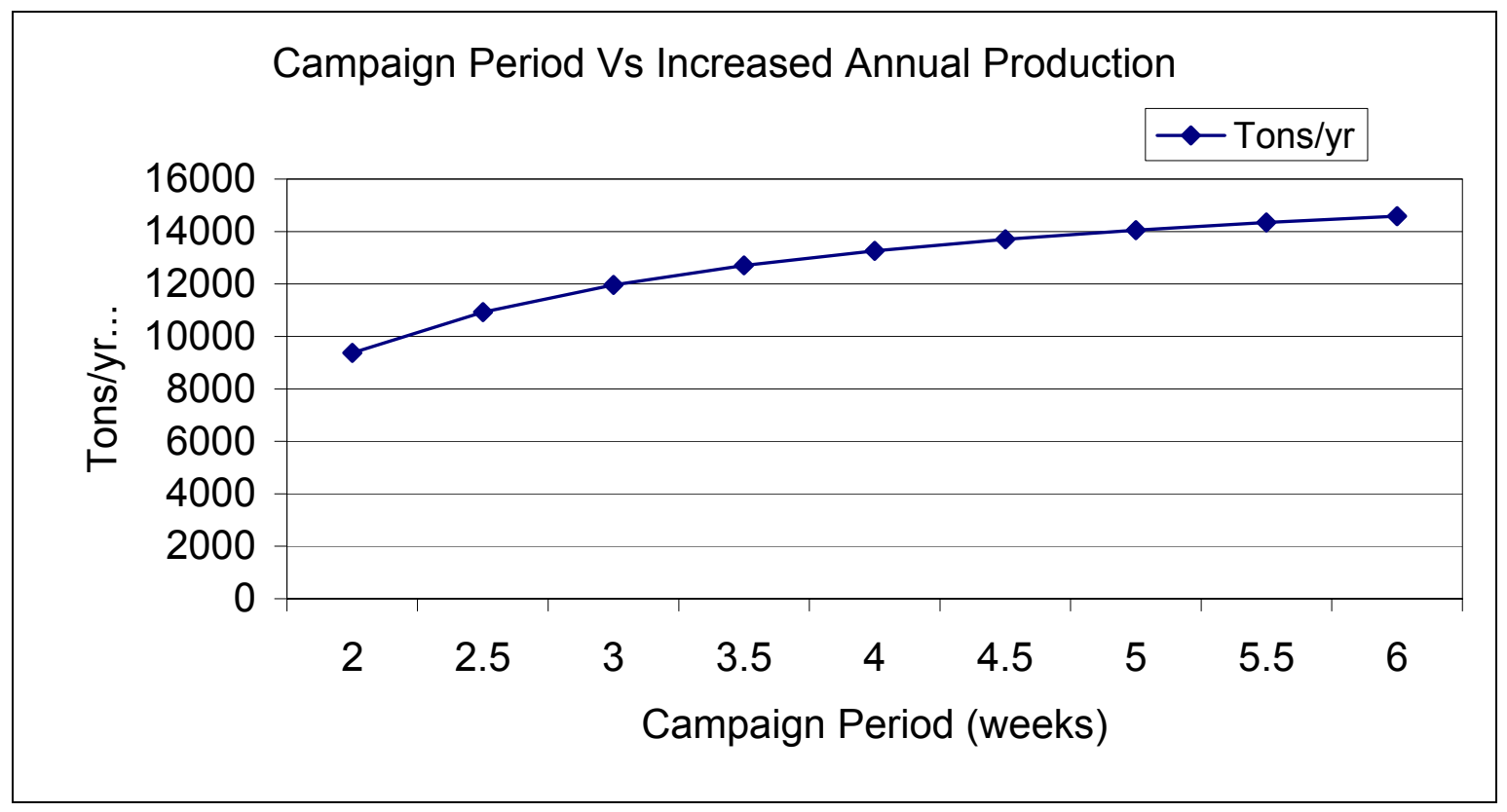

Figure 4.26: Graph of Campaign period Vs Increment in annual production

Figure 4.27 shows a plot of campaign period versus energy savings obtained as a result of increased campaign period. It can be observed that the slope of the curve starts reducing after around 4.5 weeks of campaign period.

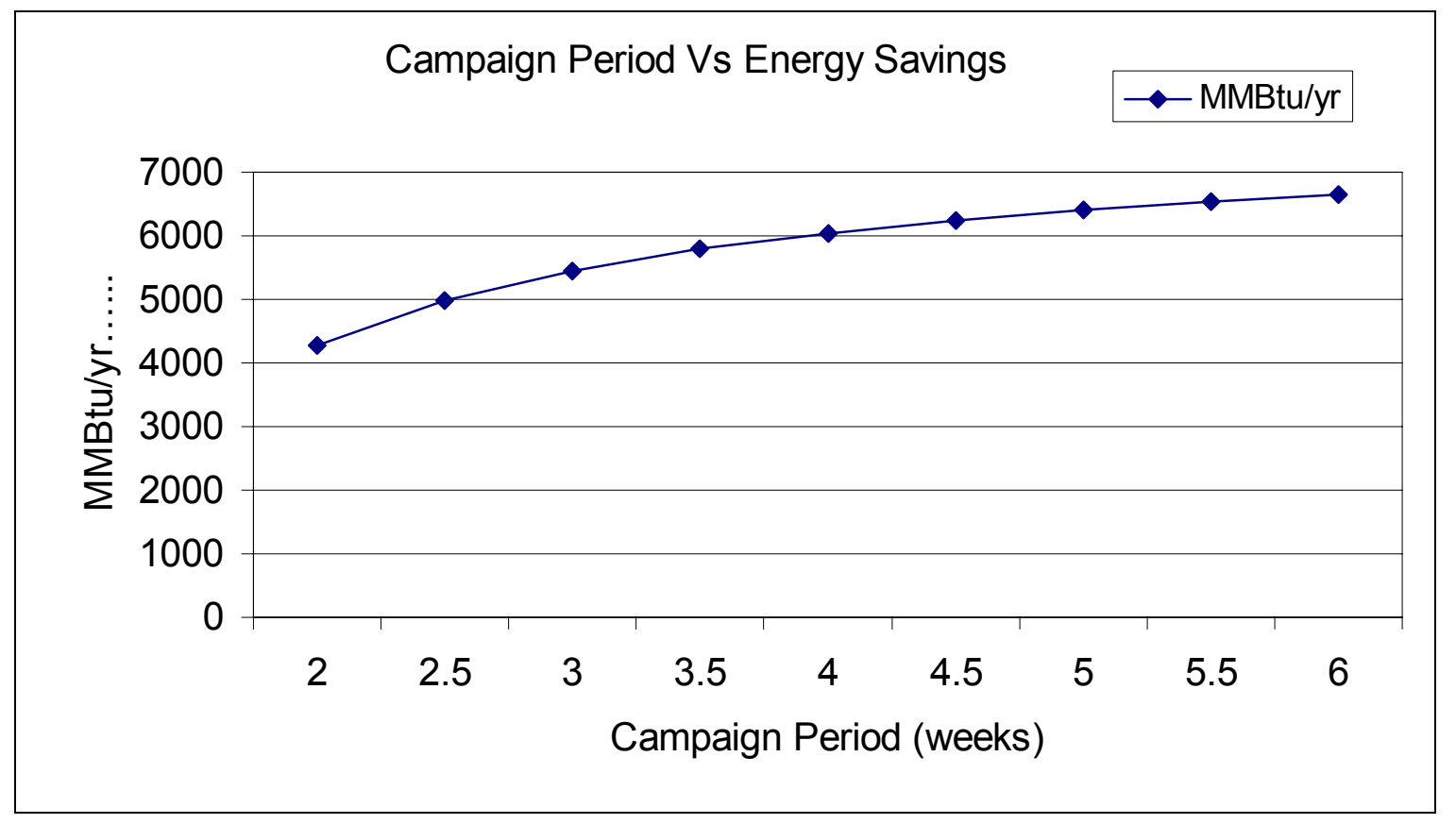

Figure 4.27: Graph of Campaign period Vs Energy savings 
It can be concluded that significant impact is produced on specific energy consumption (MMBtu/ton). It is observed that there is considerable increase in annual production (tons/year) and energy savings (MMBtu/year) with increase in campaign period up to 5 weeks. The impact on these parameters diminishes with further increase in campaign period. In addition to this, it has been noted that the equipment, other than the pot hardware, needs maintenance within 4 weeks of operating period. Most of the facilities have been observed to perform a planned maintenance shutdown every 3 weeks, since motors, pumps and other such equipment needed attention. Thus, even with an extended pot hardware life the campaign period will be restricted to four week duration with the existing technology.

\subsection{Economic Evaluation}

If the investment for new pot hardware is considerably higher than the existing, an economic evaluation can be performed to check for the return on investment. Figure 4.28 shows the snapshot for the economic evaluation spreadsheet. The analysis is performed for a 52 weeks period and the Modified Internal Rate of Return (MIRR) is calculated. The investment includes the capital cost of the rolls and bearings and the re-machining cost of the rolls. The time periods when these costs will occur vary based on the number of time the sink and stabilizing rolls can be re-machined and the campaign period. The revenue is generated from the increased production and the energy savings. The user can enter the desired rate of return to calculate the MIRR. The default value of the desired rate of return is 5\%. The MIRR [29] is calculated as follows;

$$
\begin{aligned}
& \frac{\text { Future Value of Net Cash Inflow }}{\text { Present Value of Net Cash Outflow }} \\
& =\frac{\sum_{n=0}^{N} \max \left(F_{n}, 0\right)(1+i)^{N-n}}{-\sum_{n=0}^{N} \min \left(F_{n}, 0\right)(1+i)^{-n}}=(1+M I R R)^{N} \ldots \ldots \ldots \ldots \ldots \ldots \ldots \ldots \ldots \ldots \text { Eq 4.1) }
\end{aligned}
$$

Where,

$$
\begin{aligned}
& \max \left(F_{n}, 0\right)=F_{n} \text { if } F_{n}>0 \text {, otherwise } F_{n}=0 \\
& \min \left(F_{n}, 0\right)=F_{n} \text { if } F_{n}<0 \text {, otherwise } F_{n}=0 \\
& i=\text { Minimum attractive rate of return for the firm, (MARR) }
\end{aligned}
$$


The data that required to be provided by the user for an economic evaluation is as shown in Figure 4.28. The purchase cost of the sink roll, stabilizing rolls and their bearings should be provided. Next the re-machining cost for sink and stabilizing rolls must be entered. The current campaign period is calculated automatically by the model with the help of existing production data provided by the user. The user needs to provide the new campaign period, which one expects to obtain with the new hardware in service. One also needs to provide the number of times the sink and stabilizing rolls will be remachined before they are discarded. The user may enter a salvage value for the rolls if any. Then the increased annual production obtained as a result of the new campaign period should be entered. Also the annual energy savings obtained as a result of the new campaign will be provided. Both these values can be obtained from the sensitivity analysis module shown in Figure 4.24 for the respective process. Lastly, the user needs to enter the premium or the profit per ton of steel produced. The MIRR is calculated with the help of all this information using equation 4.1.

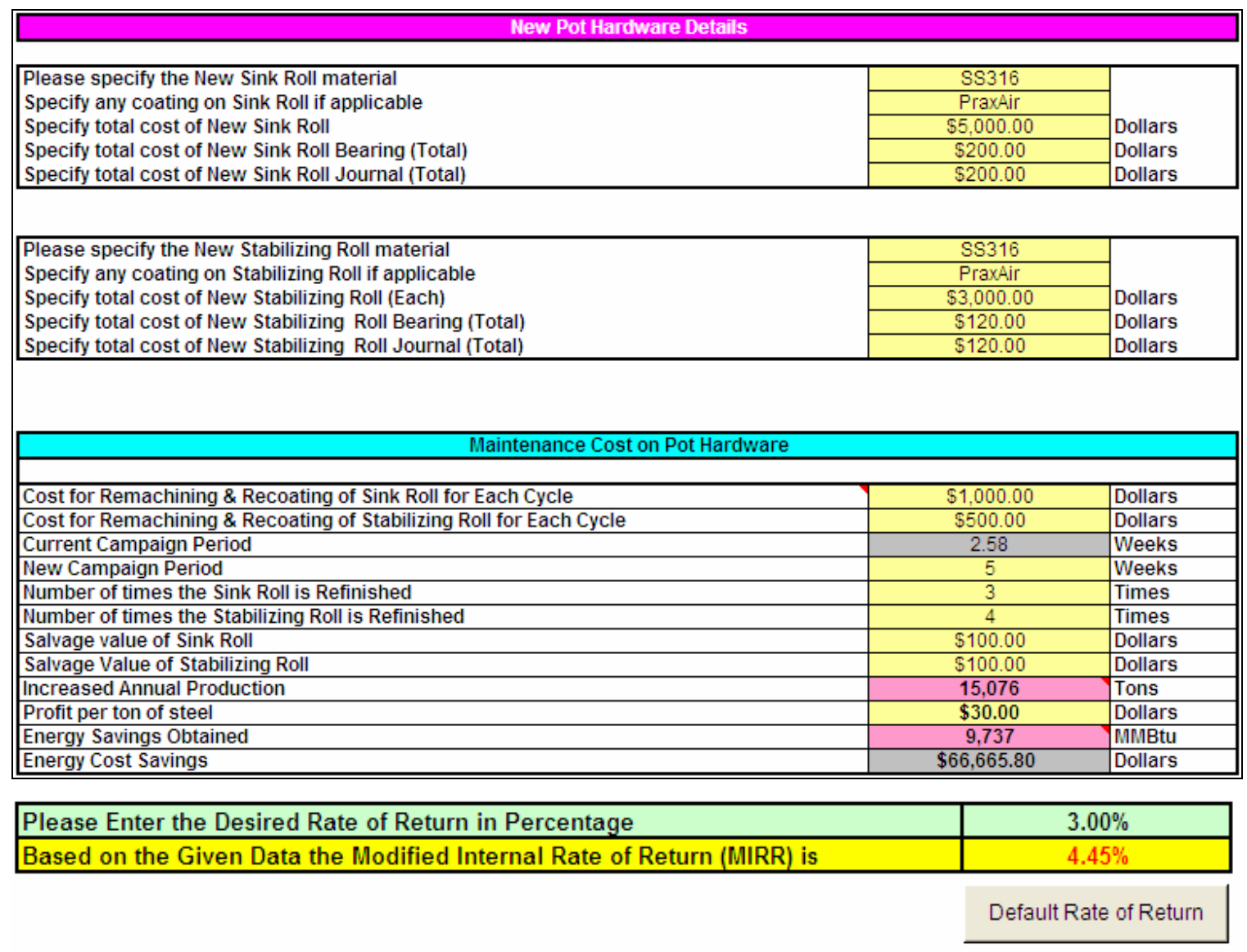

Figure 4.28: Economic Analysis 
If the MIRR is greater than the desired rate of return then, the investment is justified. It should be noted though that the analysis is being done only for 52 weeks i.e. one year period, assuming that the cost of new hardware will not be significantly higher than the existing hardware.

\subsection{Conclusion}

This chapter talks about the architecture of the decision support system and various input and output modules. These modules provide information pertaining to energy consumption during production and downtime as well as the production related information. The sensitivity analysis results show that it is not significantly beneficial to operate the line with a campaign period of more than five weeks. Also issues other than pot hardware prevent the operation of the line continuously for more than a five-week period. The investment in the new pot hardware can be justified using the economic evaluation module of the model. 


\subsection{Validating Results and Future Work}

\subsection{Validation Process}

The validation of the decision support system was done using data from four different facilities, two of which were entirely new data sets. Even though the basic galvanizing process is the same, the equipment present in every facility varies a lot. It was observed that some galvanizing lines did not have a galvanneal furnace at all. Some facilities had 2 high or 4 high mills while some had none. The number of zones in an annealing furnace, number of burners per zone, and burner capacities also varied from facility to facility. Some facilities had electric heating in annealing furnace while others used only natural gas. There was also a lot of variation in the equipment used for cleaning the strip before dipping and chemical treatment after coating. Also, the pot hardware used by various facilities differed from each other; some used coated steel rolls in the pot while some used plain SS316L rolls. The bearing material also varied from facility to facility. However, none of the facilities was observed to have more than three weeks of campaign period and most of them had a PM scheduled at the end of third week. All this variation really makes it difficult to compare one facility with another.

The procedure followed for the validation of the decision support system is described briefly. Accurate data pertaining to different equipment capacities, production and other parameters were obtained for the input section. The result from the summary sheet provides one with the annual kWh for electricity and MMBtu for the natural gas calculated by the spreadsheet. This gave the total annual energy consumed by the facility. This value was compared with the total annual energy reported on the energy bills for the facility. A factor was considered to eliminate the energy consumed by plant lighting and HVAC from the energy bills for the facility. Based on the information received from galvanizing facilities it was found that approximately $10 \%$ to $12 \%$ of the annual energy is

consumed by plant lighting, HVAC and other small office and lab equipment. A value of $12 \%$ is used in the calculations for validation. Thus, this amount is reduced during comparison since the model does not account for these energy consumptions.

The facilities will be identified as Facility 1, Facility 2, Facility 3 and Facility 4. This is done so as to protect the identity of the facilities as per the non-disclosure 
agreement. Table 5.1 shows the comparison between the calculated energy values and the energy values from the utility bills.

Table 5.1: Comparison between Actual and Calculated Energy Consumption

\begin{tabular}{|l|c|c|c|c|}
\hline & $\begin{array}{c}\text { Annual Energy } \\
\text { Consumption } \\
\text { from Energy Bills. } \\
\text { (MMBtu/yr) }\end{array}$ & $\begin{array}{c}\text { After Lighting \& } \\
\text { HVAC deduction } \\
\mathbf{1 2 \%} \\
\text { (MMBtu/yr) }\end{array}$ & $\begin{array}{c}\text { Average Annual } \\
\text { Energy Calculated } \\
\text { by the Model } \\
\text { (MMBtu/yr) }\end{array}$ & $\begin{array}{c}\text { Percentage } \\
\text { Difference. } \\
\text { (\%) }\end{array}$ \\
\hline Facility 1 & 972,588 & 855,877 & 823,005 & $3.84 \%$ \\
\hline Facility 2 & 639,288 & 562,573 & 550,931 & $2.07 \%$ \\
\hline Facility 3 & 524,537 & 461,593 & 439,306 & $4.82 \%$ \\
\hline Facility 4 & 593,063 & 521,895 & 500,024 & $4.19 \%$ \\
\hline \multicolumn{5}{|c|}{ Average } \\
\hline
\end{tabular}

The table shows that the difference between actual and calculated energy consumption averages to $3.73 \%$. Figure 5.1 shows an example of the sensitivity report for facility 2 that was obtained from the model for the existing working conditions. It can be observed from the figure that the total annual energy consumption reported by the model is 550,931 MMBtu. The report also provides a detailed listing of energy consumption by each equipment group and the annual projected production along with the MMBtu/ton for the given process.

\begin{tabular}{|l|r|l|}
\hline \multicolumn{3}{|c|}{ Sensitivity Analysis } \\
\hline \multicolumn{2}{|c|}{ Galvanize } \\
\hline Calculations for 2.67 Week/s Campaign. \\
\hline \multicolumn{2}{|c|}{19} \\
\hline Average No. of weeks operated before shutdown & 2.67 & Weeks \\
\hline Production in given weeks & 26,880 & Tons \\
\hline Furnace energy consumption for production weeks & 25114.60 & MMBtu \\
\hline Misc motor energy consumption for production weeks & 3348.54 & MMBtu \\
\hline Zn Pot energy consumption for production weeks & 175.79 & MMBtu \\
\hline Operating weeks per year & 52 & weeks/year \\
\hline Average Shutdown duration in hours & 14.00 & Hours \\
\hline Total operating hours & 8,736 & hours/year \\
\hline The number of maintenance shutdowns per year & 19 & shutdowns/year \\
\hline Total Production time & 8,471 & hours/year \\
\hline Total down time (during shutoff) & 265 & hours/year \\
\hline Energy consumed by plant during production & 541,536 & MMBtu/year \\
\hline Energy consumed by plant during shutoff & 9,395 & MMBtu/year \\
\hline Total Annual energy consumption & 550,931 & MMBtu/year \\
\hline Total Annual Production & 508,276 & tons/year \\
\hline Energy consumption per ton of steel produces & 1.08 & MMBtu/ton \\
\hline
\end{tabular}

Figure 5.1: Sensitivity Analysis 


\subsection{Results from Sensitivity Analysis}

Figure 5.2 shows the sensitivity report for Facility 3 with the increased campaign period scenario. The report is prepared for a 70-day campaign period and has calculated 48,833 tons of annual increase in production and \$193,549 energy cost savings. These values were discussed with the facility staff and were determined to be achievable and practically feasible.

\begin{tabular}{|l|r|l|}
\hline Calculations for $10.00 \quad$ Week/s Campaign & \multicolumn{1}{l|}{ Day Cycle } \\
\hline \multicolumn{2}{|c|}{10} & weeks \\
\hline Average No. of weeks operated before shutdown & 72240 & tons \\
\hline Production in given weeks & 85948.81483 & MMBtu \\
\hline Furnace energy consumption for production weeks & 13828.29362 & MMBtu \\
\hline Misc motor energy consumption for production weeks & 2803.19592 & MMBtu \\
\hline Zn Pot energy consumption for production weeks & 51 & weeks/year \\
\hline Operating weeks per year & 10.00 & hours \\
\hline Average Shutdown duration in hours & 8,568 & hours/year \\
\hline Total operating hours & 5 & shutdowns/year \\
\hline The number of maintenance shutdowns per year & 8,517 & hours/year \\
\hline Total Production time & 51 & hours/year \\
\hline Total down time (during shutoff) & 520,064 & MMBtu/year \\
\hline Energy consumed by plant during production & 1,024 & MMBtu/year \\
\hline Energy consumed by plant during shutoff & 521,088 & MMBtu/year \\
\hline Total Annual energy consumption & 366,244 & tons/year \\
\hline Total Annual Production & 1.42 & MMBtu/ton \\
\hline Energy consumption per ton of steel produces & \\
\hline \multicolumn{2}{|l|}{} \\
\hline Increased annual production & 48,833 & tons \\
\hline Energy Savings per ton & 0.07 & MMBtu/ton \\
\hline Total Energy Savings due to increased production & 26,616 & MMBtu/yr \\
\hline Total Annual Energy Cost Savings & $\$ 193,549$ & \$/yr \\
\hline
\end{tabular}

Figure 5.2: Sensitivity Analysis for Increased Campaign Period

\subsection{Summary Sheet Results}

The monthly summary for one on the facilities is attached in Figure 5.3.

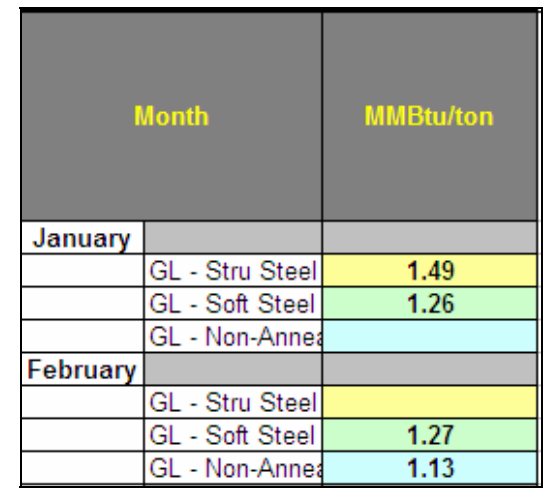

Figure 5.3: Extract from Summary Sheet 


\subsection{Graphs}

The graphs obtained for one of the facilities are shown in Figure 5.4, 5.5 and 5.6.

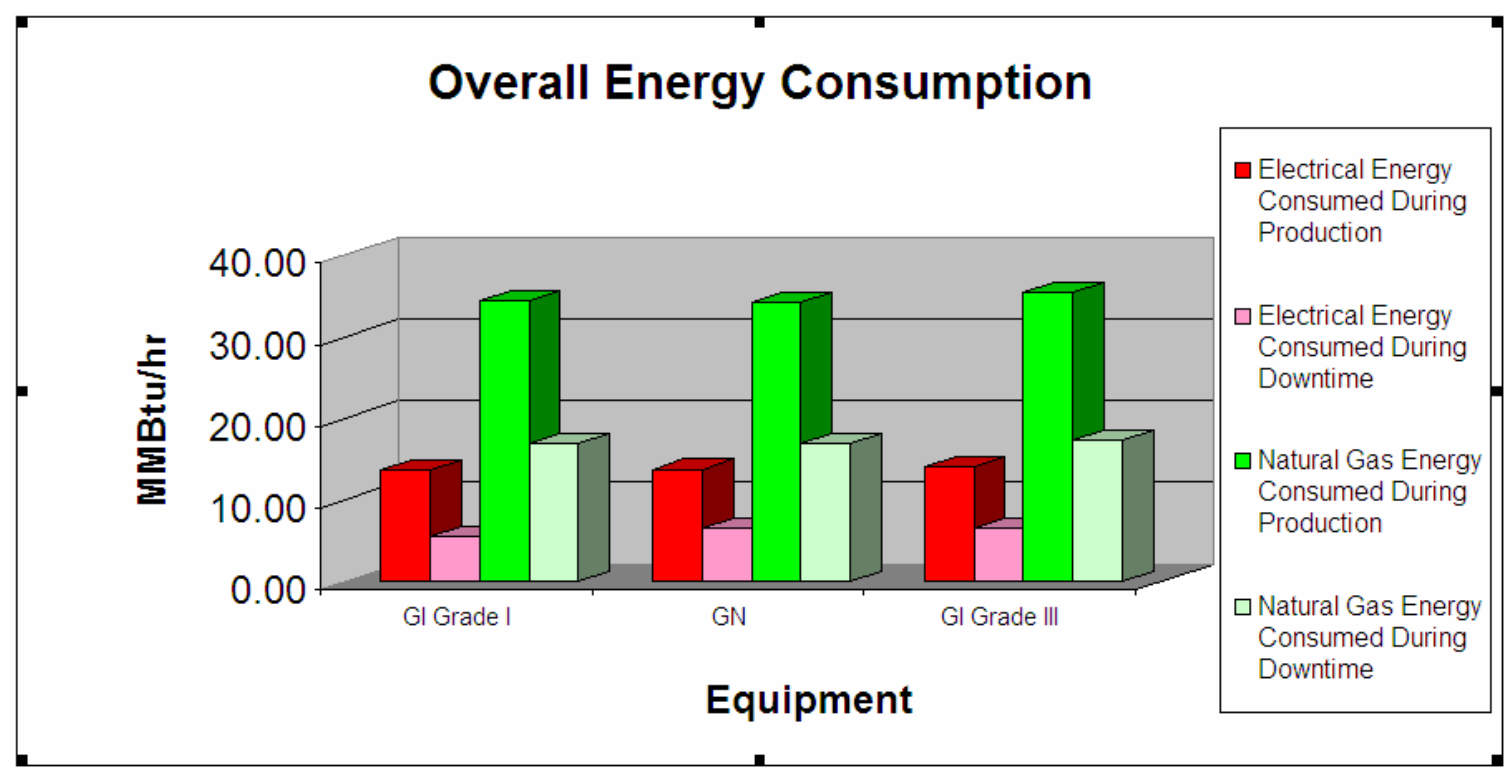

Figure 5.4: Overall Energy Consumption

Figure 5.4 shows the energy consumed by all the electrical and natural gas equipment in MMBtu/hr during production as well as during downtime. For example the energy consumed by natural gas equipment while performing process GN is 33 MMBtu/hr and is $15 \mathrm{MMBtu} / \mathrm{hr}$ when the line performing process GN is shutdown.

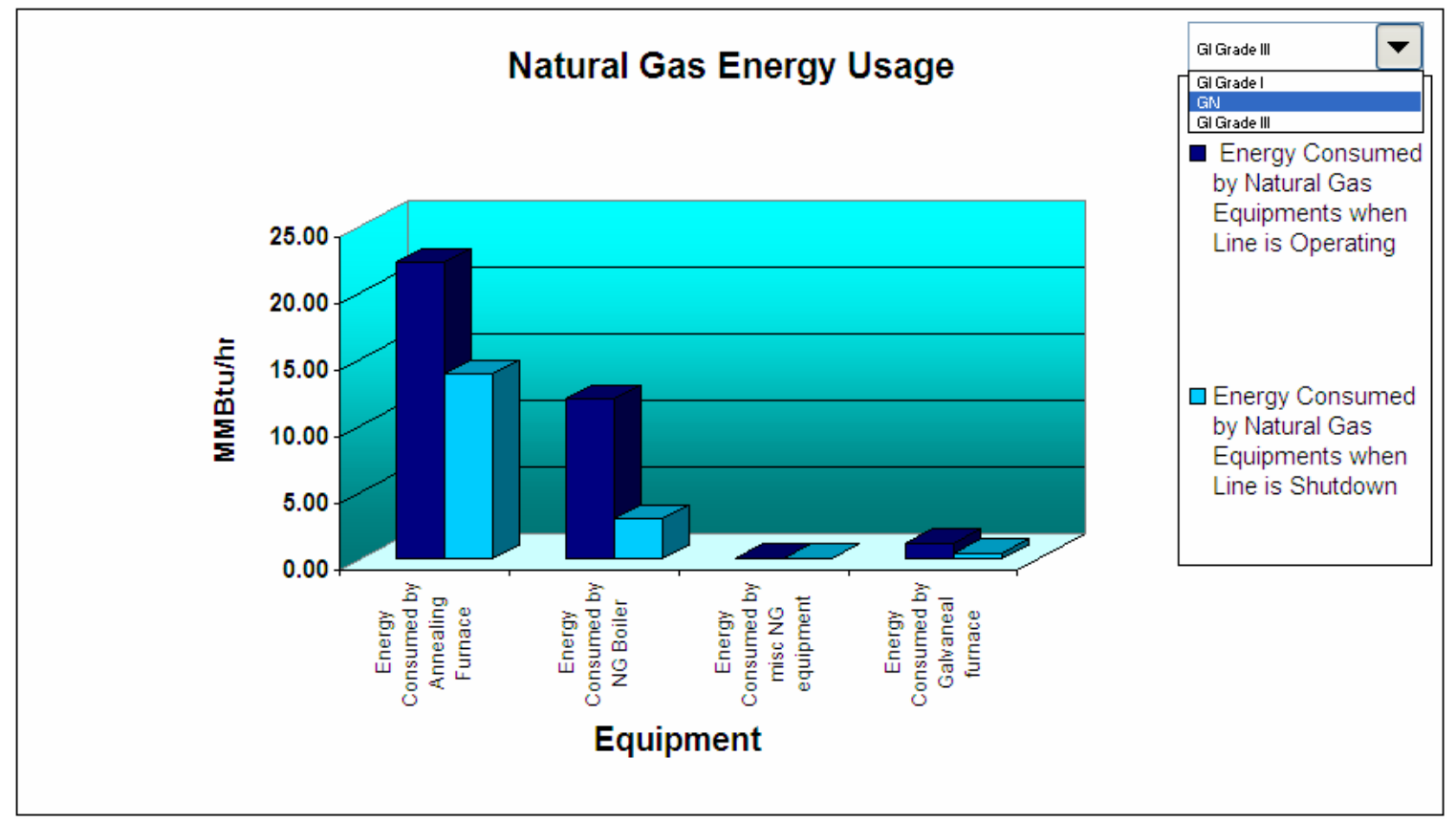

Figure 5.5: Natural Gas Energy Consumption 
Figure 5.5 shows the energy consumed by natural gas equipment, during production and downtime, for a particular process. The graphs have drop down menu to select the process for which the user wishes to see the energy consumption. For example the current figure shows the energy consumed by annealing furnace to be $20 \mathrm{MMBtu} / \mathrm{hr}$ while process Gl grade III is in production.

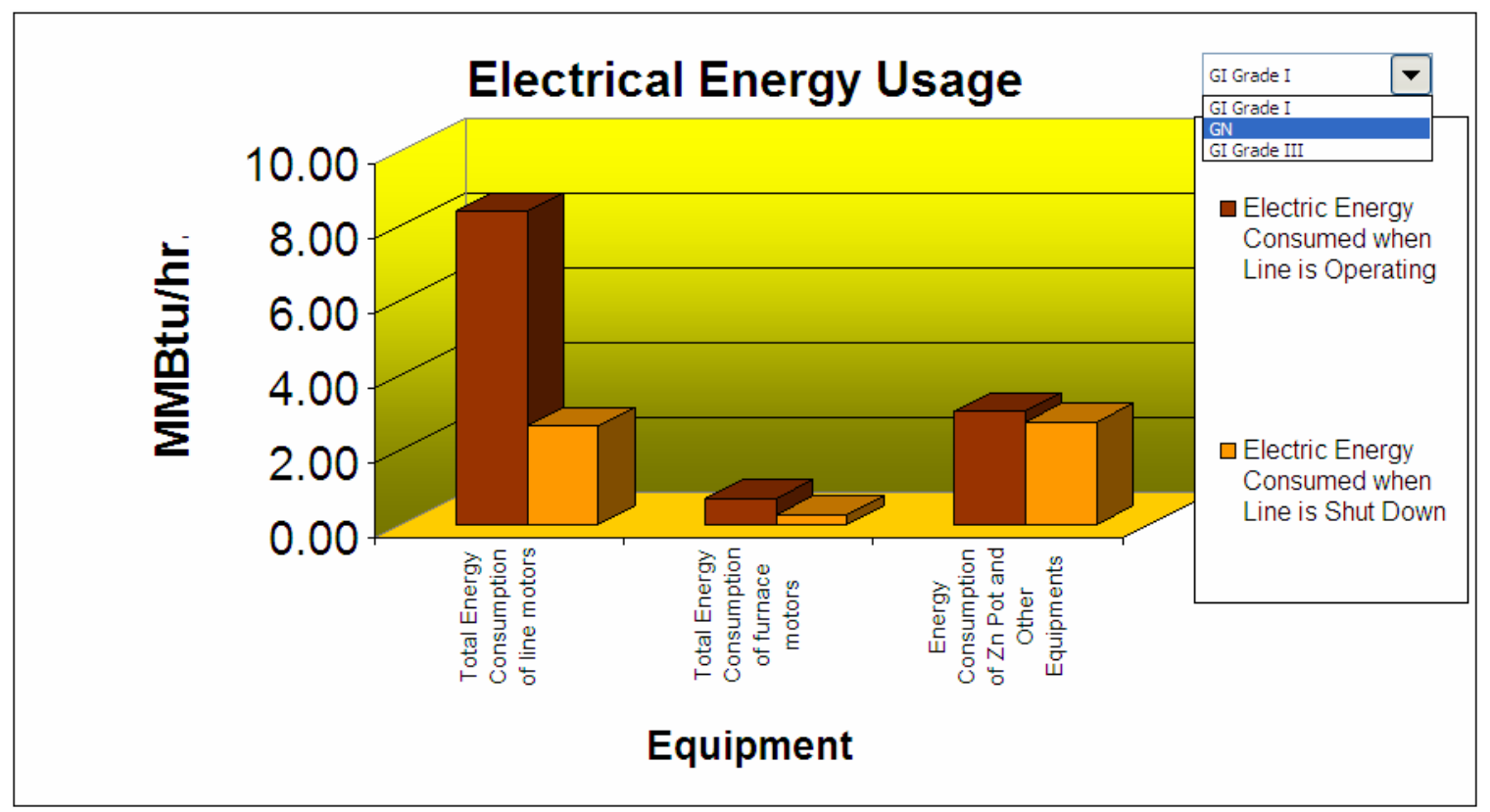

Figure 5.6: Electrical Energy Consumption

Similarly Figure 5.6 shows the energy consumed by electrical equipment during production and downtime for a particular process. For example the current figure shows the energy consumed by the $\mathrm{Zn}$ pot and other equipment to be a little over $2 \mathrm{MMBtu} / \mathrm{hr}$ during production of Gl grade I.

\subsection{Conclusion}

The comparison of the energy consumption in MMBtu calculated by the model, and that obtained from energy bills, shows that the model was accurate within $\pm 10 \%$. The more accurate the information provided, the better is the match between the two values. With the exact information on the power ratings and the load profiles on the equipment and regularly entering the production information, an exact forecast of the annual energy consumption and costs can be obtained. Also, the impact of various energy saving techniques that can be implemented on the existing equipment can be evaluated quickly. 
Based on energy cost savings obtained, the engineering team can decide whether or not to go for the implementation.

The impact of an increase in pot hardware life is evaluated in the sensitivity analysis spreadsheet and the economic feasibility can be verified for the user internal rate of return. There are cases where the line is shutdown frequently for reasons other than the pot hardware failure. In such cases the investment in the new hardware may not be justified if the hardware is significantly expensive than the existing one.

The monthly summary sheet provides extensive information on energy and cost for various processes. Based on the information and the MMBtu/ton for every process calculated for every month, certain managerial decisions can be made, for example, eliminating a particular process due to high cost and/or enhancing another process due to attractive returns.

Looking over the failure log and production details the user may be able to make decisions like whether a particular hardware material is more prone to failure for a

particular process and can avoid the future use of the material. Also, this will help the engineer identify any bottlenecks on the line such as a particular bearing or roll surface. This can also help to decide the maximum length of campaign where the quality of the coating is maintained before they shutdown for PM.

The graphs also provide the information as to which group of equipment is consuming more energy as compared to others. This information for production and downtime helps the engineer to identify and target the piece of equipment such that savings can be maximized.

\subsection{Future Work}

This model provided satisfactory results and was able to determine the extent of energy savings and energy cost savings obtained as a result of increased campaign period. This satisfies the requirements of the project. However, still future modifications and study can be carried on the model in the following areas.

1. The software can be made more user friendly by changing the Excel ${ }^{\mathrm{TM}}$ model to a Visual Basic application. 
2. Make the software interact with the facilities control system so that during a process, real time load and utilization can be obtained to calculate energy consumption.

3. The model can have an inventory of all the equipment used in a typical galvanizing line. As an example there should be drop down menus to select the horsepower of the bridle roll motors or to select the burner ratings. This can be used to lookup values like motor and burner efficiency from a database provided by the manufacturer. Thus, this type of pre-entered equipment database will help in quick filling of the fields pertaining to equipment capacities.

4. The model should be developed further by incorporating energy consumed by lighting, HVAC system and other small miscellaneous equipment as well. 


\subsection{References}

1. Bhave, G. S., "Enhancing the Effectiveness of the Utility Energy Supply Chain in Integrated Steel Manufacturing” Masters Thesis, West Virginia University, Morgantown, WV, 2003.

2. Steel Brochure - Industries of the Future, Office of Industrial Technologies, U.S. Department of Energy.

3. Development of Improved Materials for Continuous Steel Hot-Dipping Processes, Quarterly Report - December 4, 2003. West Virginia University Research Corporation.

4. Blakley, S. G., and Beck, S B M., "Energy consumption and capacity utilization of galvanizing furnaces”, Proc. Institution Mechanical Engineers, Vol. 218 Part E, Journal of Process Mechanical Engineering 2004, pg 251-259.

5. Steel Annual Report- Fiscal Year 2003, Industrial Technologies Program, U.S. Department of Energy.

6. http://www.coatfab.com/galvanizing.htm

7. http://www.corrosion-doctors.org/MetalCoatings/Galvanizing.htm

8. Bailey, R.W.,: in Proc., Second International Conference on Hot Dip Galvanizing, Düsseldorf, Germany, June 30 to July 4, 1952, Zinc Development Association, July 1953, 222-236.

9. http://www.drever.be/en/continuous_galva.html

10. Chang, K. M., Burris, M., Tang, W., and Sikka, V., Proc. Galvatech’01, Brussels, Belgium, June2001, pp.270-277.

11. Sikka, V., Progress Report, IMPH Annual Project Review Meeting, Morgantown, WV, May2003.

12. Liu, X-B., Progress Report, IMPH Annual Project Review Meeting, Morgantown, WV, May2003.

13. Proposal to US Department of Energy, Multifunctional Metallic and Refractory Materials for Energy Efficient Handling of Molten Metals, February 27, 2003.

14. DOE/ORO-2076 Report: "Opportunities for Advanced Ceramics to Meet the Needs of the Industries of the Future” Freitag, D. W., and Richerson, D. W., U.S. DOE Office of Industrial Technologies, December 1998. 
15. “Aluminum Industry Technology Roadmap”, The Aluminum Association, Inc May 1997.

16. "Energy and Environmental Profile of the U.S. Metalcasting Industry”, U.S. DOE Office of Industrial Technologies, September 1999.

17. Tang, N-Y., Dubois, M., and Goodwin, F. E., "Progress in Development of Galvanizing Bath Management Tools”, Proc. Galvatech'98, Chiba, Japan, September 1998, pp. 76-83.

18. Chen Z. W., Sharp, R. M., and Gregory, J. T., Materials Science and Technology, December 1990, Vol. 6, 1990, 1173-76.

19. Yamaguchi, S., Makino, H., Sakatoku, A., and Iguchi, Y., in Proc., Galvatech'95, Chicago, IL, September 1995, ISS, Warrendale, PA, USA, 787-794.

20. Cook, D. C., "Identification of Iron-Zinc Phases in Galvanneal Steel Coatings by Mössbauer Spectroscopy and X-Ray Diffraction”, ILZRO Project No. ZM-403, Progress Report No. 1, International Lead Zinc Research Organization (ILZRO), Research Triangle Park, NC, June, 1993.

21. Pare, A., Binet, B., and Ajersch, F., in Proc., Galvatech’95, September 1995, Chic ago, IL., USA, ISS, 695-706.

22. Qiang, N., Tang, N.-Y., and Adams, G. R., in Proc., Sensors and Modeling in Materials Processing: Techniques and Applications, ed. Viswanathan, S., Reddy, R. G., and Malas, J. C., 1997 TMS meeting, Orlando, Florida, February 1997, 397-408.

23. Tang, N.-Y., Adams, G. R., and Kolisnyk, P. S., in Proc. Galvatech'95, September 1995, Chicago, IL., USA, ISS 777-782.

24. Loth, J., Zinc-Pot Roll Bearing Design Modification for Increased Life, Galvatech 04’ Conference, Chicago, IL April 4-7, 2004, pg 657-665.

25. Snider II, J. M., "Zinc Pot Bearing Material Wear Rate as a Function of Contact Pressure and Velocity,” Masters Thesis, West Virginia University, Morgantown, WV, December 2002.

26. Barbero, E. J., Irwin, C., Liu, X.-B., Sikka, V., Goodwin, F., Development of the Next Generation of Bath Hardware Materials, Iron \& Steel Technology, October 2004, pg 31-37. 
27. Venkatesh Parthasarathy, "Long-Term Performance of Pot Hardware in Continuous Galvanizing Lines”, Master's Thesis, West Virginia University, Morgantown, WV, 2003.

28. Zhang, K., and Tang, N. Y., "Reaction of Various Materials with a Galvanizing Bath”,2003 Galvanizer’s Association, Annual Meeting, October 19 - 22.

29. Park, C. S., and Gunter P. Sharp-Bette, “Advance Engineering Economics”, pg 224-225

30. GalvInfoNote, http://www.steelmillsoftheworld.com/activities/datacenter/G_Note5.pdf

31. GalvInfoNote, http://www.steelmillsoftheworld.com/activities/datacenter/G_Note4.pdf

32. Yoshitani, N., and Hasegawa, A., "Model-Based Control of Strip Temperature for the Heating Furnace in Continuous Annealing”, IEEE Transactions on Control Systems Technology, Vol. 6, No. 2, March 1998, pg 146-156.

33. Ajersch, F., Ilinca, F., and Hétu, J.-F., "Simulation of Flow in a Continuous Galvanizing Bath: Part I. Thermal Effects of Ingot Addition”, Metallurgical and Materials Transactions B, Volume 35B, February 2004.

34. U.S. Department of Energy, http://www1.eere.energy.gov/industry/bestpractices/software.html\#mm

35. U.S. Department of Energy, http://www1.eere.energy.gov/industry/bestpractices/software.html\#air

36. U.S. Department of Energy, http://www1.eere.energy.gov/industry/bestpractices/software.html\#phast

37. 3 E Plus, http://www.pipeinsulation.org/ 
This project was sponsored by the U.S. Department of Energy. Special thanks are extended to all the PI's and industrial partners working on the project.

\section{U.S. Department of Energy}

University of Missouri-Rolla

Oak Ridge National Laboratories (ORNL)

International Lead and Zinc Research Organization (ILZRO)

Secat Inc.

Energy Industries of Ohio (EIO)

Steel \& Refractory Industry

(23 industrial partners) 